\title{
Andrea Hermann
}

\section{Zum Deutschlandbild der nichtmarxistischen russischen Sozialisten}

\section{Analyse der Zeitschrift "Russkoe bogatstvo" von 1880 bis 1904}

Verlag Otto Sagner München · Berlin · Washington D.C.

Digitalisiert im Rahmen der Kooperation mit dem DFG-Projekt „Digi20“

der Bayerischen Staatsbibliothek, München. OCR-Bearbeitung und Erstellung des eBooks durch den Verlag Otto Sagner:

http://verlag.kubon-sagner.de

( $)$ bei Verlag Otto Sagner. Eine Verwertung oder Weitergabe der Texte und Abbildungen, insbesondere durch Vervielfältigung, ist ohne vorherige schriftliche Genehmigung des Verlages unzulässig. 
ARBEITEN UND TEXTE ZUR SLAVISTIK • 4 HERAUSGEGEBEN VON WOLFGANG KASACK

Andrea Hermann

\section{Zum Deutschlandbild}

der nichtmarxistischen russischen

\section{Sozialisten}

Analyse der Zeitschrift • Russkoe Bogatstvo * von 1880 bis 1904

1974

München Verlag Otto Sagnerin Kommission 
Diese Untersuchung entstand auf Anregung von Herrn Prof. Dr. Günther Stökl, dem ich für seine wissenschaftliche Leitung und Hilfsbereitschaft sehr herzlich danke. Wein Dank gilt ferner Herrn Prof. Dr. Holfgang Kasack, der wit seinem kat steten Anteil am Entstehen der Arbeit nahm, für die Aufnahme in die Reihe "Arbeiten und Texte zur Slavistik".

Als Dissertation angenommen von der Philosophischen Pakultät der Universität zu köln aufgrund der Gutachten von Prof. Dr. Gunther Stökl und Prof. Dr. wolfgang Kasack

Alle Rechte vorbehalten

Gesam therstellung Walter Kleikamp - Köln

7615623 
Seite

VORBEMERKUNG

A. EINLEITUNG: GESCHICHTE UND IDEOLOGIE DER

ZEITSCHRIFT "RUSSKOE BOGATSTVO"

B. DAS DEUTSCHLANDBIID DES "RUSSKOE BOGATSTVO" 42

I. Der deutsche Mensch 42

1. Der deutsche Michel 42

2. Regionale Unterschiede 69

3. Die Preußen 75

II. Das Deutsche Keich 86

1. Persönlichkeiten 86

a) Bismarck 86

b) Wilhelm II. $\quad 123$

2. Anonyme Kräfte 144

a) Kapitalismus $\quad 144$

b) Nationalismus 154

c) lilitarismus 164

C. AUSKILANG: DAS VOLK DER "DICHTER UND DENKER" 170

$\begin{array}{ll}\text { IITERATURVERZEICHNIS } & 176\end{array}$ 
VORBEKILRKUNG

Diese Arbeit will das Deutschlandbild der nichtmarxistischen russischen Sozialisten um die letzte Jahrhundertwende darstellen, der sogenannten Legalen Narodniki.'

Als vuelle der Ermittlung inrer Vorstellungen, Urteile und Vorurteile über Deutschland, Deutsche und Deutsches diente inre Zeitschrift "Russkoe Bogatstvo", die - abgesehen von einer einzigen, in Zusumnenhang mit dieser Arbeit bedeutungslosen, 1879 herausgegebenen Nummer - von 1880 bis 1918 erschien.

Schon mehr als ein Dutzend Jahre vorher wurde die Phase des "Legalen Narodničestvo" abgelöst durch die Phase der Sozialrevolutionäre als Partei; damals verlor das "Russkoe Bogatstvo" einen groBen Teil seines Einflusses auf die russische Intelligencija, so dais die vorliegende Arbeit die Janrgänge nach 1904 nicht mehr berücksichtift.

Als besonders ergiebig̈ haben sich die Jahrgänge seit 1892 erwiesen, also die Jahrgänge gerade desjenigen Zeitraumes, in dem das "Kusskoe Bogatstvo" dank der Leitung H.K. luichajlovskijs (gest. 1904, vgl. Einleitung) als führendes Presseorgan der "Legalen Narodniki" das auflagenstärkste (14 000 Stück, eine für die damaligen Verhältnisse sehr große $\mathrm{Zahl}^{2}$ ) und von der Intelligencija am meisten

1) Feinheiten der Klassifizierung siehe Einleitung.

2) Vgl. Ž.I. Berezovskaja, Literaturno-kritičeskie pozicii zurnala "Russkoe Bogatstvo" 1892-1905 gg. In: Iz istorii russkoj žurnalistiki vtoroj poloviny XIX v. woskva, 1964, S. 64 . 
gelesene Periodikon war.

Sämtliche Artikel der Jahrgänge 1880 bis 1 yo4, auch die belletristischen, wurden durcngearbeitet, weil bei der arbeits- und zeitsparenden Methode, Artikel aufgrund ihrer Uberschriften $z u$ ubergehen, möglicherweise wichtige Hinweise übergenen worden wären.

Dabei stellte sich heraus, daß von den Jahrgängen 1880 bis 1891 lediglich die Ausgaben der Jahre 1888, 1889 und 1890 für das Vorhaben des Verfassers relevantes Material (Deutschland wurde in diesem Zeitraum $16 \mathrm{Mal}$ behandelt) enthielten.

Beim Verileich des gewonnenen Haterials mit den rund 120000 durcigearbeiteten Seiten ergibt sich, dab von dem verwendeten feinmaschigen Sieb doch verhältnismäbig wenig festgehalten wurde, was für das Deutschlandbild des "Russkoe Bogatstvo" von Belang ist, selbst dann, wenn man die sehr häufigen Wiederholungen mitberücksichtigt.

Das Deutschlandbild des "Russkoe Bogatstvo" war in sich einheitlich. Widersprüche waren niemals festzustellen. Deshalb sind in dieser Arbeit die Namen der Autoren von geringerer Bedeutung - die keinung des "Russkoe Bogatstvo" uber Deutschland ist mit der lieinung seiner Autoren zu identifizieren.

Trotz der relativ geringen Anzanl von wertenden Artikeln konnte sich der damalige Leser über die Geschehnisse und Fersönlichkeiten im Deutschen Reich ein sehr treffendes, auch in Einzelheiten richtiges, "objektives" Bild machen, weil die Deutschlandkorrespondenten und Berichterstatter des "Russkoe Bogatgtvo" sehr gut unterrichtet waren und sich auf die deutsche Presse aller politischen Schattierungen sowie auf die einschlägige Fachliteratur - tútzten. 
Die Lösung dieses scheinbaren Widerspruches liegt darin, dak im "Russkoe Bogatstro" über Deutschland und die Deutschen sehr viele reine Pakten, "nackte Tatsachen", stehen (darin ist das "Russkoe Bogatstro" einem neutralen, tendenzlosen Geschichtswerk vergleichbar), aber wenige Urtelle, die man für das Deutschlandbild des "Russkoe Bogatstro" auswerten kann, darin enthalten sind.

Es fällt überhaupt auf, wie wenig das "Russkoe Bogatstro" sich bei der Behandlung von Ideologien, Theorien, geplanten oder durchgefürten Maßnahmen durch deren nationale Herkunft beeinflussen läBt.

Beisplelsweise wird der Narxismus lediglich aus ideologischer tberzeugung abgelehnt, nirgendwo aber steht, er sei spezifisch deutsch und aus diesem Grunde verdammenswert. Ebenso wurden die den Narodniki besonders wichtigen Agrarfragen behandelt: Die ausländischen (z.B. Irischen, englischen, deutschen) Lösungsversuche wurden genau studiert und - ausschlieblich als (gedachte oder tatsächliche) Wodelle - für RuBland analysiert und gewertet. Sie wurden nie deswegen gelobt oder getadelt, weil sie angelsächsischer oder deutscher Herkunft waren.

Daher erbrachten alle diese sehr zahlreichen Artikel fur die vorliegende Untersuchung nichts, ebenso wenig wie z.B. die Auseinandersetzung mit der vormarxistischen deutschen Philosophie; auch die Belletristik lieferte zusätzlich zu den anderen, anderweitig bereits ermittelten Klischees nur das der deutschen Gouvernante. ${ }^{3}$

3) Siehe S. 50. 
So blieben für die Aufstellung des Deutschlandbildes, neben vielen marginalen Bemerkungen, als Bausteine im wesentlichen einige große zusammenfassende, gleicngestimmte Artikel ubrig.

Sie werden bewuBt ausführlich behandelt und teilweise wörtlich gebracnt, um lnhalt, stil und Ton der Zeitschrift $z u$ kennzeichnen. Aus dem gleichen Grund wurden auch iliedernolungen nicht gescneut und die Ubersetzung, bisweilen sogar auf Kosten gefalliger Lesbarkeit, der russischen Ausdrucksweise angeglicnen.

Als Ergebnis der Analyse des gesamten liaterials ist festzustelien, daßB sicn das Bild des "Kusskoe Bogatstvo" von Deutschland und aen Deutschen aut wenige stereotype reduzzeren läbt. Diese stereotype stenen in engstem Zusammenhang mit der Person des ersten Keichskanzlers Otto von Bismarck.

Für das "Russkoe Bogatstvo" prägten die Charakteristika der Person Bismarcks entscheidend das Bild des westlichen Nachbarn. Das Deutsche Keich war für die Zeitschrift - auch über Bismarcks Tod hinaus - das Reich des "Eisernen Kanzlers". 


\section{A : EINLEITUNG: GESCHICHTE UND IDEOLOGIE DER}

ZEITSCHRIFT "RUSSKOE BOGATSTVO"

Das "Russkoe Bogatstro" ${ }^{1}$ nimmt einen wichtigen Platz in der russischen Publizistik der zweiten Hälte des 19. und Anfang des 20. Jahrhunderts ein.

Die Zeitschrift erschien mehr als vierzig Jahre, wechselte im Laufe inres Bestehens mehrfach die Leitung und - dadurch bedingt - auch das Programm.

Der Grad ihrer Bedeutung und ihres Einflusses auf das Leserpublikum war unterschiedlich. Von einem Presseerzeugnis, das, abgesehen von einer kurzen Blütezeit Anfang der achtziger Jahre, nur einer relativ geringen Abonnentenzahl von Spezialisten Interesse bot und streckenweise ein kiummerliches Dasein fristete, wurde das $R B$ in den neunziger Jahren $z u$ einer der meistgelesenen und vieldiskutierten Zeitschriften in RuBland.

Sie wird in der Fachliteratur immer wieder als wertvolle Quelle bei der Auseinandersetzung mit den ideologischen und politisch-sozialen problemen des damaligen RuBland herangezogen.

Das RB erschien erstmalig im Jahre 1876 in Moskau, wurde von N.F. Savic, einem Oberleutnant im Ruhestand der zaristischen Armee, herausgegeben und dreimal im Monat gedruckt. 2

1) Im folgenden abgekürt: RB.

2) Vorläufer des RB war die joskauer Zeitung "Narodnyj listok sel'skago chozjajstva $i$ estestroznanija". Sie existierte von 1871-1875 und wurde von dem später auch das RB herausgebenden N.P. Savil ediert. 
Sie trug den Untertitel "zurnal torgovli, promyšlennosti, zemledělija 1 estestroznanija" und behandelte in ihrem Programm vorwiegend Fragen über Ackerbau und Wirtschaft.

In der Absicht, dem RB einen günstigeren Wirkungskreis und somit eine gröBere Bedeutung zu verschaffen, verlegte Savid Mitte 1876 das Erscheinen von Moskau nach Petersburg.

Dem RB war in seiner ersten Phase wenig Erfolg beschieden. Bereits 1878 sah sich Savid gezwungen, seine Herauggeberrechte zu veräußern. Neuer Eigentümer wurde im Dezember des Jahres der Bibliothekar D.M. Rybakov. Dieser gestaltete das RB 1879 in eine Monatszeitschrift nach Art der sogenannten "tolstye Zurnaly" (dicke Zeitechriften) un.

Unter Rybakov erschien jedoch nur eine einzige Nummer der Zeitschrift, denn schon im Mai 1879 verkaufte er die Herauggeberrechte ftir nur 300 Rubel an die Schriftstellerin S.N. Bazina, Ehefrau des bekannten Mitarbeiters der Zeitschriften "Russkoe Slovo" und "Delo", N.F. Bazin."

Prau Bazina fungierte indes nur offiziell als Herausgeberin. Faktisch gehörte die Zeitschrift einer Gruppe von Schriftstellern und Publizisten der "Narodniki"-Richtung, die ein literarisches

3) Vgl. V. Evgenev-Maksimov, Iz istoril "Russkago Bogatstra". RB (Russkija 2apiski), Petrograd, 1917, Nr. 11-12, S. 57. 
Kollektiv (artel') ${ }^{4}$ bildeten, und an deren Spitze der bekannte Publizist S.N. Krivenko stand.

Zu den Mitgliedern gehörten die Publizisten und Kritiker N.F. Annenskij, A.M. Skabicevakij, M.A. Protopopor, N.S. Rusanov, die Schriftsteller und Dichter V.M. Gargin, G.I. Uspenskij, P.V. Zasodimskij, F.D. Nefedov, N.S. Kurozkin, A.N. Pležceev, N.F. Bażin und andere. Zum Redakteur wurde N.N. Zlatovratskij bestellt.

Seit 1880 erschien dann ein vơllig neugestaltetes $\mathrm{RB} .^{5}$

Jede Nummer umfaßte drel Abteilungen mit gesonderter Paginierung. 6

Im ersten Teil findet man Belletristik und populärwissenschaftliche Abhandlungen.

Der zweite Teil war der Publizistik, Literaturkritik und Korrespondenzen gewidmet. Er lieferte auberdem bibliographische Bemerkungen und Rezensionen.

4) Es ist bezeichnend für die Narodniki, daß die Gruppe sich selbst im Sinne eines "artel'" verstand, eines spezifischen Begriffs aus der "Narodnikin-Ideologie. Auch wenn diese Bezeichnung nicht aus dem Impressum der Zeitschrift zu ersehen ist, so wird gerade in den Erinnerungen und persönlichen Briefen von Mitgliedern des "artel" immer wieder auf dieses Selbstverständnis hingewiesen. Vgl. z.B. A.M. Skabičvskij, IItersturnye vospominanija. M. - I., 1928, S. 323: und S.N. Krivenko, Sobr. sod., Bd. I, SPb, 1911, S.II und 214.

5) In der ersten Nummer des Jahres 1880 weist die Redaktion ausdruicklich darauf hin, daB ndie von diesem Jahr an herausgegebene Zeitschrift "Russkoe Bogatstro' nichts mit der ehemals von Herrn Savid edierten Spezialzeitung (gazeta) gleichen Namens gemein hat, weder im Charakter noch im Programm".

6) Diese getrennte Seitenzählung wurde vom 1.1.1883 an aufgegeben, aber am 1.1.1892 wieder eingefürt (von diesem Datum an wurde die Zeitschrift trotz ihrem sich ständig vergrößernden Umfang nur noch in zwe1 Abtellungen gegliedert). 
Der dritte Teil schlieblich, der bedeutend kleiner war als die beiden anderen, trug den Namen "Smes" (Verschiedenes) und enthielt satirische Bemerkungen, Peuilletons, Parodien usw.

Für die Zeitschrift brach eine kurze Blütezeit an. Durchschlagender Erfolg beim Leserpublikum blieb ibr jedoch trotz der liitarbeit bemerkenswerter populistischer Belletristen und Publizisten versagt. Die Konkurrenz der älteren und bekannteren Zeitschriften "Otečestvennye zapiski" und "Delo" war zu groß, und so blieb die Abonnentenzahl niedrig. 7

Ungeachtet dieser Tatsache ist das $\mathrm{RB}$ der Jahre 1880/81 ein interessantes Dokument zur Charakteristik einer bestinmten Periode des russischen Narodnicestvo.

Das Hauptinteresse der Mitarbeiter galt den Fragen der russischen Obščina und dem Schicksal des Bauerntums.

Die Kichtlinien, an denen das "artel" festzuhalten gedachte, skizzierte sein Initiator S.N. Krivenko (anonym) in der "Inlandschau" der ersten Nummer des Jahres 1880.8

Die Redaktion des RB machte sich zur Aufgabe, das Augenmerk der russischen Intelligencija in verstärkter Form auf besondere innere Probleme des Landes zu lenken:

"Wan ruB die Ideale klarstellen, die im Volksbewußtsein umgehen, die Gedanken und Gefilnle, welche mit mehr oder weniger Klarheit in der liasse des Volkes

7) Da: RB hatte zu dieser Zeit nur 700 Abonnenten. Vgl. S.N. Krivenko, Sobr. oc., a.a.0., S. LI.

8) Vgl. an., Russkaja žizh (voěsto predislovija). RB $1880 / 1$, II, S. 78-92. 
leben", schrieb Krivenko. "Es muB aufgezeigt werden, wie sich diese Ideale unter dem Einflub der Zeit und aer historischen Bedingungen veründert haben, in welchem Verhältnis diese Ideale zur Wirklichkeit stehen und welche Spuren die Hirklichkeit innen ihrerseits aufdrückt. Es muß gezeigt werden, auf welche Art und ileise das Volksdenken, das im Inneren der Weltanschauung des Volkes aufgetaucht ist und sich selbständig herausgeoildet hat, mit unseren kulturellen diaßnahmen zusammenstößt und was sich aus diesem Zusammenstob ergibt." 9

Der Herausgeber des $K B, N . N$. Zlatovratskij, kritisierte in seinem umfangreichen programmatischen Artikel "Narodnyj vopros $v$ našem obšestvě $i$ literaturë"10 antipopulistische Tendenzen, die sich seit einiger Zeit im Lager der Intelligencija bemerkbar gemacht hätten und umreibt klar seine eigene Position:

"Wir anerkennen (priznaem) die obstina in inrem vollen Umfang, mit allen ihren logischen Konsequenzen, und schließen jedwedes Schwanken, sowie Verdrehungen und Kompromisse aus... Sie möchten die Zerstörung der Obß̌icina auf dem Gesetzeswege, wir winschen glühend ihre Sanktionierung und den Schutz ihrer Grundprinzipien. Sie möchten den Schwerpunkt außerhalb der obscina liegen sehen, wir wünschen ihn auf die Obšcina zu ubertragen. Sie sind Protektionisten der kapitalistischen Industrie, wir wïnschen in gleichem AusmaB Protektionismus für die Obšina." 11

9) Ebenda, S. 87.

10) Vgl. N. Oranskij (Pseud. von N.N. Zlatovratskij), Narodny j vopros $v$ našem obక̌čestvè 1 literaturę. RB 1880/3, II, S. 25-48; RB 1880/5, II, S. 1-16; RB $1880 / 6$, II, S. $1-20$.

11) Vgl. ders., Narodnyj vopros ... RB 1880/3, II, S. 30 f. 
Nur die "Narodniki"-Intelligencija sei in der Lage, die obscina $z u$ unterstutzen und $z u$ erhalten, meinte der Autor. Jedoch könne die Intelligencija ihre Aufgabe erst erfüllen, nachdem sie ihr eigenes Problem gelöst habe:

"Wir Narodniki, wir, konsequente Anhänger der obšcina, wir, die wir vornehmlich 'Preunde des Volkes' (narodoljubcy) genannt werden, wir erklären, daß vor der 'Prage des Volkes' (narodnyj vopros) zunächst die 'Frage der Intelligencija' (vopros intelligenci1) geklärt werden muß, d.h., die Prage nach den elementarsten Rechten der geistigen und bildungstragenden Schicht (cenz). Nur eine freie Intelligencija im Vollbesitze ihrer Rechte und des freien Denkens (svobodnaja mysl') kann ihre Interessen mit den Interessen des Volkes verbinden und mutig und nutzbringend an die Lösung der Aufgaben gehen, die folgerichtig und unausweichlich für unsere Generation herangereift sind..." 12

Das Ringen um politische Freiheit unterscheidet die Narodniki von ihren Vorgängern in der ersten Hälfte der siebziger Jahre, die solchen Bestrebungen ablehnend gegenüberstanden. Zlatovratskijs Manifest der legalen ${ }^{13}$ Narodniki spiegelte Ideen wieder, die im revolutionären Untergrund im Kreise um die illegale Partei "Narodnaja Volja" entstanden waren. ${ }^{14}$

Dieser neue Aspekt in der legalen populistischen Presse wurde in der Offentlichkeit mehrfach als Entwicklung des Narodničestro zum Liberalismus

12) Vgl. ders., Narodnyj roproe... RB 1880/6, II,S.20.

13) "Legale" Narodniki, hier hauptsächlich insofern, als sie sich eines legal zugelassenen Presseorgans, in diesem Falle des RB, bedienen konnten.

14) Vgl. B.P. Kozmin, Iz istorii revoljucionnoj mysif $\nabla$ Rossil. Izbrannye trudy. Moskva, 1961, s. 4221 . und 447 . 
gewertet. 15

Die Narodniki des $R B$ wehrten sich gegen eine solche grundsätzliche Zuordnung. Zwar gestanden sie im Rahmen des Kampfes gegen den gemeinsamen Peind eine gewisse tbereinstimmung mit den Liberalen $z u$, betonten hingegen: "Wir haben mit den Iiberalen ein Stuck Teges gemeinsam, (Nam s liberalami po doroge,...) aber unsere ziele sind verschiedene, und diese sind das Wesentliche." 16

GroBe Aufmerksamkeit widmete das RB der Kernfrage des Narodnicestvo, nämlich der Prage nach der kunftigen wirtschaftlichen und sozialen Entwicklung RuBlands. Das alte Problem, das bereits bei den Slavophilen unter dem geistesgeschichtlichen Aspekt "RuBland und Europa" diskutiert wurde und bei den frühen Narodniki in der Frage mïndete, ob RuBland eine eigenständige Entwicklung nehmen könne, oder ob die Entwicklung Europas universelles Gesetz sei, diese Prage wurde nun weiter konkret1siert, und zwar in der Richtung, ob RuBland gezwungen wäre, den Weg des europäischen Kapitalismus zu gehen.

15) Diese Ansicht wurde in der zeitgenössischen Presse beispielsweise von der liberalen Zeitung "Strana" sowie der radikaleren popuI1stischen Zeitung "Nedelja" vertreten. Während die Iiberalen der Zeitung "Strans" die Entwicklung freudig begrubten, sahen die Narodniki der "Nedelja" darin einen Verrat an den zentralen Ideen des Narodnicestro, den Ideen des Volkes.

Vgl. ebenda, S. $423 \mathrm{f}$.

16) Vgl. L. Aleksẻev, Pođemu vakipel bul'on 1 podemu tepef tol'ko my obrabcaem na to sroe vnimanie.

RB $1880 / 12$, II ,S.74 
Das Narodnidestvo war Ende der siebziger/Anfang der achtziger Jahre in eine Krise geraten. Persönliche Erfahrung und detaillierte Untersuchungen hatten die Narodniki-Intelligencija mit den tatsächlichen wirtschaftlichen und sozialen Gegebenheiten auf dem Lande konfrontiert, die wenig mit inren Idealvorstellungen ubereinstimmten. ${ }^{17}$

Ein fast blinder Glaube, ein Mythos war zerbrochen. Die rein optimistische Konzeption zur Verwirklichung einer sozialen Neuordnung wich in weiten Kreisen der "Narodnikilintelligencija einer kritischeren Haltung. 18

Zu diesen eher kritisch als optimistisch gestimmten Vertretern des Narodnidestvo gehörte auch ein groBer Teil der Mitarbeiter des RB.

Zwar wurde in Belletristik und Publizistik weitgehend der russische Bauer idealisiert, seine besonderen altruistischen, kommunistischen Instinkte hervorgehoben und die Vorzüge des Landlebens vor der städischen Zivilisation unterstrichen, aber auch die negativen Akzente blieben nicht

17) Von den zahlreichen Studien dieser Art sei nur eine der bekanntesten erwähnt, und zwar die statistische Erhebung des russischen Nationalökonomen Vasilij I. Orlov, Leiter des Komitees für Statistik des ifoskauer Provinz-"Zemstvo": Sbornik statistizeskich svedenil po lloskovskoj gubernil: Formy krest' janekago zemlevladènija v Moskovskoj gubernii. Moskau. 1879.

18) Eine ausfürliche Darstellung gibt Richard Wortman, The Crisis of Russian Populism. Cambridge, 1967. 
unerwähnt. 19

Nicht mehr die "Meinungen" des Volkes waren das Credo der kritisch denkenden Intelligencija, sondern die "Interessen" des Volkes bestimmten als höchstes Leitprinzip ihre Handlungen. 20

Alle Narodniki, die optimistischen sowie die kritischen, stimmten aber nach wie vor in einer Ansicht überein, dab nämlich die Ob̧̌cina der ideale Embryo für eine zuküntige sozialistische Gesellschaftsordnung in RuBland sei.

Während für die optimistischen Narodniki kein Zweifel daran bestand, dab RuBland seinen eigenen Weg gehen und den Kapitalismus vermeiden könne, sahen die kritischen Vertreter der Bewegung - unter ihnen auch einige Theoretiker des $\mathrm{KB}$ - mit Besorgnis die Gefahr, die der obšcina drohte.

Den skeptischsten Standpunkt im $R B$ vertrat der zukünftige Sozialrevolutionär N.S. Rusanov, der zu dieser Zeit zwar bereits stark unter dem EinfluB der Theorien von Karl Marx stand, sich aber emotional nach wie vor an die Obšcina der Narodniki gebunden fülte. 21

19) Seit dem Jahr 1880 erschien im RB die Rubrik "Russkaja Žizh ", die spëter in "Chronika vnutrennej żizni" umbenannt wurde. Namhafte Publizisten nahmen in dieser spalte, sowie in Einzelartikeln, kritisch zu den verschiedensten MiBständen im Inneren des Landes Stellung. Sie brachten statistische Pakten über die Landarmut der Bauern und die drückenden Ablösezahlungen, sie berichteten von den iuängeln des örtiichen Verwaltungssystems, von der mangelhaften ärztlichen Hilfe und dem unvollkommenen Schulwesen auf den Dörfern, usw.

20) Vgl. B.P. Kofmin, Iz istorii revoljucionnoj mysli v Rossii. a.a.0., S. 433 .

21) Vgl. R. Wortman, The Crisis of Russian Populism. a.a.0., S. 147-151. 
In seinem Artikel "Sovremennyja projavlenija kapitalizma v Rossii" wertete kusanov die neuen Unterlagen über die Verhältnisse auf dem Lande aus und fällte für die Zukunft Rußlands eine duistere Prognose. 22

Ob die russische Obšina den Kampf gegen den Kapitalismus gewinnen kann, hängt nach ieinung Rusanovs ausschlieblich davon $a b$, unter welchen Verhältnissen dieser Kampf ausgetragen wird. Wenn es in der Umwelt der russischen Obžlina Èscheinungen gibt, analog denjenigen, die im ilesten zur Vernichtung der Obšlina gefihrt haben, dann kann inan ihren Untergang auch in RuBland erwarten. 23

Anhand der statistisch erfaßten Fakten erbringt Rusanov den Beweis, daß es solche analogen Erscheinungen in RuBland bereits wirklich gibt.

$\mathrm{Zu}$ den hervorstechendsten Merkmalen zählt er die ständig fortschreitende Landarmut der Einzelbauern (obezzemelenie sel'skich proizvoditelej-chozjaev), die auf Grund dieser Tatsache zu Proletariern werden. 24

22) Vgl. N.S. Rusanov, Sovremennyja projavlenija kapitalizma v Rossii. RB 1880/1, I, S. 79-108; RB 1880/2, I, S. 49-88.

23) $\mathrm{V}_{\mathrm{gl}}$. ders., Sovremennyja projavlenija... RB 1880/1, $I, S .95 f$. Es ist bezeichnend für dem Zwiespalt in Rusanov, dab er, obwohl von den Theorien Marx' beeinfluBt, einen für die Narodniki typischen Standpunkt vertritt, indem er sich der jberzeugung anschließt, daß die Obžzina nur durch den Einfluls feindlicher Einwirkungen von außerhalb zerstört werden kann:"..Wir müssen im Gedächtnis behalten, daß es in der eigentlichen Urobstina keinerlei Keime für ihre Zersetzung gibt. Diese Keime liegen in der Atmosphäre der Beziehungen zwischen den Obžlinas ( $v$ atmosfere mežduobž̉innych snošenii), und schlagen Wurzeln, dank des unbewuBten Verhaltens der Wilden (dikarej) zu inrer obscina, zu ihrer 'Alma mater', die sie selbst (zwar) nicht zerstören, aber auch nicht besonders sorgsam beschüzen." Ebenda, S. 90 .

24) Vgl. ders., Sovremennyja projavlenija... RB $1880 / 2$, I, S. 49 . 
Die unzureichende Anzahl von Bodenparzellen, die Last der Verpflichtungen und steuern, das alles zwingt den Bauern dazu, das Land $z u$ verlassen und sich, ganz gleich wohin, auf die Suche nach Lohnarbeit zu machen. 25

Ebenso schlecht wie mit der Landwirtschaft ist es um die Heimindustrie (melkaja kustarnaja promyšlěnnost') bestellt. Die "Kustari" (Heimarbeiter) werden von den zahlreichen GroB- und Kleinaufkäufern, die sich auf ihre Kosten bereicnern wollen, ausgenüzt und betrogen. Eine immer größer werdende lienge von "Kustari" muB deshalb die Heimproduktion aufgeben und geht allmänlich, ebenso wie die Bauern, in die keihen der Proletarier über.

Nach Rusanovs Ansicht werden sich in absehbarer Zukunft alle diese Formen des Erwerbs von liehrwert in ein echt westeuropäisches Fabrikregime verwandeln. 26

Die abschließende Stellungnahme Rusanovs zu der Prage "Obscina oder Kapitalismus" lautet folgendermaßen: "wir stehen an der Schwelle des Kapitalismus. Die Ob̧xina ist, bei all inrem wohltuenden Einflub auf das Volk, solange es mehr oder wenicer versorgt ist, nicht in der Lage, es vor der 'freidenkerischen' Bourgeoisie zu retten, sobald es sich in schlechten wirtschaftlichen Verhaltnissen befindet. Im Gegenteil, sie selbst zerfillt, infolge des Bestrebens der bäuerlichen Bevölkerung, sich vom iande loszumachen, einer Bestrebung, die durch eben diese schlechten wirtschaftlichen Verhältnisse erzwungen wird... Die Obšina verhutet die ungleiche Aufteilung des Landes beim Volk ( $u$ naroda), aber sie

25) $V_{E}$. ebenda, S. 49-51.

26) Vgl. ebenda, S. 63-69, 76 . 
ist nicht imstande, gegen die GleichmäBige Ausbeutung des Volkes zu kämpfen.

Darüber zu sprechen, was in einem solchen Pall unternommen werden muB, ist dieser Artikel nicht der (richtige) Ort." 27

Aus dem letzten Satz des Artikels kann man folgern, daB Rusanov, trotz seiner negativen Beurteilung der Lage, die Möglichkeit nicht ausachlieBt, die Ob̧cina könne mittels irgendwelcher MaBnahmen doch noch gerettet werden.

Ebenfalls kritisch, aber doch weit optimistischer als kusanov, beurteilte zur gleichen zeit

G.V. Plechanov im RB das Problem. 28

Der künftige Marxist war damals noch Anhänger des Narodnicestro.

Auch er sah in der Obšcina "Symptome der Verdrehung ihres Grundprinzips und sogar Pälle von dessen völliger Zersetzung", 29 war jedoch uberzeugt, daB Intelligencija und Bauernschaft mit vereinten Kräften die Wirkung der feindlichen Einflusse bedeutend abschwächen und letztlich sogar bezwingen könnten.

Nach seiner Meinung gab es für die "gegenwärtige Landumteilungsgemeinde", die obscina, 30 nur eine

27) Vgl. ebenda, S. $87 f$.

28) G.B. (Pseud. von G.V. Plechanov), Obszina i e ja verrojatnoe budušcee. RB 1880/1, II, S. 35-55; RB 1880/2, II, S. 17-36.

29) $\nabla_{g l}$. ders., Obžrina.... RB 1880/2, II, S. 34 . 30) Die "gerechte" Umteilung des Landes war nur eine der Funktionen, die die obslina erfüllte. 
einzige Alternative: Entweder "der rechtzeitige tbergang zur kollektiven Bearbeitung der Felder, oder (aber) die Zerstörung im Kampf mit dem herannahenden Kapitalismus."

Wielchen dieser beiden Hege die weitere Entwicklung dèr russischen obšcina gehen wird, hängt wesentlich davon $a b$, "ob unsere Intelligencija die wirtschaftlichen Aufgaben unseres Heimatlandes richtig versteht." 31

Plechanov glaubte also daran, dab die Intelligencija nocn die Möglichkeit habe, in den Lauf der Entwicklung einzugreifen und durch inr bewubtes Verhalten auf das Schicksal der Obšina und damit auf die Zukunft RuBlands Einfluß zu nehmen.

wan kann mit Sicherheit annehmen, dab diese positivere Einstellung den meisten Mitgliedern des "Artel" mehr zusagte, als die Schwarzmalerei Rusanovs. 32

Sie wollten ihre Hoffnung auf einen Fortbestand der obščina nicht zerstört sehen. Dieses Anliegen kam deutlich in einer Reihe von anderen Aufsätzen über das gleiche Thema zum Ausdruck.

Den optimistischsten Standpunkt vertrat in zwei Artikeln der radikale Adelige und frühere Landarzt

31) $\mathrm{Vgl}$. ebenda, S. $35 \mathrm{f}$.

32) Rusanov fand anscheinend auch von Seiten des"Artel'"nicht genügend Unterstützung. Er stellte nämlich nach kurzer Zeit seine Mitarbeit am $R B$ ein und verlegte seine literarische Tätigkeit völlig auf die Zeitschrift "Delo". Vgl.: B.P. Kokmin, Iz istorii revoljucionnoj mysii v Rossii. a.a.0., S. 439. 
V.P. Voroncov, der unter den Initialen "V.V." schrieb. 33

Während Plechanov zwar an einen Sieg der Obščina glaubte, aber aucn die Möglichkeit ihres Untergangs im Kampf init dem Kapitalismus nicht ausschloB, bestand für Voroncov kein 2 weifel am günstigen Ausgang dieses Kampfes. ir war der festen Uberzeugung, daß der Kapitalismus in kubland nicht Fuß fassen könne. 34

Nicht so katetorisch hinsichtich des Resultats äuBerte sich der Publizist V.v. Bervi-Flerovskij. 35 Im Gegensatz zu Flechanov glaubte er an die Nöglichkeit, der Obščina mittels friedlicher Niaßnahmen zum sieg zu verhelfen und den revolutionären ileg zu vermeiden. Da er aber stark bezweifelte, ob die Intelligencija in der lage sei, den dazu nötigen "Geist und gesunden hienscnenverstand" aufzuwenden und "mehr Ordnung und Wirtschaftichkeit in die Staatsfinanzen" zu bringen, enthielt auch für ihn die Zukunft eine Unbekannte. 36

33) 1. Mysli o buduščem poměščičich chozjajstv. RB 1880/10, I, S. 43-82.

2. V zaščitu kapitalističeskago pessimizma. RB $1881 / 2$, II. S. 1-20.

34 ) Voroncov gehörte $z u$ den russischen theoretikern der achtziger Jahre, die sich zur iufgabe gemacht hatten, den"Narodnikil-Glauben an das Bauerntum zu retten. Ansatzpunkt war die Politökonomie, welche die geheiligtsten tberzeugungen der Intelligencija in Frage gestellt hatte. Voroncov versuchte, die Nichtanwendbarkeit von westlichen Lehren auf russische Verhältnisse zu beweisen und die Besorgnis in "Narodnikl-Kreisen zu zerstreuen. Ausführlicher über die Rolle Voroncovs und seine Theorie: R. Wortman: The Crisis of Russian Populism. a.a.0., S. 158-172.

35) Vgl. V.B. (= V.V. Bervi-Plerovskij), Poèzija i filosofija agronomii. RB 1880/5, I, S. 51-101.

36) Vgl. ebenda, S. $53 f$. 
Trotz unterschiedlicher Auffassung im Detail stiminten die Autoren in einem Punkte uberein: Sie alle betrachteten den Kapitalismus als Ubel. Ihrer Ansicht nach wäre es besser für ruBland, wenn es diesen Weg der wirtschaftlichen Entwicklung nicht zu gehen brauchte, sondern seiner zukiunftigen Gesellschaftsordnung die Obščinid zu Grunde legen könnte.

lian war sich weiterhin, mit Ausnahme von Voroncov, darijber einig, daB der Ob̧̌ina ernsthafte Gefahr drohte, und dals sie sich aus eigener kraft nicht werde retten können. - Daher der Appell Zlatovratskijs an die Intelligencija, sich ihre politische Freiheit zu erkimpfen, um stark genug für ihre Aufgabe, die Unterstützung und Erhaltung der Obšlina, zu sein. -

Die Zensur bemerkte rasch, daß sich der Charakter des $R B$ verändert hatte, seitdem die Zeitschrift in den Besitz des "Artel" übergegangen war, und bezeichnete sie Anfang der achtziger Janre als "tendenziös". 37

37) Vkil. B.I. Esin, Kusskaja Zurnalistika 70-80-ch Eodov XIX veka.MI.1963, S. 101. Das RB unterstand bis Ende $1905^{\circ}$ der sogenannten Vorzensur (predvaritel'naja cenzura), das bedeutete, dals jeder Artikel, der zur Veröffentlichung im $\mathrm{KE}$ vorgesehen war, zunüchst von eirem Zensor voruntersucht wurde. Dieser konnte je nach Gutdüken Worte, Zeilen, Absätze, ja sogar den ganzen Artikel streichen, ohne eine Erklärung abgeben $z$ muissen. Die Kedaktion legte zwar manchmal schriftlichen protest ein, aber selten mit irfolg. Von Ende 1905 bis September 1914 erschien das RB olıne Vorzensur. Um gegen die Zeitschrift angehen $z u$ können, muBte man sich dann an ein Gerichtsorgan ouer an die zustandige Zentrale Verwaltungsbehörde wenden.

Vgl. V. Evgehev-iuaksimov, Iz istorii "Russkago Bogatstva". a.a.0., S. 55f. -

Näheres über fresse und Zensur im zaristischen KuBland siehe Jacob Walkin, The Kise of Democracy in Pre-kevolutionary Kussia. Hew York, 1962, S. 109-120; Kichard Kindersley, The First kussian Revisionists. Oxford, 1962, S. 234-236;

Ernfried Eduard Kluge, Die russische revolutionäre Presse in der zweiten Halfte des neunzehnten Jahrhunderts. Zürich, 1948. 
"Wem ist nicht bekannt" - so schrieben die Zensoren - "daB die Redaktion der Zeitschrift 'Russkoe Bogatstro' es sich zur Aufgabe macht, extreme sozialistische und radikale Ideen in die Gesellschaft zu leiten, und dab sich um die Redaktion der Zeitschrift sogenannte neue, progressive literaten nihilistischer Färbung gruppiert haben..." 38

Das RB sah sich alsbald fortwährenden Attacken seitens der Obersten Zensurbehörde ausgesetzt.

So verbot das St. Petersburger Zensurkomitee beispielsweise die "Inlandschau", die in der Augustnummer des Jahres 1880 erscheinen sollte. Die Begründung: der Autor habe die "ausweglose Notlage" der bäuerlichen Bevölkerung in RuBland dargestellt. 39

Die verschärfte Reaktion, die nach der Ermordung Alexanders II. einsetzte, erschwerte auch die Situation des RB. 40

Im März 1881 trat Zlatovratskif als Redakteur der Zeitschrift zurück. Seinen Platz nahm im April der Bibliograph und Dichter P.V. Bykov ein, der weder litglied des "Artel"war noch in irgendeiner Beziehung zu ihm stand. Zur gleichen Zeit veränderte

38) Vgl. Otzyv cenzora Lebedeva s pravkoj sekretarja cenzurnogo komiteta panteleeva. CGIAL (= central 'nyj gosudarstvennyj istoriceskij archiv SSSR v Leningrade), $f .777$, op. 3, ed. chr. 35, ¿. II, 1.40. Zit. nach B.I. Esin, Russkaja Zurnalistika. a.a.0., S. 101 .

39) Vgl. V. Evgeńev-liaksimov, Iz istorii "Russkago Bogatstra". a.a.0., S. 58 .

Der Artikel über die Geschichte des RB stutzt sich auf Archivmaterial der "Zentralbehörde für presseangelegenheiten" (glavnoe upravlenie po dělam pečati).

40) Vgl. B.I. Esin, Russkaja Žurnalistika. a.a.0., S. 101 und B.D. Letov, Russkoe Bogatstvo. In: ožerki po istorii russkoj Zurnalistiki i kritiki. Bd. II, Leningrad 1965, S. 415. 
sich auch der Mitarbeiterstab des RB wesentlich. Fast alle Mitglieder des "Artel" verließen die Zeitschrift, und an ihre Stelle traten neue Kräfte. Nach insgesamt füfzehn Nummern, zwölf im Jahr 1880 und drei im Jahre 1881, hörte das $\mathrm{RB}$ somit faktisch auf, Organ eines "Artel'n zu sein. 41

Unter dem neuen Redakteur wurde die Zeitschrift farblos und verlor viele Abonnenten. Dafür trug nicht zuletzt die allgemeine politische Lage, sowie die Zensur Verantwortung. 42

Hinzu kamen finanzielle Schwierigkeiten, die das RB zu einer "kaum tragbaren" (neudobonosimoe) Bürde für die Eigentumer machten. 43

$41) \mathrm{Vgl}$. B.P. Kokmin, Iz istoril revoljucionnoj mysil v Ros8i1. a.a.0., S. 409-411. Noch im gleichen Jahr erwarb das Schriftsteller"Artel" in etwas erweiterter Besetzung eine neue Zeitschrift namens "Ustoi". Ihre erste Nummer erschien im Dezember 1881.

Eine ausfühliche Charakteristik des "Ustoi" gibt B.P. Kokmin, ebenda, S. 449-482.

42) Die Zentralbehörde für Presseangelegenheiten verweigerte im März 1882 ihre Einwilligung, das Programm des RB um einen Beitrag zu erweitern, der die politische Seite des Auslands behandein sollte.

Vgl. V. Evgehev-Maksimov, Iz istoril "Russkago Bogatstran. a.a.0., S. 58 .

Im April 1882 wurde die Rubrik "Polit1飞eskaja rubrika" verboten und andere Beschränkungen eingefuhrt. Vgl. CGIAI. f. 777 . op.3, ed.chr. 35, c.II, 1.97 i dr., zit. nach B.I. Esin. Russkaja Zurnalistika.a.a.0., S. 101 .

Im August 1882 erlaubte man der Herausgeberin Frau Bazina nicht, das RB in "Zarnica" umzubenennen. Begründung: Die Ausrichtung der Zeitschrift könne nicht als "loyal" (blagonamerennyj) angesehen werden.

Vgl. V. Evgehev-Maksimov, Iz 1storil "Russkago Bogatstva". a.a.0., S. 58

43) Vgl. B.D. Letov, Russkoe Bogatstvo. a.a.0., S. 415 . 
In Oktober 1882 wurde das KB schlieblich an den schriftsteller, Philosopicen und Kritiker I.E. Obolenskij verkauft. Die Zentralbehörde für presseangelegenheiten weigerte sich jedoch nach absprache mit dem Polizeidepartement, den neuen Herausjeber als kedakteur zu bestätigen. Deshalb wurde neben $\mathrm{H} . V$. Bykov als fiktiver kedakteur aer Arzt Dr. s.I. Fopov eingesetzt. 44

Vom Januar 1883 an erschien das $\mathrm{xB}$ mit dem Untertitel "Literarische und wissenschaftliche ionatszeitschrift" (ežeměsjačnyj literaturnyj i naǔ̌nyj zurnal). 45

In dieser neuen Periode ihres Bestehens, von Anfang 1883 bis Ende 1891, in welcher das $A B$ mit dem Namen Obolenskij verbunden blieb, präsentierte sich die Zeitschrift hauptsächlich als wissenschaftlich-philosophisches Organ und wies keine scharfwrissene gesellschaftspolitische Linie auf.

Der Publizistikteil änderte unter Obolenskij nicht sofort die Richtung. Eine Zeitlang wurden noch Beiträge von bännern wie S.X. Krivenko, I. Juzov (I.I. Kablic) und V.j. rrugavin geliefert und traditionelle Fräen ces llarodnicestvo, wie "die rechtslage der Ob̧̌cina", oder die "Bauernbank", diskutiert, aber allmählich verschoben sich die Arzente immer deutlicher. Obolenskij wurde zun überzeugten Verkinder des philosophischen positivismus Auguste Comtes.

Die Belletristik spielte nur noch eine sekundire Rolle. Die Beiträge rekrutierten sich vorwiegend

44) VGl. V. Evgeńev-liaksimov, Iz istorii "irusskago Bogatstva". a.a.0.. S. 59

45) In Jahr 1852 wurden nur 8 Nummern, Jaruar bis August, publiziert. 
aus mittelmäßigen ilerken wenig bekannter Autoren. Von Zeit zu Zeit steuerte der Herausgeber unter dem Pseudonys Mi.I. Krasov eigene komane und Erzählungen bei. Etwas belebt wurde die kubrik lediglich durch die Ubersetzungen von Arbeiten ausländischer Sciriftsteller wie Alphonse Daudet, Emile Zola, Guy de liaupassant und einiger englischer, amerikanischer und polnischer Literaten.

Der Schwerpunkt der Zeitscnrift lag auf wissenschaftlichem und philosopnischem Gebiet, wobei moralphilosophische und religiöse Themen fürend wurden; sogar die literaturkritischen Beiträge nahmen häufig diesen Charakter an.

Besonders geprägt war das $\overline{K B}$ seit uitte der acht$z$ iger Jahre von den religiös-ethischen Ideen des Grafen Lev N. Tolstoj.

Obolenskij, ein persönlicher Anhänger tolstojschen Gedankenguts, suchte die Theorien des Grafen mittels zahlreicher Aufsätze in seiner Zeitschrift unter das Leserpublikum zu verbreiten, wobei er sich häufig auch mit den Kritikern Tolstojs auseinandersetzte. 46

46) Die Auseinandersetzung der Intelligencija mit den Ideen Tolstojs in den acintziger Jahren gehört in den Ranmen der allgemeinen Reaktion auf den gescheiterten Versuch, die politische und soziale Ordnung RuBlands auf revolutionärem llege $z u$ ändern. Auf die Zeit der "großen Ideen" in den siebziger Jahren folgte eine Periode der Ernüchterung und Besinnung, die durch eine weitverbreitete Hinwendung $z u$ den "kleinen Taten" gekennzeichnet war.

Näheres siehe Erwin Oberländer, Tolstoj und die revolutionäre Bewegung. Nüncien, 1965. 
Bisweilen erschienen auch Studien und Betrachtungen Tolstojs selbst. ${ }^{47}$ Viele seiner Beitrüge wurden jedoch von der $Z$ ensur verboten und konnten daher nicht abgedruckt werden.

Beachtenswerte Informationen erhielt der Leser durch die "Inlandschronik" (chronika vnutrennej žizni). Hier wurde über aktuelle innere Angelegenheiten geschrieben, so zum Beispiel über die Landwirtschaftskrise Ende der achtziger Jahre und das industrielle Leben des Landes.

Im Dezember 1887 führte Obolenskij eine neue Spalte "Has geschieht im Ausland?" ( 8 to dělaetsja za granicej) ein. Ihre Gestaltung war äußerst vielseitig. Neben Schilderungen sensationeller Skandale oder Beschreibungen internationaler Ausstellungen wurde außer spezifischen Sitten und Gebräuchen die soziale Ordnung der westlichen Länder charakterisiert. Später erhielt die Rubrik den Namen "Auslandschronik" (chronika zagranilnoj żizni). Sie bestand annähernd drei Jahrzehnte.

Das gröBte Interesse der Zeitschrift in den achtziger Jahren boten wohl die Artikel berihmter russischer Gelehrter. Darunter Physiker, Astronomen, Hygieniker wie Glazenap, Lesgaft, Portugalov und andere. Die Zensur verhielt sich anfänglich

47) Z.B.: L.N. Tolstoj, Žizh v gorode. $\mathrm{RB} 188573$ und $1885 / 4$;

- ders., Derevnja 1 gorod. RB 1885/12;

- ders., Mnogo-li delověku zemli nužno. $\mathrm{RB}$ 1886/5;

- ders., Trud mžzzin 1 zenžrin. RB 1886/6. U.A. 
etwas milder als in den Jahren zuvor. ${ }^{48}$

Der Zensor Kosovid bezeichnete die Zeitschrift als "gemäbigt" und sah, nach seinen eigenen Worten, "in der allgemeinen Ausrichtung der Publikation nichts Verurteilungswürdiges $n .49$

Aber schon Ende 1883 forderte die Zentralbehörde für Presseangelegenheiten das Zensurkomitee auf, seine Hachsamkeit in Bezug auf das RB nicht zu verringern, und Kosovid erhielt für seine tolerante Haltung einen Verweis. 50

Das RB Obolenskijs fand in der Offentlichkeit wenig Beifall, und die Leserzahl verringerte sich fortwährend.

48) Der Zensor Kosovid gab folgende Beurteilung $a b$ :

"Unter dem neuen Herausgeber hat sich die Richtung der Zeitschrift stark verändert. Belletristik und Polemik sind völlig in den Hintergrund getreten; die Rubriken 'ilissenschaft', 'wissenschaftliche Philosophie', 'Kritik' und 'wissenschaftliche Neuheiten' wurden erweitert... Die Ausgabe nahm die Gestalt einer fast ausschlieblich wissenschaftlichen, periodischen Zeitschrift an. Dem Belletristikteil wurde gleichbleibend nicht mehr als ein Drittel des Buchumfangs gewidmet. Dieser mehr oder weniger spezielle Charakter der Zeitschrift.... wendet sich an einen begrenzteren Kreis von Lesern ... und verlangt von ihnen eine sehr solide Bildung. In einer derartigen periodischen Zeitschrift ist die Belletristik genaugenommen Ballast und wird von eben diesen soliden, gebildeten Leuten, für die solche Ausgaben ausschlieblich bestimmt sind, (nur) überflogen."

Vgl. CGIAL, f.777, op.3, ed.chr. 35, ¿. II, 1.106. 2it. nach B.I. Esin, Russkaja Zurnalistika. a.a.0., S. 102

49) Ebenda.

50) Ebenda. 
Der EinfluB der Zeitscinift in der russischen Journalistik der achtziger Jahre war unbedeutend.

In januar 1892 san sich Obolenskij ge zwungen, seine ierausgeberrecilte abzutreten. 51 liit dem ubergang an neue kedakteure ve Ëann die gewichtigste feriode in der vescnichte des $x B$.

Das Schicksal der Zeitschrift entschied sich in Herbst des Jahres, als der berihmte Journalist, Literaturkritiker und Soziologe Hikolaj nonstantinovic Uichajlovskij den Entschlub fábte, das ki zusamuen mit einigen "Narodnikt"-r'reunden neu $z u$ beleben.

liichajlovskijs ungeheuere popularität und sein weitgestreuter Einfluß verliehen der Zeitschrift niegekanntes Ansehen.

Seit den siebziger Jahren galt er als Idol der Jugend und der Intelligencija. "Seine Artikel wurden vom ganzen denkenden Rußland gelesen." 52

Ein Zeitgenosse beschreibt inn als "'Beherrscher der Gedanken' der damaligen jungen Generation, soweit diese Generation linksgerichtet war", als "hervorragendste Berümtheit des Narodniki-Lagers. 53

51) Die Zeitschrift wurde zunächst an $\dot{A} . S$. TuganBaranovskaja verkauft, welche sie unnittelbar darauf E.M. Garšin ubergab. Garšin war of̉fizieller Herausgeber von junuar bis November 1092 .

52) Vgl. Jakov I. Teitel, Iz moej žizni. Paris, 1925, S. 102

53) Vgl. P. Percov, Iiteraturnye vospominanija 1890-1902 gg. H.-I., 1933, S. 49. Percov gehörte ab 1892 eine Zeit lang zun: :.itarbeiterstab des $\mathrm{KB}$. In seinen literarischen Erinnerungen scinildert er u.a. interessante Details aus den finfangsjahren der neugestalteten Zeitschrift. -

Zur Fersönlicnkeit lichajlovskijs uni seiner Folle ir. der revolutionären Bewegune KuBlands in der zweiten Hëlfte des neunzehnten Jahrhunderts siehe die umfassende Darstellune von James F. Eillington, liikhailovsky and Russian Populism. Oxford 1958 . 
iicnajlovskij war der liagnet, der namnafte "NurodnikinTheoretiker und Schriftsteller zur litarbeit an seiner Zeitschrift anzog.

Zunächst wurde das "Artel""-Prinzip wieder hergestellt. Im April 1893 schlossen die Teilnehmer ein Abkommen, wonach folgende hauptuitarbeiter des RB als Hiteigentiimer fungierten: N.K. Micnajlovskij, S.N. Krivenko, K.l.. Stanjukovid, G.I. Uspenskij, A.I. I vancin-Pisarev. Spëter kamen V.G. korolerko, J.N. Južakov, N.F. Annenskij und einige andere Literaten hinzu.

Die finanzielle Seite des Unternehmens wurde durcn die Einricintung einer Art Aktiengesellschaft gelöst. Die käufer der Aktien waren Persönlichkeiten, die der Zeitscnrift nahestanden und das Herausgeberrisiko auf sich nehmen wollten. 54

Als offizielle verantwortliche Redakteure liehen wiederum die AuBenseiter Bykov und Popov inre Namen. Erst im Jahr 1900 entschied sich die Zentralbehörde für Presseangelegenheiten, die tatsächlichen Gegebenheiten $z u$ akzeptieren und die faktischen Redakteure N.K. jicinajlovskij und V.G. Korolenko zu bestiatigen. 55

54) Vgl. B.D. Letov, Russkoe Bogatstvo. a.a.0., S. 418 .

55) Die offiziellen Herausgeber des RB waren: Ab November 1892 N.V. Michajlovskaja, die Frau des Schriftstellers N.G. Garinàichajlovskij; ab liai 1894 N.V. Wichajlovskaja und O.N. Popova; vom Liai 1895 an N.V. Wichajlovskaja und V.G. Korolenko; ab 1897 N.K. ifichajlovskij und V.G. Korolenko. ab 1904 V.G. Korolenko. 
Onter der neuen Redaktion wurde das $k B$ zum fürenden legalen Presseorgan des Narodnicestvo in den neunziger Jahren. Die Narodniki hatten somit nach langer Pause 56 wieder eine "eigene" Zeitschrift, die inre Botschaft ins zwanzigste Jahrhundert hinubertrug. 57

Die besondere Bedeutung der Zeitschrift bestand darin, daB sie zur Arena fur die Vertreter einer neuen pro-liberalen Richtung im Narodnicestvo wurde.

Der Kreis un das RB mit Michajlovskij an der Spitze setzte sich vorwiegend aus den "Legalen Narodniki" zusammen, aus deren Reihen Anfang der neunziger Jahre der Feldzug gegen die russischen Warxisten eröffnet wurde.

Das "Legale Narodničstro" stellt das Bindeglied zwischen den beiden revolutionären Phasen der Bewegung dar. 58

Seine Annänger bildeten die einzige im wesentlichen nichtrevolutionäre Gruppe in der Geschichte des

56) Die "Narodniki"-Zeitschrift "Otezestvennye zapiski" war bereits 1884 geschlossen worden.

57) Der Zeitgenosse P. Percov sah das Zustandekommen einer solchen Zeitschrift "als Anfang eines Ausweges aus der 'Totenstille' der achtziger Jahre und als Vorboten eines neuen, revolutionären Auf schwungs."

Vgl. Iiteraturnye vospominanija. a.a.0. S. 54.

58) $\mathrm{Vgl}$. zu diesen beiden revolutionären Phasen:

a) zum revolutionären Narodnicestvo der siebziger Jahre: Franco Venturi, Roots of Revolution. Iondon, 21964 .

b) zu den Sozialrevolutionären: Oliver H. Radkey, The Agrarian Foes of Bolshevism. New York, 21962. 
Narodnicestvo. Sie waren zwar weiterhin Befurworter des Agrarsozialismus, zogen aber politische Reform dem Aufatand vor, und anstelle konspirativer Tätigkeit im Untergrund wählten sie die legale Form der Verfechtung ihrer Ideen. 59

Michajlovakij, dem selbst vom damaligen Polizeidepartement die "Ausübung eines psychischen Zaubers auf die Jugend" 60 bescheinigt wurde, und sein ebenfalls nicht unbekannter Schriftstellerfreund Korolenko sammelten seit 1892 eine Reihe Intellektueller um das RB, die sich, wenn man gewisse graduelle Unterachiede auBer Acht läBt, zumindest bis um die Jahrhundertwende alle unter den Begriff "Legale Narodniki" subsumieren lassen: so die

59) Michajlovskij hatte einer Massenrevolution immer schon ablehnend gegenübergestanden, und sein Verhaltnis zu den liethoden des Terrors war trotz seiner ehemaligen Beteiligung an der Kampforganisation "Narodnaja Volja" äuBerst zwiespältig. Nach Aussagen von Victor Cernov soll er diesen Weg in den neunziger Jahren endgültig verworfen haben. (Vgl. Arthur P. Niendel, Dilemmas of Progress in Tsarist Russia. Cambridge/Mas8., 1961, S. 83-96.

So brach Michajlovakij im Fruhjahr 1892 seine Verbindungen $z u$ einer noch im Petersburger Untergrund regsamen revolutionären Gruppe der "Narodnaja Volja" ab, die einen "offenen Kampf gegen die Selbatherrschaft" im revolutionären Sinne postulierte.

(Vgl. Dietrich Geyer, Lenin in der Russischen Sozlaldemokratie. Köln/Graz, 1962, S. 22.)

Als es sich jedoch im Sommer 1893 un die Mitarbeit an der kurzlebigen proliberalen Partei "Narodnoe Pravo" handelte, zeigte er sich zur Kooperation mit dieser konspirativen Unternehmung bereit.

(Vgl. George Fischer, Russian Liberalism. Cambridge/Mass., 1958, S. 93-94. D. Geyer, Lenin, a.a.0., S. 22-23. A.P. Mendel, Dilemmas, a.a.0., S. 95-96.)

6o) Vgl. Boris Nikolaevakij, Delo "Russkago Bogatstva". Iz materialov archiva byv̧ago Departamenta Policii. In: RB 1918, Nr. 1-2-3, S. 89. 
beiden liberal gestimmten Zemstvo-Statistiker Nikolaj Annenskij und Aleksej Peß̌echonov, und die Historiker $N$. Kareev und Benedikt lijakotin, von denen letzterer seinen Kollegen, den Noskauer Privatdozenten Yavel $\mathrm{N}$. juiljukov, an die Zeitschrift heranfürte. 61

Langjähriger Mitarbeiter am RB war der führende Nationalökonom des Narodnicestvo N.F. Daniel'son (Nikolaj-on), Ubersetzer des liarxschen "Kapital" und Briefpartner von Karl Marx und Friedrich Engels; dann frühere Kollegen Michajlovskijs bei den "Otečestvennye zapiski" wie S.N. Južakov und N. Kusanov, und nicht zuletzt Viktor Cernov, der zukünftige Fürer der "Partei der Sozial-Revolutionäre".

Unter den Mitarbeitern des $R B$ herrschte nie völlige geistige Ubereinstimmung.

Von Anfang an zeichneten sich klar divergierende Tendenzen $a b$ : Der Narodniki-Theoretiker $V$. Voroncov (V.v.) und der Nationalökonom S. Krivenko hingen dem minimalistischen Virtschaftsreformprogramm an, während Daniel'son und Južakov das maximalistische Programm einer radikalen wirtschaftlichen Umwandlung befürworteten. 62

61) Vgl. P.N. Miljukov, Vospominanija, 1859-1917. 3d. I, New York, 1955, S. 193. -Annenskij, Peßechonov und Mjakotin spielten eine führende Rolle in der liberalen Bewegung am Vorabend der Revolution von 1905.

Später gründeten sie die kleine Partei der "Narodnye socialisty" und nahmen in ihr Programm die eklektische Sozialphilosopinie ihres Lehrers lifichajlovskij auf. (Michajlovskij selbst hingegen zeigte sich zwar zur Zusammenarbeit mit Liberalen bereit, stand aber der konstitutionellen Bewegung skeptisch gegenüber, da sie für ihn die Gefahren des "bürgerlichen" Liberalismus enthielt, den Verrat an den Interessen des Volkes.)

Vgl. A.P. Nendel, Dilemmas, a.a.0., S. 77-103.

62) Näheres $z u$ diesen beiden 7 irtschaftsprogrammen siehe A.P. Mendel, Dilemmas, a.a.0., S. 37-76. 
Schon bald distanzierte sich die Redaktion von den steril gewordenen Doktrinen Voroncovs, der den Standpunkt des gemäßigteren rechten Flügels im Narodnicestvo vertrat. ${ }^{63}$

luichajlovskij lehnte sogar den Terninus "Narodnicestro" ab, soweit diese Theorie das "Narodnicestro" Voroncovs beinhaltete. 64

Er kritisierte scharf Voroncovs "naiven" Glauben an das Volk und legte dar, daß die vielgepriesene obšcina nicht nur in Auflösung begriffen sei, sondern auch keinesfalls die hohen etnischen ierte in sich vereinige, die Voroncov ihr zuschrieb. sin weiterer Angriffspunkt war Voroncovs Tendenz, die "lvieinungen" der Landbevölkerung höher $z u$ bewerten als die Ansichten der Intelligencija. Michajlovskij hingegen blieb bei seiner alten Individualismustheorie, die jeden Vertreter der Intelligencija, der dem Volk echt dienen wollte, mahnte, $z$ wischen den "Meinungen" und den "Interessen" des Volkes $z u$ unterscheiden. 65

63) Im Jahre 1892 wurden im RB fünf Artikel Voroncovs veröffentlicht, die mit dem Titel "Popytki obosnovanija narodničestva" überschrieben und mit den Initialen "V.V." unterzeichnet waren:
(1) $\mathrm{RB} 1892 / 2$, I, S. 39-63.
2) RB $1892 / 3$, I, S. $68-88$.
3) RB $1892 / 6, I, S .118-148$.
4) RB $1892 / 10$, II, S. 1-26.
(5) RB 1892/11, I, S. 36-52.

64) Vgl. N.K. Michajlovskij, Literatura i žizń. $\mathrm{RB} 1893 / 4$, II, S. 124 .

65) Vgl. N.K. Michajlovskij, Iiteratura i žizh. RB 1893/10, II, S. 108-141. 
Auf Grund dieser ideologischen MiBstimmigkeiten verlieb Voroncov das $R B$ und veröffentlichte seit 1894 seine Artikel vorläufig in der zeitung "Nedelja", der Propagandistin der "kleinen Taten".

Zum offenen Bruch kam es bald auch mit Xrivenko. Dieser übernahm im Jahr 1895 die Leitung der minimalistisch ausgerichteten Zeitschrift "Novoe Slovo". 66 Seine Anhänger im RB, wie A.M. Skabižev akij, L.E. Obolenskij, V.G. Jarockij und einige andere folgten inm nach. 67

Krivenkos Zeitschrift war jedoch bei weitem nicht so erfolgreich wie das $R B$.

In den Reihen des RB sah man den Grund dafur in der Tatsache, dab Michajlovakij dem RB durch Einfuihrung "breiter Horizonte, radikaler Programme und mabgebender kritischer Abhandlungen" ein Leserpublikum hatte verschaffen können, das sich mit Krivenkos "engstirnigem und beschränktem" Programm nicht gewinnen lieb. 68

Die betont oppositionelle Ausrichtung der zeitschrift trug wesentlich $2 u$ ihrem Renommee in Intelligencijakreisen bei.

Die Publizisten des RB polemisierten gegen rechtspopulistische Presseorgane, sie kritisierten Relikte der Leibeigenschaft, die Ideen des "Tolstovstro" und die "Philosophie der Versöhnung"

66) Die Zeitschrift "Novoe Slovo" wurde später als Organ der russischen Marxisten bekannt.

67) Auch Voroncov beteiligte sich aktiv an Krivenkos "Novoe Slovo".

68) Vgl. S.N. Južakov, Pamjat1 S.N. Krivenko. RB 1906/7, II. S. 182 . 
Dostojevskijs; sie protestierten gegen die Willkür der Polizei im Land, prangerten die Auswüchse des Bürokratismus an und traten für nationale Gleichberechtigung ein. Alle wichtigen innerrussischen Geschehnisse wurden aufmerksam verfolgt und kommentiert.

Besonderes Aufsehen erregten die zahlreichen Berichte über die Lebensverhältnisse in der Provinz.

Zentrale Bedeutung kommt in diesem Zusammenhang der publizistischen Spalte "Chronika vnutrennej žizni" zu, aus der sich am deutlichsten die jeweilige redaktionelle Grundstimmung ablesen läßt:

Im Zuge der allgemeinen gesellschaftlichen Erregung, die mit zunehmender politisierung und Radikalisierung verbunden war, verschäfte sich seit Mitte der neunziger Jahre auch der Ton des RB.

Die Redaktion fand S.N. Južakov, den bisherigen Gestalter der "Inlandchronik", als für diese Aufgabe nicht mehr tragbar. Seine Ausfihrungen erschienen $z u$ utopisch und $z u$ wenig der veränderten sozio-ökonomischen Lage angepaBt.

Neuer Berichterstatter wurde N.F. Annenskij, der die "Chronika" oft in Zusammenarbeit mit V.G. Korolenko unter dem Pseudonym "O.B.A." ${ }^{69}$ veröffentlichte.

Viele Beiträge des $R B$ zeichneten sich in der Folgezeit durch eine verstärkte oppositionelle Haltung gegenuber allen Baßnahmen der Regierung und systematische Kritik an der zaristischen

69) Das bedeutete "oba" = Beide. 
Selbstherrschaft aus. ${ }^{70}$

Gesteigertes Interesse beim Leserpublikum rief auch die "Chronika zagraničnoj žizni" hervor. Auslandsexperten und stänùige Korrespondenten unalysierten in dieser Rubrik und in speziellen Briefen dus politische und kulturelle Leben der westlichen Linder. Entiland, Frankreich und Deutschland wurden besonders austührlich behandelt. 71

Das Petersburger Polizeiuepurtewent wertete diese Artikel als Versuch "den Leser in einfacher, allgemeinverständlicher Form $z u$ beweisen, wie tüucklich unsere westlichen Nachbarn sind und wie unglücklich hingegen wir Russen." 72

Darüber hinaus wurde dem RB Diskreditierung der Administrationsorgane und die Zerstörung der Autokratie als zielsetzung vorgeworfen. ${ }^{73}$

Tegen "nacnweisbarer Schädlichkeit" unterstand das RB fast zwei Jahre lang - von der Novembernummer 1897 bis zur Septembernummer 1899 - der besonderen

7o) In einer sovjetischen Speziuluntersuchung aus jünister zeit, die dem $\mathrm{KB}$ im Rahmen der Auseinandersetzung zwischen Narodniki und liarxisten besondere Beachtung schenkt, wird die "Demokratisierung" der Zeitschrift ab witte der neunziger Jahre betont und in wesentlichen als Verdienst von Annenskij und Korolenko angesehen. Der Autor weist zudem darauf hin, daB diese "Berichtigung (vypravlenie) der Linie der Zeitschrift" in früheren sovjetischen Arbeiten nicht beachtet worden sei.

Vgl. V.G. Choros, Narodničskaja ideologija i marksizm. Hoskva, 1972, S. 106-112.

71) Die wichtigsten Auslandskorrespondenten waren: Dioneo für England, N.S. (N. Kudrin) für Prankreich, A.K. (A. Kovrov) und Reus für Deutschland. Auf die Darstellungen von Kovrov und Keus wira im Hauptteil ausführlich eingegangen.

72) Vgl. B. Nikolaevskij, Delo "Russkago Bogatstva". a.a.0., s. 88 .

73) Ebenda. 
Aufsicht des Polizeidepartements. Zudem muBte die Zeitschrift in libi 1899 laut einer Verfügung des Innenministeriuras fiur drei lionate ihr Erscheinen einstellen. Die Bestrafung erfolgte auf Grund "tenaenziöser Auslegun von Gesetzen" in der "Chronika vnutrennej żizni" ( herrscherlichen Kechte der Obersten Gewalt in Grobfürstentum Finnland festlegen." 74

Neben bemerkenswerten publizistischen Beiträgen zeichnete sich aas $K B$ vor allem durch seine Belletristikabteilung aus, die nacn flan der Herausgeber von sntung an breiten kium einnarm.

Die leitscnrift veröfentlicnte zainlreiche arbeiten bekannter russischer literaten und bichter, wie Wamin-jioirjak, Kuprin, Bunin, Veresaev, Bal'nont, und machte inre leser mit ausgewahlten jchöpfungen ausliandischer literatur vekannt.

Wie kichtung in der Literaturkritik bestimmten die Artikel von ilichajlovskij, Korolenko und Gornfel'd. 75

Am bekanntesten wurde das $K B$ jedoch auf Grund seiner wichtigen Funktion im Rahmen der iuseinandersetzung zwiscren Narodniki und russischen biarxisten. Die groBe Debatte zwischen den Vertretern dieser beiden rivalisierenden Varianten des Sozialismus begann Anfant der neunziger Jahre ${ }^{76}$ und wurde

74) Vyl. den Erlaß des Innenministers vom 4. Liai 1899, abgearuckt auf einer unbezifferten joncierseite in $\mathrm{kB} 1899$, $\mathrm{Nr} .5(8)$..Anstelle der l.ai-, Juni- und Julinuminer erscrien 1399 ein "Sbornik zurrala 'Russkoe Bogatsvo'".

75) Näheres sier.e tei Z̆.I. Berezovskuja, Literaturnokritičeskie pozicii žurnala "Russkoe bogatsvo" 1092-1905 tef. In: Iz istorii russkoj žurnaiistiki vtoroj poloviny XIX v. ...oskva, 1964, 3. 62-136.

76) Die Lehre von barx war in kufilund scinon vorher bekannt. Jer erste band des "sajital" erschien bereits $1 \& 72$ in russischer Uoersetzung. aber erst in den neunziger Jihren begann die neue Ideoloie unter der radikalen russischen Intelligencija fuszufissen. 
nach außen hin im Wesentlichen von den "Legalen Narodniki" und den "Legalen Marxisten" ausgetragen. 77

Die Intensität, mit der sich führende Theoretiker des Narodnicestvo in einer der damals meistgelesenen Zeitschriften mit dem harxismus auseinandersetzten, hat eine entscheidende Rolle bei der Verbreitung marxistischen Gedankenguts in Rubland gespielt. Viele Vertreter der radikalen Intelligencija schlossen erst infolge der Artikel des $\mathrm{KB}$ - durch die Diskussion um das "Kapital" und die haufigen Zitate aus den iferken und Briefen von iuarx und Engels - nähere Bekanntschaft mit der "neuen" Ideologie. Das Interesse für die marxistische Idee wuchs in zunehmendem Maße. Um die Nitte der neunziger Jahre hatte der Larxismus die radikale Jugend definitiv für sich gewonnen, zumindest so lange, bis die Sozialrevolutionäre Anfang des zwanzigsten Jahrhunderts eine neue Phase der Auseinandersetzung zwischen Narodniki und Marxisten einleiteten.

77) Der Terminus technicus "Legaler Marxist" wird im weitesten Sinne auf diejenigen liarxisten angewand, welche in den neunziger Jahren ihre Schriften legal in RuBland publizierten.

Nach R. Kindersley, The First Russian Revisionists, a.a.0., S. 232, war ein "Legaler Marxist" ursprünglich "merely a Marxist of any shade of conviction who enjoyed legal status."

Diese sehr allgemeine Zuordnung wurde allmählich durch eine ideologische Komponente konkretisiert und uberlagert. Unter "Iegalem Marxismus" versteht man danach eine bestimmte Richtung im russischen Marxismus, als deren Repräsentanten P. Struve, M. Tugan-Baranovskij, S. Bulgakov, N. Berdjaev und S. Frank gelten. Im Gegensatz zu den "orthodoxen biarxisten" wie G.V. Plechanov, V. Zasulit, I. Aksel'rodOrtodoks und V.I. Lenin wandten sich die "Legalen Marxisten" vom revolutionären Sozialismue ab. Als sich gegen Ende des Jahrhunderts bei den "Iegalen Harxisten" deutlich der Einfluß 
77) Ports.

E. Bernsteins und des deutschen Revisionismus

bemerkbar machte, brachen die russischen

Marx-Schüler endgülig in verfeindete Gruppen

auseinander. Die "Legalen Narxisten" verän-

derten von da an ihre Position in Richtung

auf einen religiösen Liberalismus hin.

Zwischen "legalen" und "orthodoxen" diarxisten

bestand bis zu inrem endgultigen Bruch, der

auf das Jahr 1902 angesetzt wird, (vgl.

V.P. Buldakov, I storiografileskaja problematika

'legal'nogo marksizma'. In: Istoriceskıe

zapiski. Moskva, 1971, $\mathrm{Nr} .87, \mathrm{~S} .289$.

eine ideologische und organisatorische Allianz.

Ihre Hauptaufgabe sahen sie im vereinten

Kampf gejen das Narodnicestvo, sowie in der

Propagierung einer ihrer Auffassung nach

realistischeren Konzeption. In der Konfron-

tation mit den Narodniki traten jedoch die

"Legalen Marxisten" mehr als inre "orthodoxen"

Verbindeten in den Vordergrund. Sie waren es,

die in den neunziger Jahren am meisten schrie-

ben, am meisten gelesen wurden und sich daher

in der interessierten öf fentlichkeit eine

Prominenz als die russischen liarxisten

schlechthin erwarben.

Von den zahlreichen Studien und Interpre-

tationen des "Legalen Marxismus" seien hier

nur einige angeführt und bereits im Zusammen-

hang zitierte Autoren noch einmal besonders

hervorgehoben:

1) Richard Kindersley, The Pirst Russian Revisionists. A study of "Legal Marxism" in Russia. Oxford, 1962.

2) V.P. Buldakov, Istoriograficeskaja problematica 'legal'nogo marksizma'. In: Istoriceekie zapiski. hoskau, 1971, $\mathrm{Nr}$. 87, S. 287-333.

3) Bertram D. Wolfe, Three who Made a Revolution. New York, 1948, S. 118-126.

4) John Maynard, Rusgia in Plux. Before October. London, 21946 , S. $258 f$. --

Zur Auseinandersetzung 2 wischen "Legalen

Narodniki" und "Legalen Harxisten":

1) Arthur P. Hendel, Dilemmas of Progress in Tsarist Russia. Legal hiarxism and Legal

Populism. Cambridge/Mass., 1961.

2) V.G. Choros, Narodniceskaja ideologija

i marksizm. Noskva, 1972.

3) Dietrich Geyer, Lenin in der Russischen

Sozialdemokratie. Köln/Graz, 1962, passim.

4 ) George Pischer, Kussian Liberalism.

From Gentry to Intelligentsia, Cambridge/

Mas8., 1958, S. 85-116. 
Im Herbst 1893 kritisierte der 23-jährige

Petersburger Student P.B. Struve in einew Artikel in Berliner "Sozialpolitischen Centralblatt"78 heftig Nikolaj-ons sozialökonomische Diagnose, die dieser in seinen "Očerki našego poreformennago obక̌cestvennago chozjajstva" 79 für Rußland gestellt hatte.

Als Antwort erschienen unmittelbar danach im $R B$ entrüstete Artikel von Južakov und Krivenko, 80 die Nikolaj-ons Theorien gegen den marxistischen Anwurf verteidigten.

Wichajlovskij hatte bereits in der Oktobernummer des $R B$ eine bevorstehende "Polemik mit unseren sogenannten 'Líarxisten' oder 'Sozialdewokraten'" angekündigt. 81

Im Januar und Februar 1894 eröffnete er die Attacke mit einer ausführlichen inalyse des russiscinen liarxismus in seiner regelmäßig erscheinenden kritischen Spalte "Literatura i žizn". ${ }^{82}$

78) "Zur Beurtheilung der kapitalistischen Entwickelung RuBlands". In: Sozialpolitisches Centralblatt. Hrs. Heinrich Braun, 3. Jg., Nr. 1 (2. Okt. 1893), s. 1-3.

79) $\mathrm{SPb}, 1893$.

80) Vgl. S.N. Južakov, Voprosy èkonomičeskago razvitija Rossii. RB 1893/11, I, S. 202-227; RB 1893/12, I, S. 210-224. Und S.N. hrivenko, Po povodu kul'turnych odinocek. RB 1893/12, II, S. 160-192.

81) Vgl. N.K. Nichajlovskij, Literatura i žizn. RB 1893/10, II, S. 138f.

82) Vgl. ders., Literatura i žizn. $\mathrm{RB} 1894 / 1$, II, S. 88-123. RB 1894/2, II, S. 148-168. -Lichajlovskij antwortete mit diesen beiden Artikeln auf Briefe von russischen liarxisten, die sich durch frühere kritische Bemerkungen aus seiner Feder angegriffen und beleidigt fülten. 
Die russischen liarxisten befanden sich im Anfangsetadiun der Auseinandersetzung von den technischen köglichkeiten her gesehen eindeutig in Nachteil ihren Kontrahenten gegenüber. Die legale populistische presse mit dem $\mathrm{RB}$ an der Spitze konnte mit Auflagen operieren, die in die Zehntausende gingen, während dieser lieg der legalen Publikation für die russischen ilarxisten bis in die zweite Hälfte der neunziger Jahre praktisch verschlossen blieb. 83

Dennoch setzten sie sich kurz nach den scharfen Angriffen seitens des RB im Rahmen ihrer Möglichkeiten zur wehr.

Eine der ersten gezielten Antworten aus dem marxistischen Lager war Lenins Kampfschrift "Čto takoe'druz'ja naroda'i kak oni vojujut protiv social-demokratov", die in Form von hektographierten Pamphleten in Sommer 1894 illegal in der Hauptstadt zirkulierten. Der Autor dieser anonymen "gelben Hefte" ging in aggressivster Art und Heise gegen die Kampagne des $R B$ an und bezeichnete die Polemik der Zeitschrift als "Strom liberalen und von der Zensur beschützten Schmutzes. " 84

Im Herbst des Jahres erschien in Buchform P. Struves "Kritið̌eskija zametki k voprosu ob ékonomið̌skom razvitii Rossii". 85

83) Erst 1897 verfügten die russischen Narxisten mit der Ubernahme von "Novoe Slovo" uber eine eigene Zeitschrift.

$\mathrm{Ab}$ Ende 1895 und 1896 erschienen bisweilen vereinzelte Artikel von Struve und Tugan-Baranovskij in "Mir Bož" und "Russkaja Mysl"".

$84)$ Vgl. V.I. Lenin, Polnoe sobranie socinenij. Bd. 1, Hoskva, 1958, S. 279.

85) $\mathrm{SPb}, 1894$. 
Mit diesem "Manifest des Legalen Harxismus" gelang es Struve, erstmalig das Publikationsmonopol der Narodniki zu durchbrechen.

Ein junger marxistischer Verleger namens A.N. Potresov, mit dessen Hilfe auch Struves Arbeit veröffentlicht worden war, druckte schlieblich Anfang 1895 ein llanuskript Plechanovs, das er sich bei dem in London lebenden Verfasser abgeholt hatte.

Plechanovs Buch "K voprosu O razvitii nonisticeskago vagljada na istoriju" 86 rührte an die ideologischen Grundfesten des Narodnicestvo und trug durch die Stringenz der Argumentation entscheidend dazu bei, dab sich die radikale linke mehr und mehr dem iuarxismus zuwand te.

Das monistisch-materialistische Geschichtsverständnis, das Plechanov bei Marx gefunden hatte und nun unter seinen russischen Lesern propagierte, stand in krassem Gegensatz zur "Ieltanschauung des Narodnicestvo. 87

Die "Legalen Narodniki" erfaßten nach Wichajlovskijs "Fortschrittstheorie" die Geschichte vom lienschen her und nicht von den unabwendbaren Gesetzen der "Produktionsverhältnisse". Sie glaubten an den freien Villen des Individuums und an die Fühigkeit der kritisch denkenden Persönlichkeit, auf den Lauf der Gescnichte Einflub zu

86) Das Buch erscinien unter dem Pseudonym "N. Bel'tov", SPb, 1895, und hatte den Untertitel "Otvět $g B$. Michajlovskomu, Kareevu i komp."

87) Das RB griff Plechanovs Arbeit unmittelbar nach threm Erscheinen mit einem gezielten Artikel von N. Kudrin (Pseudonym von Rusanov) an, der die ironische toerschrift "Na vysotach ob-ektivnoj istiny" trug. Vgl. RB 1895/5, II, S. 144-170. 
nehmen, was gleichzeitig eine Legitimation der Intelligencija bedeutete.

Der :arxistische Standpunkt hingegen, wonach die ijenschen durch ihre materielle Umwelt bestimnt werden, stellte in ihren Augen eine ungeheuerliche Degradierung ebendieses Individuma dar: die ilenschen wurden wie "Objekte oder Larionetten aus geneimnisvollem Untergrund durch die der historischen liotwendigkeit immanenten Gesetze bewegt". 88

עer gesaúte Feldzug der "Legalen Narodniki" gegen die russiscien liarxisten basierte auf der strikten Ablehnung dieser Geschichtsphilosopnie, wihrend sie hingegen Karl uiarx als bedeutenden Nat1onalökonomen schätzten.

ivirx' Analyse der westeuropaischen ilirtschaftsprozesse akzeptierten sie uneingeschränkt; sie bedienten sich bei der Diskussion wirtschaftlicher Probleme weitgehend marxistischer Terminologie und sinen in "Kapital" eine wertvolle quelle zur Illustrierung der Schrecken des Kapitalismus.

Zentraler Streitpunkt war indess die Frage nach der Anwendbarkeit der Larxschen Lehre auf kußland. Die "Legalen Narodniki" beschuldigten die russischen kiarxisten, die sie als "Yseudomarxisten"

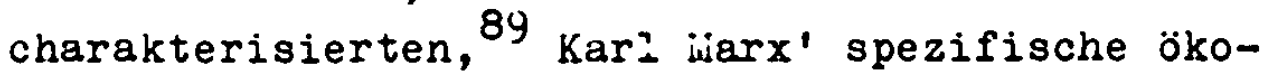
nomische Analysen zu einer allgemeingütigen Gescinichtstheorie erheben zu wollen.

Sie vertraten die Ansicht, daB die russischen biarxisten die Ideen von kiarx nicht in ihrem

88) Vgl. N.K. ¿̈icinajlovskij, Literatura i žizn'. RB 1894, 1, II, S. 113.

89) Vgl. S. Krivenko, Po povodu kul'turnych odinoček. RB 1893/12, II, S. 184 . 
ursprunglichen Sinn und in der von iurx intendierten Bedeutung weitertradierten, sondern sie verfälschten, indem sie seine Gedanken aus dem $\mathrm{Zu}$ sanmenhang herausrissen und sie $z u$ Doginen verabsolutierten. 90

Den Beweis der Unzulänglicnkeit der "pseudomarxistischen" Theorien versuchten die Virtschaftsexperten unter den Narodniki zu fuhren. 91

Die Vorvirfe gegen inren Gegner gipfelten in der Anschuldigung, die historische Sonderstellung rulilands aus den Augen verloren und einer Doktrin geopfert zu haben. Zur Untermauerune ihrer Argumente beriefen sie sich wiedernolt auf uen

90) Vgl. N.K. Liicnajlovsixij, Literatura i Zizh. RB 1894/1, II, S. 111. fhnlich auch li.B. Katner, ris'mo v redakciju. RB 1899/9(12), II, s. 197.

Auf gleicher Ebene liegt auch ihre auffällige

Vorliebe fïr einen bekannten Ausspruch yon

Karl hiarx, den sie wahlweise als "Hoi-nême je ne suis pas liarxiste" oder "hoi je ne suis pas liarxiste" zitieren:

2.B. V. Zernov, Po povodu novoj knigi os ékonomiCeskom materializmè. RB 1899/9(12), I, j. 152; wi.B. Ratner, ris'mo v redakciju. a.a.0., s. 195 G. Stil'man, spory o teorii obni ̌̌anija. RB 1900/7, II, s. 121. V.G. Podarskij, Naša tekušcaja žizń. RB 1902/4, II, S. 100. -.

Diesen Ausspruch von Viarx gibt Engels in einem Brief an Paul Lafareue vom 27. Ausust 1890 (Original in französiscner Sprache) foliendermaßen wieder: "Diese Herren machen alle ir. i.arxismus, aber sie gehören zu der Sorte, die Sie vor zenn Jahren in Frankreich kennengelernt nuben und von denen jarx sagte: 'Alles, was ich weib, ist, dab ich kein ivarxist bin!" VGl. Karl "arx/Friedrich Engels, ierke. Bd. 37, Eerlin (DJk), $1967, \mathrm{~S} .150$. 91) Nikolaj-on setzte sicn in mehreren Artikeln kritisch mit den Ansichten $r$. Struves auseinander:

1) Necto ob uslovijach našego chozjajstvennago razvitija. KB 1894/4, II, S. 1-34, und $\mathrm{RB} 1894 / 6$, II, S. $66-130$.

2) Apologija vlasti deneg, kak priznak vremeni. RB 1895/1, II, s. 155-187, und RB 1895/2, II, S. 1-34.

3) Čto ze znacit ekonorničeskuja neovchocimost'? RB 1895/3, II, S. 44-58. Downloaded from PubFactory at 01/11/2019 11:53:00AM 
beriunten Brief von Karl Marx 92 , worin dieser einen Sonderweg Rußlands zum Sozialismus unter Umgehung des Kapitalismus für möglich erklärt natte. ${ }^{93}$

Narx persönlich galt es insofern zu tadeln, als sich die russischen luarxisten bei ihren Folgerungen eindeutig auf seine Theorie des dialektischhistorischen Determinismus stütten.

Im Gegensatz zu dem großen Renommee, das hiar $x$ bei den "Legalen Narodniki" als Nationalökonom EenoB, lennten sie inn als Sozialphilosophen ab. sie empfanden seine Lehre als zu sehr von der Philosophie Hegels beeinfluBt und als unzureichend wissenschaftlich begründet. ${ }^{94}$

92) Diesen Brief schrieb Karl Marx im November 1877 an N.K. Michajlovskij in dessen Funktion als Herausgeber der "Otečstvennye zaniski", er war jedoch als direkte Antwort auf den polemischen Artikel liichajlovskijo "Karl t.arks pered sudom g. Ju. Žukovskago" in "Otečestvennye zapiski", 1877, Nr. 11, gedacht und zur Veröffentlichung vorgesehen. Nach harx' Tod wurde der Brief in seinem NachlaB entdeckt und 1888 im "Juridičeskij věstnik", $\mathrm{Nr}$. 10, abgedruckt. Nach diesem Abdruck zitierten inn die Narodniki.

93) Vgl. N.S. Krivenko, Po povodu kul'turnych odinozek. a.a.0., S. 186f; Nikolaj-on, Néct to ob uslovijach... (Teil 2), a.a.0., S. 110; ders., Apologija vlasti deneg... (Teil 2), a.a.0., S. $26 f$.

94) An dieser Stelle müssen zwei RB-Artikel genannt werden, die sich mit $F$. Engels "Der Ursprung der Familie, des Privateigentums una des Staats" und dem "Anti-Iühring" auseinandersetzen:

I. Zak, Istoričeskij materializm.

$\mathrm{RB} 1895 / 1$, II, S. $1-34$.

I. B-skij (Pseudonym eines unbekannten Autors), Nẻ to o dialektizeskom me todé.

RB $1895 / 4$, II, S. 44-72. 
In der zweiten Hilfte der neunziger Jahre bildete sich im RB eine etwas andere Tenoenz in der Auseinandersetzung mit den russiscinen lJarxisten heraus. Jurch die allgemeine Entwicklung in land sahen sich die "Legalen Narodniki" zur Anerkennung einiger Grundlagen der marxistischen tberzeugung gezwungen; unter anderem mubten sie einsehen, daB der Kapitalismus in Rubland nicht mehr umgangen werden konnte, da er bereits ein Paktum war. 95

Die Konfrontation mit den russischen luarxisten in der ersten Hilfte des Jahrzehnts hatte einen ProzeB eingeleitet, der $z u$ einer gewissen Assimilation an den Harxismus im Sinne des Revisionismus funrte. 96

Anfang des zwanzigsten Jahrhunderts begannen in Rubland parteipolitisch orientierte Aktivitäten eine zunehmend gröBere Rolle zu spielen. Im Zuge der parteipolitischen Differenzierung und

95) Vgl. N.F. Annenskij, Chronika vnutrennej žizni. RB 1896/2, II, S. 202.

96) In diesem Zusammenhang sind zwei Artikel von $V$. Cernov besonders relevant, die deutlich den Einflub Bernsteins und Simmels spüren lassen:

1) Tipy psichologiceskago i sociologiceskago monizma. RB 1899/1, I, S. 33-69.

2) Sub-ektivnyj metod $v$ sociologii i ego filosofskija predposylki.

RB 1901/7, I, S. 231-256;

$\mathrm{RB} 1901 / 8, I, \mathrm{~S} .219-262$;

RB $1901 / 10, I, S .107-156$;

RB $1901 / 11$, I, S. 115-162;

RB 1901/12, I, S. 123-175. - -

H.B. Ratner schöpft bei einer Untersuchung der Agrarfrage aus den Werken von Herz, irnst, David und Schippel:

Agrarnyj vopros $v$ evropejskoj literaturě. RB 1899/8(11), I, S. 148-179, und

RB $1899 / 9(12), I, S .215-247$. 
Formierung der Gesellschaft sah sich auch das $R B$ gezwungen, seinen ehemalig parteipolitisch neutralen standpunkt aufzugeben.

Nach der ersten russischen Revolution stand die Zeitschrift der kleinen Partei der "Narodnye Socialisty" am nächsten, die einen Platz zwischen Sozialrevolutionären und Kadetten einnahm. Tonangebend wihrend dieser neuen Periode ihres Bestehens waren neben Korolenko, der nach dem Tode Michajlovskijs im Jahre 1904 als alleiniger Herausgeber fungierte, A.V. Pešechonov, V.A. Mjakotin und N.F. Annenskij. Vom Herbst 1914 bis zum Frühjahr 1917 erschien das RB unter dem Namen "Russkija zapiski". 97

1918 nahm die Zeitschrift wieder ihre alte Bezeichnung an, wurde jedoch im gleichen Jahr durch ein besonderes Dekret der Sovjetmacht endgülig elngestellt.

97) Im Jahre 1906 war es eine kurze Zeit lang (zwischen Januar und Mai) als "Sovremennye zapiski" und "Sovremennost'" herausgegeben worden. 


\section{B. DAS DEUTSCHEANDBILD DES "RUSSKOE BOGATSTVO"}

I. Der deutsche Mensch

1. Der deutsche Michel

So vielfültig sich die "Stämme" eines Volkes auch voneinander unterscheiden, so besitzen sie doch gemeinsame Eigenschaften, die für ihr Volk kennzeichnend sind - wenigstens glauben dies sowohl die eigenen Landsleute als auch deren Nachbarn.

Dabei sieht jedes Volk verständlicherweise mehr seine erfreulichen Züge, während den fremden Völkern mehr die weniger angenehmen auffallen, man denke an die eingewurzelten Denkvorstellungen vom steifen Englishman, vom eitlen, frivolen, prahlerischen Franzosen, vom gemütlichen Österreicher, stolzen Spanier, Wodka saufenden Russen, oder auch an die (hoffentlich einmal verschwindenden) Vor u rteile, die aus Bezeichnungen sprechen wie Muffrika (holländisch für Deutschland), Krauts oder Hunnen (amerikanisch für die Deutschen), sales boches, dreckige Polen, faule südländer, Makkaronis, Butterfresser, Hammeldiebe. ${ }^{1}$

Nicht selten erhalten derartige Volksgestalten Namen; es ist bemerkenswert, wie oft dabei der im christlichen Morgen- und Abendland so beliebte Johames

1) Zur Vorurteilsforschung siehe z.B. Gordon it. Allport, Die Natur des Vorurteils. Köln, 1971; K.S. Sodhi und R. Bergius, Nationale Vorurteile. Eine sozialpsychologische Untersuchung an 881 Personen. Berlin, 1953. 
eine Rolle spielt: Ivan, Jean Fotage, John Bull, Hans ilurst, Dummer Jan. Doch bekan die Nationalfigur "des" Deutschen diese Bezeichnung nicht, obwohl vom 13. bis zum 18. Jahrhundert Johann der verbreitetste Vorname in Deutschland war. ${ }^{2}$

Vielmehr wurde das Selbstbildnis der Deutschen "Michel" genannt; beim ersten nuftreten in der Literatur (Sebastian Franck, Sprichwörter. Bd. II, Frankfurt a.14., 1541, BI. 49) noch mit Johann gekoppelt: "Ein grober Algewer Bauer, ein blinder Schwab, ein recht dummer Jahn, der teutsch Michel..."3

Hier braucht auf die verschiedenen Ansichten über die Ursachen der Fixierung "des" Deutschen an den Namen wichael nicht nüher eingegangen $z u$ werden, es sei dazu auf die einschlägige Iiteratur verwiesen. ${ }^{4}$

Der irzengel lüichael habe bei der Namensgebung als Schutzpatron der Deutschen Pate gestanden, St. Michael, schon bei den Germanen der Nachfolger irodans. 5

2) Gegen Ende des 18. Jahrhunderts war Johann als Rufname fast der Berufsname der Kutscher und Dzener geworden. Daher mußte Goethe den Dr. Johann Faust in Heinrich umtaufen; denn wenn am Schlub des ersten Teils "eine Stimme von innen verhallend" gerufen hätte: "Johann! Johann!" dann wäre das Publikum, bis dahin zu Tränen gerührt, in lautes Lachen ausgebrochen.

3) Nach hdolf Hauffen, Geschichte des deutscinen Michel. Prag, 1918, S. 42.

4) A. Hauffen, a.a.0.;

Carl Rademacher, ilodan - St. Wichael - cier deutsche líichel. Köln, 1934;

Ernst Boenlich, Johann Wichael Elias Obentraut. Zur Geschichte und Legenae des "Deutscien ichel". In: Bausteine, Festschrift zum 70. Geburtstage von hiax Koch. Breslau, 1926.

5) Vgl. C. Rademacher, a.a.0. 
Sein Bild habe auf den Bannern der deutschen Kreuzfahrer geprangt und daher seien die Deutschen nach ihm benannt worden; ${ }^{6}$ zu Beginn des DreiBigJährigen Krieges habe der Reiterfuhrer Johann Michael Elias Obentraut wegen seiner Tapferkeit den Ehrentitel "Deutscher Michel" erhalten. 7 Es se1 auch an Grimmelshausens Schrift "DeB Weltberuffenen Simplicissimi Pralerey und Gepräng mit seinem Teutschen Michel", 1670, hingewiesen doch schrieb Sebastian Pranck mehr als hundert Jahre früher.

Merkwirdig erscheint auch, daB die St. Michaelsbanner den anderen kreuzfahrenden Nationen bel ihren gemeinsamen Kriegsfahrten so wenig aufgefallen sind, dab sie diesen Erzengel nicht zu den sieben Streitern der Christenheit zählten. 8 Vermutlich liefen mehrere Fäden nebeneinander, verflochten sich manchmal, gingen aber nicht ineinander uber.

Vielleicht war Michael so wie Christoph ein verbreiteter Name bel den deutschen Bauern des Mittelalters.

Vielleicht bekam Michel im Laufe der Zeit einen le icht pejorativen Klang, so wie dies beim Kosenamen Christoffel, Stoffel der Fall ist. Wie dem auoh sel, se1t dem 15. Jahrhundert etwa haftete Michael als nomen pro toto an dem deutschen Bauern, dem bauernschlauen, anders ausgedruckt:

6) Vgl. A. Hauffen, a.a.0.

7) Vgl. E. Boehlich, a.a.0.

8) Es waren St. Georg fü England, St. Andreas für Schottland, St. Patrick fur Irland, St. David (lebte um 600) für Wales, St. Denis für Prankreich, st. Jago für Spanien und

St. Antonio fur Italien. 
dem dummpfiffigen, auch schlafmütigen (die Zipfelmutze kam als kennzeichnendes Nerkmal rund 300 Jahre später auf), schwerfälligen, aber gutmütigen Taps. Wenn man will, kann man ihn als "tumb" bezeichnen und $z u$ einem Parsifal ivagnerscher' Provenienz hinaufsteigern.

Doch kommt es uns hier auf dasjenige Bild an, das sich der kritische Deutsche (und auf seinen Spuren der kritische Auslënder) seit dem 19. Jahrhundert bis in die Zeit vor dem ersten iieltkrieg von seinen Landsleuten gemacht hat, zunächst wohl von den Bauern, dann aber von den Bürgern, nachdem der Schwerpunkt sich $z u$ innen verlagert hatte.

Danit verlagerten sich natürlich auch die als hervorstechend empfundenen Eigenschaften, so ironisiert Goethe 1797 in seinem Gedicht "Wusen und Grazien in der Mark" die satte Selbstzufriedenheit des Spiebbürgers, wenn er ihn sprechen läbt:

Zu dem Dörfchen laB uns schleichen, Mit dem spitzen Turme hier; Welch ein Wirtshaus sondergleichen! Trocknes Brot und saures Bier!

Selbst die Wissenschaft verlieret Nichts an ihrem raschen Iauf; Denn bei uns, was vegetieret, Alles keimt getrocknet auf.

LaB den Witzling uns besticheln! Glücklich, wenn ein deutscher Mann 
Seinem Preunde, Vetter Micheln, Guten Abend bieten kann. ilie ist der Gedunke labend: Solch ein idler bleibt uns nah!

Immer sagt man: "gestern abend War doch Vetter Michel da!"

Wir sind bieder und natürlich, Und das ist genug gethan. 9

Der SpieBer, der "lederne Philister", wurde seitens der Iiteraten leidenschaftlich bekampft (unabhängig davon, ob sie antisemitisch-rechts eingestellt waren wie Clemens Brentano ${ }^{10}$ oder gesellschaftskritisch wie Heinrich Heine), der träge, politisch uninteressierte, staatstreue Duckmäuser war nun der deutsche Michel. Als Beleg nur der Anfang des Heineschen Gedichtes "Michel nach dem iürrz".

Solang' ich den deutschen wichel gekannt, War er ein Bärenhäuter; 11

sowie die SchluBverse:

Derweil der Michel geduldig und gut

Begann zu schlafen und schnarchen, Und wieder erwachte unter der Hut Von 34 Monarchen.

9) Anspielung auf ein Volkslied un 1760. Goethe verhöhnte in seinem Gedicht den Prediger und Idyllendichter Fr. W. Aug. Schmidt, gen. Schmidt von Werneuchen, den Herausgeber des "Kalenders der Musen und Grazien".

10) C.B., Der Philister vor, in und nach der Geschichte. 1811.

11) Es sei darauf hingewiesen, daB Grimmelshausen im gleichen Jahr, 1670, in dem die Pralerey mit seinem Teutschen Michel erschien, das Schriftchen "Der erste Bärnhäuter" veröffentlicht hat. 
Von da an erhielt der Deutsche Michel seine politische Gestalt in Zeitgedichten und Spottbildern. Man versuchte, den Michel als Verkürperung der liasse herauszureiBen aus seiner Geduld, seiner Gutmütigkeit, seiner verschlafenen Unentschlossenheit.

Oder man ging ihm um den (auf keinem Bild vorhandenen) Bart, hob inn aufs schild als ehrlichen geraden, ticntigen, hunorigen, friedlichen, leicht verträumten ienschen, der allerdings, wenn zu sehr gereizt, sich leidenschaftlich zur iehr setzt, doch nach verpuffter Wut wieder in seine Sanftneit zurücksinkt. ${ }^{12}$

Diese fast heldische, sicher aber liebenswerte ligur, nach dem Siege 1870/71 über Frankreich Gemeingut der sich immer rascher industrialisierenden deutschen Gesellschaft, änderte sich mit zunehmender "Reichsverdrossenheit". Wan kritisierte nunmehr - am schärfsten im "Simplizissimus" (München) - die einzelnen Typen der herrschenden Klasse, vor allem die vom Staat besonders hochund herausgestellten offiziere, Junker, Corpsiers.

Die dort erscheinenden beißenden Satiren und Karikaturen haben das Deutschlandbild des $K B$ mitgeprägt; denn seine Berichterstatter waren offensichtlich eifrige Leser und Bewunderer des "Simplizissimus", der es verstand, die Schwächen der Stützen des Regimes in ebenso eleganter wie boshafter Heise blobzustellen.

Im übrigen stimmt das $\mathrm{RB}-\mathrm{Bild}$ vom "typischen" Deutschen in Vielem mit dem Bild vom "Deutschen

12) Vgl. C. Rademacher, a.a.0., S. 97-101; A. Hauffen, a.a.0., S. 92-95. 
Michel" uberein, das die Deutschen selbst von sich entworfen hatten. Der Name "Michel" für "die Deutschen" wird sehr häufig vom RB verwendet, ${ }^{13}$ sogar eine 37 Seiten lange Abhandlung trägt die tberschrift: "Michel unter Waffen". 14

In RB werden den Deutschen folgende Hauptcharakteristika zugeschrieben: "Beständigkeit, Ausdauer, FleiB und Initiative". 15 Der "Deutsche Nichel" ist friedlich, 16 hat einen "beherrschten geduldigen Charakter" und "geht niemals bis zum Äußersten, ohne wirklich ernsthafte Gründe" 17 AuBerdem ist er "verhaltener in seinen Gefühlsregungen" als andere Völker. ${ }^{18}$ Die "spezifisch deutsche Sentimentalitä" findet mehrfach Beachtung, 19 ebenso die "deutsche Akkuratheit", die ubergroBe Genauigkeit,. die von den Russen halb bewundert und halb belächelt wird. 20

13) Vgl. z.B. A.K., Iz Germanii. RB 18y5/2, II, S. 118; Reus, Pod znamenem kapitalizma. RB 1903/6, II, S. 156, 190; Keus, I z Germanii. RB 1903/7, II, S. 84f; Reus, Simplicissimus (Pismo iz Germanii), RB 1904/5, II, S. 57; Reus, Gospoda junkery (Pifmo iz Germanii), RB 1904/11, II, S. 111 .

14) Vgl. Reus, inichel' pod ruž'em (Piśmo iz Germanii). RB 1903/11, II, S. 145-181.

15) Vgl. an., Novyja knigi, RB 1899/8(11), II, S. 24. A.K., Iz Germanii. RB 1895/9, II, S. 120.

16) Vgl. Reus, Michel' pod ruz'em. (Pis'mo iz Germanii). RB 1903/11, II, S. 165.

17) Vgl. V.T., Chronika zagraniènoj žizni. RB 1893/7, II, S. 80 .

18) Vgl. V.T., Chronika zagraničnoj zizni. RB 1893/5, II, S. 89.

19) Vgl. A.K., Iz Germanii. RB 1895/9, II, S. 121. A.K., Iz Germanii. RB 1895/10, II, S. 183. N.A. Iuchmanova, Dvadcat' let nazad. RB 1893/10, I, S. 151, a.a.

20) Vgl. S.N. Južakov, Dnevnik zurnalista. $\mathrm{RB} 1897 / 5$, II, S. 141 . an., Novyja knigi. RB 1898/5, II, S. 38. 
Während die "enorme Fähigkeit" des Deutschen, "das Nutzliche mit dem Angenehmen zu verbinden", bestaunt wird, 21 empfindet das RB die "traditionelle deutsche Grobheit" als unangenehm. 22

Ebenso wenig schmeichelhaft ist de Meinung des RB, das Philistertum sei äuBerst charakteristisch für die Deutschen. Es definiert den Philister als "Mensch mit kleinlichem und engstirnigem Egoismus", als "Wesen, das keinerlei Uberzeuguniten hat", als "passives Werkzeug, dazu geboren, bevormundet, gelenkt und geleitet $z u$ werden", als "die eingefleischte Bereitschaft $z u$ allem und jedem, wenn inm nur eine kleine Rente oder Besoldung gesichert 1st; seine Beeinflubbarkeit und seine Leichtfertigkeit haben keine Grenzen, seine Selbstaicherheit und Impertinenz ebenfalls". 23

Ein solcher Wenschentypus ist in jedem Volk anzutreffen, wenn jedoch, wie im Falle RB, die Bezeichnung "Philister" sehr häufig dann verwendet wird, wenn von der breiten Masse der deutschen Bevölkerung gesprochen wird, "Philister" also mit "dem Deutschen" gleichgesetzt wird, dann kann man folgern, daB nach Ansicht des RB die Summe der charakteristischen Eigenschaften des Deutschen geradezu prädestinfert ist, den Typus des "Philistera" hervorzubringen, daB er von seinen Anlagen her mehr als andere dazu geschaffen ist, Philister zu sein.

21) A.K., Iz Germeni1. RB 1895/5, II, S. 112.

22) Vgl. N.K. Michalovskij, Iiteratura 1 žizn'. $\mathrm{RB} 1895 / 1$, II, S. 139

23) Vgl. Reus, Pod znamenem kapitalizma. Pismo iz Germanii. RB 1903/6, II, S. 166. 
"Durch die Philister ist die Herrschaft der Schreiberlinge - Bürokratie genannt - entstanden", sast das $R B, 24$ stellt aber Eleichzeitig fest, daß der Kung zur Bürokratie den Deutschen aligemein angeboren sei. 25

Auf diesem biirokratischen Wesenszug fubt, seiner seinung nach, auch die Titelsucht der Leutschen, diese ausgeprägte "Schwache zur Kangliste"26

Diese allgemeine Beurteilung der Deutschen stirimt in wesentlichen Zügen überein mit der Charakteristik einzelner Deutscher, die in rubland leben:

Da gibt es einen jungen deutschen Gärtner namens Schridt, "eine echte engstirnige, formale, deutsche jeele, mit kriegerischer Prägung, mit einer unverhohlenen, auf nichts begrindeten iberneblichkeit allem kussischen gegeniiber," 27 die unterwirfige aeutsche Bonne, die stシ̈ndig "sehr gut, Madarie" sagt und Knickse macht, 28 uni die "kleinliche" deutsche Erzieherin in russischen Internaten. 29

24) Ebenda.

25) Vgl. A.K., Iz Germanii. KB 1895/8, II, S. 119.

26) Ebenda. - und A. Kovrov, Iz Gernanii. RB $1896 / 2$, II, S. 89 . Hierbei hat das $R \exists$ offensichtlich den Splitter im Auge des Nachbarn Nichel bemerkt und den "Čin"-Balken in Auge des eigenen Landes (iatthäus 7,3 ) ubersehen.

27) Vgl. S. Krivenko, Po povodu kul'turnych odinoček. RB 1893/12, II, S. 173.

28) Vgl. N.G. Garin, Dětstvo Teuy. KB 1892/1, I, ذ. 22 .

29) Vgl. N.A. Iuchmanova, Dvatcat' lět nazad. KB $1893 / 10, I, S .151$. 
Zwar werden den Deutschen im $\mathrm{RB}$ auch einige liebenswerte Eigenschaften, neben den eben genannten schlechten, zugestanden, jedoch dominiert für es immer ihr Hang zum MittelmäBigen und spiebigen.

Der Deutsche wird als "Gemütsmensch" bezeichnet, 30 "den es in den Schatten der blühenden Apfelbäume zieht, dem sein stilles Heim teuer ist, und der sich bemüht, sein Leben so zu gestalten, dab solange wie möglich die offenherzige und bisweilen naive Heiterkeit des erwachsenen kindes bewainrt bleibt". 31

Sein "Gemütsmenschsein" schlägt sich in seinem Bedïrfnis nach "Gemütlichkeit" nieder, die vom RB fast schon als Sucht empfunden wird. Diese spezifisch deutsche "Gemiutlichkeit" - ein Wort, das man laut Auskunft des RB nicht ins Russische übersetzen kann, 32 sei für den Deutschen lebensnotwendig, weil sie eine äußere Atmosphäre schafft, die sein Innenleben in Watte packt und beschützt. 33

Die tiberbetonung des "gemütlichen und hübschen Heims" wird als "rein nationales Lebensstreben" des deutschen Michel angesehen: Der russische Berichter stützt seine Behauptung auf die für ihn "verblüffende" Beobachtung, daB "sowohl das Heim eines reichen Millionärs, als auch das Heim des bescheidensten 'königlichen Heizers' in ein und demselben Stil eingerichtet ist: der einzige Unterschied liegt im Preis und in der vualität." 34

30) Vgl. Reus, Simplicissimus (Piśmo iz Germanii). $\mathrm{RB}$ 1904/5, II, S. 47, 48 .

31) Ebenda, S. 48.

32) Ebenda, S. 48.

33) Ebenda, S. 50.

34) Ebenda, S. 48. 
Die Ausfuhrlichkeit und die Art und Weise, in welcher das deutsche Heim geschildert wird, deutet darauf hin, daß der Berichter keus in diesem Heim die Verkörperung charakteristischer deutscher Eigenschaften, gleichsam ein Spiegelbild deutschen Wesens, gefunden zu haben glaubt.

Mit der allgemeinen Peststellung, daB der Durchschnittsdeutsche "keinen Wert auf asthetik, wie etwa der Franzosen 35 lege, ist sein Geschmack schon klassifiziert.

Für äußerst aufschluBreich hält Reus in diesem Zusammenhang das Vokabular, das der Deutsche gebraucht, wenn er etwas bewundert: der Deutsche sagt niemals "das ist schön, das lst hinreißend, das lat groBartig", 36 sondern "wie ist das lieb, wie ist das niedlich, wie ist das angenehm!n 37

Was der Deutsche unter "Gemütlichkeit" versteht, deren er so notwendig bedarf, erscheint dem Russen als "künstlich gemacht", 38 Ausdruck dieser Gemülichkeit ist die Gestaltung seines Heims: "Dem kunstlerischen Gefuhl sagen alle diese Petzen wenig, die so sorgfältig an Wänden und Penstern aufgehängt sind", schreibt Reus, "alle diese billigen Büsten und Väschen, die zum unvermeidichen Zubehor jeder echtdeutschen Tohnung gehören. Aber all das finden die Deutschen 'nett' und 'hübsch'...n39

35) Ebenda, S. 48

36) Ebenda.

37) Ebenda, S. 50.

38) Ebenda, S. 49.

39) Ebenda, S. 48 
"Die Zimmer sind vollgestopft mit einer kienge unnötiger viöbel, in der Wohnung ist weder Raun noch Luft zu spüren; Holz, Stoff und Wände scheinen $z u$ einer Art Kapsel zu verschmelzen, die auf Teufel komm raus einen gemütlichen Eindruck hervorbringen soll, aber in Wirklichkeit nur ein großer Staubaufbewahrungsort ist, mit dem das gesamte weibliche Personal der Familie energisch und une rmüdlich kämpft." 40

Die Art und Vise, wie sich der Deutsche selbst etwas vormacht, wie er besonders in Zeiten außerer Wirrnisse (soziale Unruhen, Wirtschaftskampf,

40) Ebenda, S. 49.

Der Anschaulichkeit nalber soll die Beschreibung des deutschen Heims an dieser Stelle noch vervollständigt werden:

"Geschnitzte Holzstühle mit unbequemen Lehnen und Holztäfelchen an den Wänden, dunkle drapierte Vorhange an Fenstern und Türen, riesige Holzbetten mit riesigen Federbetten und die unvermeidliche marmorne Waschschüssel; eine Masse höchst simpler Bilder an den Wänden und zwischen innen obligatorisch die Portraits des Großen Kanzlers und des nicht weniger großen ehrwirdigen, greisen Kaisers; Bouquets aus getrocknetem Gras, Vasen und Statuetten uberall, wo man sie nur hinstopfen kann; völliges Pehlen von licht in allen Zimmern infolge der ewig heruntergelassenen Jalousien, welke Pflanzen in papiergeschmulckten Vasen und auf allem der Stempel der MittelmäBigkeit und des Friedens, eines unkomplizierten Gefühls und vielerlei Erinnerungen: von jeder Reise ein mitgebrachtes Krüglein mit Aufschrift, von jeder Familienfeier beiseitegelegte Souvenire; an den Wänden prunken Gruppenbilder zur Erinnerung an gemeinsame Kommerse und Kneipen; aber alles ubertreffen die Postkartenalben, und, wenn welche vorhanden sind, die nicht weniger bemerkenswerten Alben mit Glückwunschtelegrammen, die zu Pamilienfesten eingegangen sind..." Ebenda, S. 49. ---

(Tatsächlich unterschied sich das Arbeitszimmer z.B. des Journalisten Lindau von dem $201 a s$ oder Ibsens oder gar Lakarts höchstens in Preis des Plüschmobiliars! Dieser "Makartstil" war damals internationale Mode.) 
Klassenkampf) mit unso "größerer Hartnäckigkeit und Beharrlichkeit" in sein Heim strebt und "mit desto mehr Eifer" in seiner Umgebung "Gemütlichkeit und Harmonie" zu schaffen sucht", 41 wie er sich gegen alle äußeren Einflússe, die ihm seine Ruhe und seinen Frieden rauben könnten, hermetisch abkapselt, ${ }^{42}$ dies alles erscheint dem KB wie eine kindliche Vogelstraußpolitik.

Der Deutsche versuche, alles "durch die Brille des Angenehmen" 43 zu sehen und sich eine heile ifelt vorzugaukeln.

Aus dieser Haltung resultiere aber der "fortwaihrende Vorrat an Unbekummertheit", der "unkomplizierte Humor" und die "allversöhnende, allesausgleichende Routine" des Deutscnen, eben jene Eigenschaften, die ihm "eine erstaunliche Standfestigkeit in allen ... Stiurmen..." verleihen, die "erstaunliche Kraft des passiven iijderstands in den schrecklichsten Notlagen" hervorbringen, und ihm erlauben, "verhältnismäßig leicht ... die größten Veränderungen in seinem schicksal und der gesellschaftlichen Lage" zu uberstehen. 44

Andererseits sieht er gerade in dem mit "'lieben' und zu nichts nützen Dingen vollgestopften Heim" und in der "zum Schutz mit gutmütiger Gleichgütigkeit und 'lieben' Vorurteilen bedeckten Seele" 45 den Boden, auf welchem so úppig die altdeutsche

41) Ebenda, S. 48 .

42) Ebenda, S. 48-50.

43) Ebenda, S. 50.

$44)$ Ebenda, S. 49.

45) Analog etwa den intimakassardeckcinen auf dem Sofa des "Salon" der damaligen Zeit. 
Treue gedeihen konnte, und mit inr auch der unbewußte und unkluge Fatriotismus." 46

Vie unverständlich für einen kussen dies alles sein mußte, manifestiert sich darin, daß keus den Deutschen, diesen "Gefülsmenschen", mit einem "Apparat" vergleicht, "der in viele einzelne Zellen abgeteilt ist": "Der Deutsche verausgabt sich niemals ganz"... "Nach dem Miab der Notwendigkeit offnet er in seiner Seele einzelne klappen und lebt nur durch sie". ${ }^{47}$

Eine dieser Klappen ist der deutsche Humor: "Die Deutschen halten Humor für eine spezifische Eigenschaft des deutschen Volksgeistes", stellt das RB fest.

Entsprechend der Charakterisierung des Deutschen als Gemütsmensch mit der Tendenz, sich allem Komplizierten, Unruhigen und Verfeinerten zu verschließen, kann auch sein Humor weder kompliziert noch raffiniert sein.

"Es gibt wohl kaum ein Volk, das sich so ernsthaft mit solch sympathischen Dummeiten, mit solch relativ naiven Unsinnigkeiten beschäftigen könnte, uber die sich ... der Deutsche freut", 49 urteilt Reus.

Br illustriert den typisch deutschen Humor, den er als "plumpen Humor des Unsinns" (neukljužij

46) Vgl. Reus, Simplicissimus. a.a.0., S. 50.

47) Ebenda, S. $49 f$.

48) Vgl. A. Kovrov, Iz Germanii. RB 1896/1, II, S. 145 .

49) Vgl. Reus, Simplicissimus, a.a.0., S. 51. 
jumor neleposti) $)^{50}$ bezeichnet, an zwei Beispielen:

Für äußerst charakteristisch hält er zunächst ein deutsches Buch, das dem Jackel gewidmet ist, dieser "Verkörperung von Hundeverstand und Verspieltheit", der für den Deutschen "Lieblingsschmuck" seines Heimes und "tröstender Engel" zugleich set, wie Reus seinen russischen lesern erläutert. 51

Diese "Epopöe" uber den Dackel, die aus Darstellungen des "gescheiten Tierchens" in jeder nur denkbaren Form und Situation von Hand der "besten Künstler Deutschlands" bestehe, vermittele zunächst etwas über die "innige Beziehung" des Deutschen zu seinem krumbeinigen liebling und zeige auBerdem, über welch harmlose und einfache Dinge sich der "Gemütsmensch" amüsiert. 52

50) Ebenda. -

Es ist an dieser stelle vielleicht nicht uninteressant zu erwähnen, dab Reus diesen für die Deutschen charakteristischen "plumpen Humor des Unsinns" von deutscher Seite am besten in den Arbeiten von Wilhelm Busch eingefangen sieht. Ebenda.

51) Ebenda, S. 50.

52) Ebenda. -

Der Dackel war in Ausland (nicht nur in RuBland) der typische Begleiter des deutschen wichel und des deutschen Gretchens. Dies gilt bis in die Gegenwart, man denke an den "Olympiadackel" von 1972. --

Seinerzeit waren die Zeichner A. Roeseler und A. Oberländer die beliebtesten Dackeldarsteller in dem unpolitischen iitzblatt "Pliegende Blätter". Ihre Bildchen wurden viel geliebt und viel belacht. 
Alle Merkmale der "Dackeliade", die Reus als so bezeichnend für die besondere Art des deutschen Humors empfand, begegneten inm im Münchner Karneval wieder.

Der Russe hat dieser Masse von sonst so biederen und disziplinierten Deutschen, die sich einmal im Jahr in die groteskesten Kostijme hullen und fröhlich sein wollen, weil Karneval ist, sicherlich etwas verwirrt und hilflos gegenubergestanden. 53

Verblüft haben muB inn dabel aber die Erfahrung, daB der Deutsche, auch wenn er hier, entsprechend der Theorie rom Apparat mit einzelnen Zellen, nach dem NaB der Notwendigkeit nur wieder eine Klappe in seinem Inneren freigelegt hat, innerhalb dieses kleinen Ausschnitts uberzeugend wirkt. Obwohl diese Art von deutschem Humor fur inn fremd und unverständich war, fülte er sich unwillkürlich infiziert: "Hier gab es weder französische

53) Das Phänomen des karnevalistisch gestimmten Deutschen wird von Reus sehr einprägsam vermittelt: "der dicke Kutscher, im Babykostüm, der seinen Bierbauch in kurzen Samthöschen versteckt, seinen dicken roten Hals mit einem Kinderkrägelchen aus Spitze eingerahmt hat und einen Schnuller im Mund trägt. Der dicke Pleischergeselle im Trikot und Damennachthemd als verschämte Schöne, die gerade aus dem süBen Lotterbett gerissen wurde. Ein ungeheuerlicher Gendarm mit rot glänzender Nase und einem Schnurrbart aus Bast, der sich in absurder Tht auf die harmlosesten Karnevalsanhänger sturzt. Schlieblich ganze Scharen von Bergateigern,. die sorgfältig jede entgegenkommende StraBenlaterne hinaufklettern; riesige Gruppen von unvorstellbaren Raubern, Vagabunden und mit allen Regenbogenfarben geschmickten Säufem und Sträflingen - all das bewegte sich m1t Geschre1 und Lärm am Palast des Prinzregenten und an Theater vorbei, fullte die breite StraBe und uberschuttete die weiBen Clowns, die bunten Harlekins .... mit einem Meer von Konfetti und Papierschlangen". Ebenda, S. 51. 
Eleganz, noch italienische Leidenscinaft, die 'ilitze' fielen schwer und plump aus und waren bisweilen grob, aber uber allem lag eine solche Atmosphäre von naiver, fast kindlicher Fröhlichkeit, so gutmutig wurde selbst die miBlungenste Posse aufgenommen, so aufrichtig wollten alle fröhlich sein, dab man unwillkürlich von irgendeiner halbdummen, halbfrohen stimmung erfabt wurde und über die Fliege an der Wand lachen konnte". 54

Dieser Eindruck muß für Reus umso verwunderlicher gewesen sein, als nach seiner Theorie der karnevalistische Humor ebenso systematisch geplant war wie alles in der Deutschen Arbeits- und Freizeit. "Seine Lebensweise ist nach einem streng gegliederten Plan eingeteilt und verblüft oft durch ihre Gradlinigkeit." 55

Scinon lange vor Anbruch eines Feiertags beispielsweise, sei das Programm für diesen Tag "bis zum letzten Detail ausgearbeitet", und nur die "unüberwindlichsten Wetterumschwïnge könnten thn daran hindern, dieses Programm von Anfang bis Ende durchzusetzen". 56

An solchen Tagen entwickele er eine Art von "Lebensfreude", mit der sich "allein nur die Deutschen zu maskieren fähig sind". 57

54) Ebenda, S. 51.

55) Vgl. A.K. Iz Germanii. KB 1895/6, II, S. 107.

56) Ebenda.

57) Ebenda, S. 108. 
Er gehe ins Theater oder ins Kaffee, besuche ein Platzkonzert oder veranstalte ein Picknick im Grünen und spreche vor allem dem deutschen Nationalgetränk, dem Bier, zu. 58

Nach der russischen Schilderung zu urteilen, erweckt der Deutsche den Eindruck, als wenn er selbst seine Lebensfreude rationiere, er kann wohl sehr ausgelassen und fröhlich sein, aber nur dann, wenn bei einem festgesetzten AnlaB die Klappe "Lebensfreude" geöffnet werden darf.

Immer in dem Bestreben, seine kleine Welt zu erhalten, enge der Deutsche sie auch dadurch künstlich ein, daB er sich am liebsten in Gesellschaft einer bestimmten Anzahl inm bekannter leute aufhält, die alle den gleichen Geschmack und gleiche Ansichten, wianieren und Angewohnheiten haben. 59

Auf derselben Linie liege auch sein Bestreben, an einer vertrauten Umgebung festzuhalten: "der Deutsche liebt sein Gasthaus, seinen festen

58) Den genauen Ablauf eines solchen Feiertags, in diesem Palle Pfingsten, des "Lieblingsfeiertags des Deutschen", schildert der Deutschlandkorrespondent A. Kovrov, ebenda, S. 107-111..--

Des Deutschen Vorliebe für Bier scheint den Russen besonders aufgefallen $z u$ sein, denn immer wieder wird er als "Bierliebhaber" hervorgehoben, z.B. A. Kovrov, Iz Germanii. RB $1895 / 11$, II, S. 128-129. A. Kovrov, Iz Germanii, RB 1896/2, II, S. 91, $92,93$.

Reus, Michel' pod ružem. KB 1903/11, II, S. 149 und Reus, Burenoscy (Pis'mo iz Germanii) RB 1904/3, II, S. 72, 75.

59) Vgl. Reus, Burenoscy. a.a.0., s. 75. Reus bezeichnet diese Haltung als "philisterhafte Cliquenwirtschaft", die bei den Deutschen besonders ausgeprägt sei. Ebenda. 
Platz, seinen Stammtisch und seinen Verein". 60 Komme er abends von der Arbeit nach Hause, so eile er gleich nach dem Abendessen in ein Gasthaus, um dort sein obligatorisches Bier zu trinken. "Und dort sitzt er stundenlang entweder hinter der Zeitung oder zusammen mit Freunden an einem festen, bestimmten Tisch". 61

Dabei sel bezelchnend fur die Natur des Deutschen, $d a B$ er nicht varilert: "Wenn er sich heute einen bestimmten Platz für sein Bier auggesucht hat, so kommt er auch morgen, übermorgen, in einer Woche und in zwei."62 Diese Erscheinung nennen die Russen "Bierkonservatismus". 63

Nach Ansicht des RB erfüllt dieses Ritual beim Deutschen zwei Aufgaben: er kann sich eine Scheinwelt aufbauen und auf Zeit alle Unannehmlichkeiten des wahren Lebens vergessen, zudem bleibt er von der Notwendigkeit verschont, sich etwas Neues ausdenken zu müssen, über Unbekanntes nachzusinnen und auf neue Eindrücke zu reagieren. So wird der Stammtisch zum "Apparat zur Konservierung von Philisterhirnen- und herzen, ein. freiwilliges Gefängnis fur die selbstzufriedene Trägheit." 64

Die Stammtischfreunde begnügen sich oft nicht mit den gebräuchlichen Nebenbeschäftigungen, mit denen sie ihre Liebe zum Bier zu untermalen pflegen, wie Karten-, Schach- und Billardopielen. Sie greifen ein gemeinsames Interesse auf, setzen sich ein

6o) Ebenda, S. 76

61) Ebenda, S. 75 .

62) Ebenda, S. 76 .

63) Ebenda.

64) Ebenda. 
bestimmtes ziel und gründen einen kleinen verein. 65

Der Deutsche strebt also sehr wohl nuch dem Höheren, jedoch bewegen sich auch seine geistigen Interesser irrer in einem fest abgesteckten Rahmen.

Der Deutsche ist kein Individualist. Er verspüt den unwiderstehlichen Drang, sich auf allen Gebieten zu assoziteren und zu institutionalisieren. 66

Dieser $Z u g$ ist so ausgeprägt, daB sich Deutschland geradezu den Ruf als "klassisches Land" aller uberhaupt möglichen Vereine und Verbände erworben hat. 67

AuBerdem wird es als "klassisches Land" aller nur denkbaren Tagungen und Kongresse angesehen. 68 Diese Vorliebe ziehe sich durch sämtliche gesellschaftlichen Schichten. 69

65) Ebenda, S. 75 . "Ein solcher Verein macht sich etwa zur Aufgabe, die italienische Sprache und Italien zu studieren, - ein anderer betreibt Graphologie oder Handlesen. Einer gestattet nur Gespräche über Politik, der andere nur über Kunst." Ebenda.

66) Vgl. U.a.: A. Kovrov, Iz Germani1. RB 1896/2, II, S. 90:

Evgraf Kovalevakij, V velikom gercogstvě Ijuksemburgskom. RB 1892/1, I, S. 76; an., Novyja knigi. RB 1899/8(11), S. 24 .

67) Vgl. A.K., Iz Germanii. RB 1895/5, II, S. 103; A.K., Iz Germani1. RB 1895/8, II, S. 120 an., Chronika zagranienoj zizni. RB 1890/8, S. $164 f$.

68) A.K., Iz Germanii. RB 1895/5, II, S. 103.

69) "Politiker, Gelehrte, Lehrer, Studenten, katholische und protestantische Geistlichkeit, Kaufleute, Handwerker, Arbeiter - kurzum, Leute aus allen Schichten benutzen einen Feiertag oder eine ganze Perienwoche dazu, in irgendeinen gastilchen Winkel zu einem Kongress zu fahren und dort bei einem Krug Bier uber das zu sprechen, was sie bewegt. Eine bessere Erholung kann sich der geschäftige Deutsche nicht vorstellen." Ebenda; oiehe auch A.K. Iz Germanil. RB 1895/6, II, S. 111. 
Eine dieser Schichten, die deutsche studentenschaf: genauer, die Korporationsstudenten - werden zu den "charakteristischsten Typen des deutschen Volkes" gerechnet, 70 vielielcht deshalb, weil bet diesen einige der den Deutschen als kennzeichnend zugeschriebene Eigenschaften auf die Spitze getrieben erscheinen.

Dabei betrachtete das RB fast ausschlieBlich die farbentragenden Korporationsstudenten, die von ihm als die offiziellen Repräsentanten der deutschen akademischen Jugend angesehen wurden. ${ }^{71}$

Vereinsgeist, verbunden mit Systematik, sei von diesen jungen Leuten zum Selbstzweck erhöht worden, der für die Berichter geradezu grotesk ubertrieben erscheinen muß.

Das RB kann nicht verstehen, wie sich die schlagenden Studenten dem strengen Reglement, dem Comment, freiwillig unterwerfen können, der den Studenten derart fesselt, $d a ß$ er völlig in seinen Verpflichtungen aufgeht: er diene sich zunuchst biertrinkend rom "Fuchs" bis zum "aktiven Bursch" empor, dabei bleibe für das Studium natuirlich kaum Zeit. ${ }^{72}$

Im Rang eines aktiven Burschen - Traum eines jeden deutschen Schullers - sei er ausschlieblich damit

70) VEl. A. Kovrov, Iz Germanii. RB 1896/2, II, S. 86 .

71) Ebenda, S. 86, 96.

72) Der Deutschlandkorrespondent Kovrov demonstriert die fremdgeleitete Pflichtauffassung der deutschen Couleurstudenten an dem Studentenlied: "In Halle angekommen, Cerevisia cerevis!

Als Füchsle in aufgenommen, - Cerevisia Cerevis! Da ging es gleich an ein flott Commersieren, denn studieren darf ein krasser Fuchs noch nicht! - Cerevisia cerevis!"

Ebenda, S. 91 . 
beschäftigt, allen vorgeschriebenen Konventionen nachzukommen: Fechtkurse, obligatorische Frühund Dänmerschoppen, Exbummel und Stiftuntsfeste verschlängen seine Zeit und sein Geld. ${ }^{73}$ ir befolge das studentische keglement mit solchem Pflichteifer, solcher Systenatik und Disziplin, als handele es sich dabei um eine höhere Lebensaufgabe. Sogar das Trinken, das Hauptvergnügen, werde so systematisch betrieben, dab es einer Exerzierübung gleichkomme, bei der gar die Ehre auf dem Spiel steht. Abfällig schreibt Kovrov von den verschicdenen Bierritualen wie "Bierskat, Rammes, Cerevis, Quodlibet" und dem anschliessenden "Biergericht", und kommt zu folgendem SchluB: "So zu trinken, wie das in den farbentragenden Korporationen geschieht, nach einem festgesetzten, genau ausgearbeiteten Bierkodex, dem sogenannten biercomment, und dies zur Heldentat $z u$ erheben derartige Sitten sind gelinde gesagt primitiv, roh und unzeitgemäß". 74

Ebenso vernichtend beurteilt er auch das studentische Duell, die Uensur, die seiner Ansicht nach auch nicht eine Spur von Tapferkeit beinhaltet.

Er konstatiert, daß der SchmiB für den deutschen Studiosus die gleiche Verzierung bedeute, "wie die Tätowierung für den vilden" und schilt die Mensur "Relikt mittelalterlicher Barbarei". 75

2u den verschiedenen Zeremonien, die das Leben eines Couleurstudenten ausmachen, gehöre auch ein

73) Ebenda, S. $91 f .$, S. 89.

$74)$ Ebenda, S. 93.

75) Ebenda, S. 95 
bestimmter Manierenkodex im Umgang miteinander. Wie "chinesische Mandarine" kommen sie Kovrov vor, obwohl selbst jene, wie er meint, ungekünstelter miteinander ungingen, als diese Kommilitonen unter sich. 76

Als einziges gutes Resultat der jahrhundertelangen korporativen Erziehung erkennt Kovrov die Diszipliniertheit der deutschen studentenschaft an, 77 im ubrigen betrachtet er die Korporation als Anachronismus. 78

In früheren Zeiten habe den Verbindungen (gedacht ist an die Burschenschaften) eine Idee zugrunde gelegen, sie hatten politische Funktion, der deutsche Student war noch Träger hoher Ideale. 79 Heute nähre sich der Couleurstudent nur noch von den alten iraditionen, die Idee sei durch Uberkultivierung von AuBerlichkeiten und Getue ersetzt worden. 80

Welchen Sinn haben diese Korporationen in der Gegenwart uberhaupt noch? Warum finden sie weiterhin solchen Zulauf, frät sich Kovrov. Die eigene Motivation der Verbindungsstudenten (hochtrabende

76) Ebenda, S. 92.

77) Ebenda, S. 991.

78) Ebenda, S. $88,90$.

79) Ebenda, S. 86, 89f., 92, 94.

80) Ebenda, S. $86,91 f ., 94,97$, und Reus, Iz Germani1. RB 1903/7, II, S. 991; -Nur noch "unter AikoholeinfluB und in Momenten festlicher Hochstimmung (toržestrennaja pripodnjatost') ist er glühender Enthusiast des nationalen Stolzes, der nationalen Unabhängigkeit, Einheit, usw. usw."

$\mathrm{VGl}$. A. Kovrov, Iz Germanil. RB 1896/2, II, S. 86; siehe auch A.K., Iz Germani1. RB 1895/2, II, S. $119 f$. 
Worte wie: im deutschen Volke "das gesunde Nationalgefül" und das "stolze Bekenntnis zur nationalen Ehre" aufrecht erhalten ${ }^{81}$ ) widerlegen sie durch inr Verhalten.

Die Mitarbelter des RB waren über alle Vorkommnisse und Einrichtungen in Deutschland auBergewöhnlich gut unterrichtet, auch über die Verhältnisse an Deutschlands hohen Schulen. Sie kannten die Unterschiede zwischen "Pinken" oder "Wilden" und Korporierten, zwischen farben- und nichtfarbentragenden Verbindungen, zwischen konfessionellen und freien Vereinigungen, zwischen schlagenden und nichtschlagenden, zwischen Landsmannschaften, Burschenschaften, Turnerschaften und Corps. Dabei war dem RB klar, daB die Corps ${ }^{82}$ Leitbilder für die anderen schlagenden Verbindungen waren, so daB diese, sich hauptsächlich aus dem Mittelstand rekrutierend, vorwiegend dem "äußeren Glanz" huldigten, auch wenn dies ihre finanziellen Verhältnisse überstieg. 83

Vermutlich sei dieses Gebaren auf den im deutschen Bürgertum so ausgeprägten Standesgeist zurückzufuhren. 84

Tatsache se1, dab sich die deutschen korporativen Studenten "in ihren bunten Mützen und inren durch

81) Vgl. A. Kovrov, Iz Germanil. $R B$ 1896/2, II, S. 91 .

82) Gemeint sind vermutlich die im Kösener S.C. zusammengefabten Corps an den Universitäten, z.B. Borussia-Bonn, zu dem vor allem der Hochadel, und Palatia-Bonn, zu dem die Geldaristokratie strömte.

83) Vgl. Kovrov, I a Germanil. $1896 / 2$, II, S. $91 f$.

84) Vgl. Reus, Simplicissimus, a.8.0., S. $69 f$. 
¿iensuren und Duelle zerschnittenen Gesichtern" nicht nur selbst als "Halbgötter der deutschen bürgerlichen "̈elt" fühlten, 85 sondern auch wirklich von der bürgerlichen Gesellschaft als solche angesehen und behandelt würden. 86

In den Augen vieler unschwebe den Verbindungsstudenten immer noch die "Aureole mittelalterlicher Romantik und Poesie". Zudem glaube man, daß das korporative Leben, so wie es vei den farbentragenden studenten praktiziert werde, groBe erzieherische Bedeutung habe: "Hier sollen angeblich feste Bande der Freundschaft für das ganze Leben geknüpt werden, hier bilden sich die Charaktere heraus, nier eignet man sich gute ianieren an, nun, in einem ilort, auch Bismarck war zu seiner Zeit Corpsstudent..." 87

Kovrov macht nachdrücklich darauf aufmerksam, dab die farbentragende Studentenschaft in inrer Eigenschaft als offizielle Repräsentation der deutschen akademischen Jugend, der Ausgangspunkt für die sich immer mehr zuspitzende Studentenfrage in Deutschland sei, wobei diese Frage letztlich auf die Frage nach dem Schicksal und der Rolle der deutschen Intelligenz, d.h. der geistigen Aristokratie des Landes hinauslaufe. ${ }^{88}$

85) Ebenda, 5. 7of.

86) Ebenda, S. 70; siehe auch A. Kovrov, Iz Germanii. R.B $1896 / 2$, II, S. 94 .

87) Vgl. A. Kovrov, Iz Germanii. RB 1896/2, II, S. 86, 97 .

(Tatsächlich hat sich Bistarck als Angehöriger des Göttinger Corps "Hannovera" genau so benommen wie oben geschildert.)

88) Ebenda, S. $86 f$. 
Für eine bedenkliche Erscheinung hält man von russischer Seite auch die von ihr als unangenehm empfundene Rolle, die frühere Corpsstudenten im Staatsdienst spielen. Dieses Monopol erscheine umso unverständlicher, als die Professoren ständig auf die wachsende Faulheit der wohlhabenden Jurastudenten hinwiesen. Dabei seien besonders diejenigen gemeint, "welche die bunten Korporationsbändchen tragen und sich danach der administrativen Tätigkeit widmen. Völlige 'Gleichgültigkeit allem gegenüber', 'völliges Fehlen einer idealistischen Lebenssicht', 'oberflächliches, leichtfertiges Urteilen über alle Dinge', solcherart sind die Merkmale, durch die sich diese Auserwählten des Schicksals auszeichnen; und das hindert sie keineswegs daran, eine ungebildete aber fest organisierte Kaste von privilegierten Fuhrern des Staats zu bilden. Die Herren Corpsiers ziehen einander die Leiter des dienstlichen Erfolgs empor und verhalten sich mit äuBerster Feindseligkeit und tberheblichkeit allen gegenüber, die des Glückes entbehren, sieben Generationen hochgeborener Ahnen zu haben, als Fuchs 6000 Mark im Jahr zu versaufen und das weiBe Cerevis mit den preuBischen Landesfarben ${ }^{89} \mathrm{zu}$ tragen."

Leute wie der preubische Innenminister von Hammerstein - "selbst Zögling einer korporativen Pflanzschule" - verteidigen die Korporationen und singen sogar inr Loblied.

Sie bezeichnen die korporativen Hof schranzen als "treue Diener ihres Königs und ihres Vaterlands", sagen, daB sie in den Korporationen eine "hervorragende Erziehung" erhalten und daß deshalb jeder

89) Schwarz-weiB! Also Borussia-Bonn! 
Korporationsstudent eine "unstreitige Vorrangstellung" vor den ubrigen habe.

"Muß man wirklich, um preubischer Beamter zu sein, ausgerechnet die Vorbereitung genossen haben, die in aristokratischen Korporationen vermittelt wird? Kann man etwa ohne diese Schule hemungsloser Trunksucht, gegenseitigen Verstümelns der Physiognomie und lächerlicher, theatralischer Prozessionen kein fähiger Beamter werden? Und ist die tiefe Ignoranz und die Zähigkeit der Kastenvorurteile allein der fruchtbare Boden zur Aufzucht der wuchernden Blüten des heiligen Bürokratius?

Wir zweifeln daran; aber wo es um die Pestigung der Klassenherrschaft des glerigen und beschränkten Junkertums geht, lst es selbstverständich, dab ein Hammerstein keine bessere Schule für administrative Begeisterung und polizeliche Verwegenheit findet, als die Korporationen: nur bel volliger Verachtung der Geschichte, nur be1 taschkentischem ${ }^{90}$ Analphabetismus kann man mit solchem Getone die Prinzipien eines Rechtsstaats so mit puBen treten, wie dies die inm untergeordneten Verwaltungsgeneräle und die deutschen GroBschnauzen in allen möglichen Rängen und Stufen tun." 91

90) Im deutschen Reich konnte das RB keine derartige Gegend finden!

91) Vgl. Reus, Gospoda junkery. a.a.0., S. 104 . 


\section{Regionale Unterschiede}

Wichel wurde als Repräsentant des deutschen Volkes gewiirdigt, des Volkes, "einig in seinen Stämmen", 92 welches das Reich bildete, aber auf die regionalen Unterschiede dieser "Stämme" ging das RB ebenfalls ein:

"Die Deutschen sprechen immer von Mainlinie, Ostelbien, Nord- und Süd-, Ost und Westdeutschland. Charakteristisch ist dabei, dab es sich hier nicht blob um geographische Bezeichnungen handelt, sondern um Begriffe, die einen ernsten kulturpolitischen Inhalt haben.

Für einen Ausländer mögen diese Gegenüberstellungen innerhalb eines geeinten deutschen Reiches zunächst merkwiurdig erscheinen, aber die Erfahrung lehrt ihn sehr bald, dab zwischen den einzelnen Regionen Deutschlands wirklich mehr als blob geographische und ethnographische Unterschiede bestehen, die von jedem Deutschen durch einen urtumlichen Lokalpatriotismus anerkannt werden." Z.B. sei tbereifer ein Charakteristikum der Preußen und Sachsen,. während man sich in Bayern, Baden und Württemberg bei weitem "freier und gemütlicher" füle, da die Suiddeutschen kulanter und nicht so unangenehm übergenau seien. 93

92) Vgl. den Anfang der Verfassung des Deutschen Reichs von 1871: "Das deutsche Volk, einig in seinen Stämmen, ..."

93) Vgl. A. Kovrov, Iz Germani1. RB 1895/Il, II, 134f. Im gleichen Sinne: ders., Iz Germanil. RB $1896 / 6$, II, S. $153 f$. 
Die Gründe für den Kontrast zwischen Süd- und Norddeutschland lägen hauptsächlich in den Besonderheiten des Volikscharakters.

Durch diese Unterschiede erkläre sich auch die Tatsache, warum Deutschland später als andere Völker zur nationalen Einheit gelangt ist, die im übrigen auch jetzt mehr mechanisch als organisch sei.

Deutschland beherberge sozusagen zwei verschiedene völkerschaften. Die Ostelbier, das seien die Deutschen auf der rechten Seite der Elbe, das Deutschland der Junker, der Feudalordnungen und anderer Relikte des Nittelalters. Und obwohl die Ostelbier über die Hegemonie im ganzen Land verfügen, sei es ihnen nicht gelungen, den Geist der altdeutschen Freiheit und Unabhängigkeit ihrer ilitbruider auf der linken Seite der Elbe zu vergiften.

Dazu müsse man wissen, daß der Südwesten Deutschlands griechisch-römische Bildung in sich aufgenommen hat. Dies Land könne auf eine fast zweitausendjährige Kultur zurückblicken, eine ungefähr ebenso alte wie die Frankreichs. 94

Währenddessen sei der Nordosten Deutschlands noch lange nach der volkerwanderung, bis zum $X$. Jahrhundert unserer Zeitrechnung, von wenig kultivierten Stämmen bewohnt gewesen. "Die Kultur aut der rechten Seite der Elbe ist fast um die Hälfe jünger als die auf der linken." (..."Dieser spürbare Unterschied hat indes den Fürsten Bismarck nicht daran gehindert, einmal im Reichstag auszurufen: 'iir sind den Suddeutschen zu Iiberal!' Das ist

94) Für die frankophilen Narodniki des RB bedeutete dies ein grosses Kompliment für die Suddeutschen. 
einer von den zynischen Aphorismen, mit deren Hilfe der Eiserne Kanzler die Wahrheit zu vertuschen liebte." $)^{95}$

Das $R B$ verabsäumt nicht, immer wieder seine zuneigung zu Suideutschland auf Grund der höheren Kultur und der angenehmeren Art der lienschen uort, die der "Širokaja natura" der Russen näher steht, als die der Preußen und Sachsen, zu betonen. 96

Nünchen, das "deutsche Athen an den Ufern der Isar", wird über die Maben gelobt, als eine der wenigen deutschen Städte, wenn nicht als die einzige deutsche Stadt, deren Eleganz und Schönheit auf den ersten Blick bezaubert. Nur hier allein könne der russische Reisende seine in Bezug auf Deutschland "vorgefaßten Erwartungen" verwirklicht sehen. Nicht die "Sauberkeit, die gute Straßenbeleuchtung, die hervorragende Kanalisation und Vasserversorgung" faszinierten inn an München, denn dies seien lierkmale jeder "wohlgeordneten deutschen Stadt", sondern seine "alte und sich beständig vervollkommnende Kultur", seine Verbundenheit mit den besten Kunstarten und seine liebe zu allem Schönen". 97

Das künstlerische Zentrum sei zur gleichen Zeit auch die "berïnmte deutsche Bierhauptstadt". "Kunststadt und Bierstadt vertragen sich prächtig miteinander, sie wirken aufeinander ein und inspirieren sich gegenseitig". Sogar die Biertempel hätten hier einen kulturellen Anstrich. 98

95) Vgl. A. Kovrov, Iz Germanii. $\mathrm{RB} 1895 / 11$, II, S. $135 f$.

96) Vgl. z.B. A. Kovrov, Iz Germanii. RB 1897/7, II, S. 96-107.

97) Vgl. A. Kovrov, Iz Germanii. RB 1895/11, II, S. 1241 .

98) Ebenda, S. 128. 
Das politische und gesellschaftliche Leben in München verlaufe sehr ruhig, da es völlig im Schatten des dominierenden Einflusses von bildender Kunst, Theater und Musik stehe. "Hier herrsch; das, was der Deutsche mit dem Nort 'Bierbankpolitik' ausdrückt, - eine Hirtshauspolitik bei einem Krug Bier, ohne Iërm und ohne Erregung." 99

Wieviel anders seho es hingegen in Berlin aus, diesem "preubischen Zentrum", dem die Bayern "leidenschaftlichste Abneigung" entgegenbringen, und das immer wieder unliebsam die öffentliche iieinung beschäftige. 100

Nicht nur in Bayern allein bekomme man indes bei Jeder Gelegenheit den Satz "Ich kann den Preußen nicht ausstehen" zu hören, ${ }^{101}$ auch die übrigen Süddeutschen, die Badener und die iürttemberger, teilten diese tiefe Antipathie.

Das Gros der Bevölkerung empöre sich in höchst unzweideutiger Art und Weise gegen PreuBen, in den es "die Verkörperung der Soldatcina" sehe. Die Suddeutschen wollten zwar "Deutsche eines geeintel Reiches" bleiben, aber nicht "verpreust" werden. 102 Sie könnten das thergewicht des "preubischen Korporalstvo" kaum ertragen. Kein Wunder deshalb, dab sich partikularistische Tendenzen immer mehr

99) Ebenda.

100) Ebenda.

101) Ebenda.

102) Vgl. A.K., Iz Germanii. RB 1895/1, II, S. 93. 
bemerkbar machten, ${ }^{103}$ und sich Regierungen wie Bevölkerung Süddeutschlands immer mehr solidarisch fühlten und $z u$ einer Einheit verschmölzen. 104

Den Berlinern mangele es indessen nicht an Selbstbewubtsein. ${ }^{105}$ Sie blickten hochmitig auf alles herab, was außerhalb Berlins liege und für sie mit "Provinz" gleichgesetzt werde.

Die so von den PreuBen abqualifizierte Provinz mache sich ihrerselts uber die "Arroganz des preußischen Emporkömmlings" lustig, der "lediglich eine fünfundzwanzigjährige Reichshegemonie aufzuweisen hat." 106

103) So habe beispielswelse grosse Verstimmung anläBlich der Ablösung Caprivis geherrscht, die ohne Gedankenaustausch mit den Regierungen der Bundesstasten und fur diese unerwartet vonstatten gegangen war.

$V_{g l}$. ebenda, S. $92 f$.-

Auch bei der Abstimmung uber die Heeresvorlage von 1893 seien die Differenzen 2wischen "Ost- und Westelbien" deutlich zutage getreten. Vgl. A. Kovrov, I z Germanil. RB 1895\%11, II, S. 135. Siehe auch V.T., Chronika zagranienoj zizni. RB $1893 / 5$, II, S. 99. Im Rahmen der Auseinandersetzung um die Einführung von neuen Tabak- und Heinsteuern, von der sich Suddeutschland, insbesondere Wurttemberg, am stärksten getroffen fuhlte, spricht das RB sogar von einer "offenen Separatismuserklärung" durch wurt temberg. Vgl. V.T. Chronika zagraniénoj żizni. RB 1894/1, II, S. 139.

104) Vgl. A.K., Iz Germanil. RB 1895/1, II, S. 93. In diesem Zusammenhang gibt Kovrov den Inhalt einer, wie er schreibt, in Süddeutschland sehr populären Schulgeschichte wieder: "Der Lehrer: 'Nenne mir die äuBeren Feinde des Deutschen Reiches?' - Schüler: 'Pranzosen und Russen'. - 'Und wie heiBen die inneren Feinde?' - 'Die PreuBen!'n - Bbenda.

105) A.K., Iz Germanif. RB 1895/10, II, S. 176.

106) Vgl. A. Kovrov, Iz Germanil, RB 1896/5, II, S. 67. 
$\mathrm{DaB}$ auch das $\mathrm{RB}$ in Berlin den Emporkömmling sieht, wird immer wieder zwischen den Zeilen deutlich. Zwar bemühen sich die Schreiber des RB um Objektivität, sie stellen fest, dab "die jünste Hauptstadt der Welt" 107 in erstaunlich kurzer Zeit zur iveltstadt herangewachsen sei und sich tatsächlich fast zum "Weltzentrum des gesellschaftlichen, wissenschaftichen und politischen Lebens" entwickelt habe, ${ }^{108}$ sie bewundern Berlins technische Errungenschaften und andere unbestreitbare Vorzüge, ${ }^{109}$ verabsäumen aber nicht, darauf hinzuweisen, daB diese Erscheinungen von einer unangenehmen Großmannssucht begleitet werden. ${ }^{110}$

Vor allem kommt immer wieder zum Ausdruck, daß Berlin in kultureller Hinsicht nicht für voll genommen wird. 111

Man bezweifelt nicht nur, daB der "norddeutsche KoloB" in absehbarer Zeit München die Vorherrschaft als Kunstzentrum Deutschlands streitig machen könr:te, ${ }^{112}$ sondern ist darüber hinaus der Ansicht, daf Berlin, die Hauptstadt des geeinten Deutschen Reiches, in Bezug auf kulturelles Niveau, Traditionsreichtum und vor allem Internationalität noch weit hinter anderen europäischen Hauptstädten zurücksteht. 113

107) A. Kovrov, Iz Germani1. RB 1896/5, II, S. 58

108) A. Kovrov, Iz Germanii. RB 1895/11, II, S. 125.

109) A. Kovrov, Iz Germani1. RB 1896/5, II, S. 59; und A.K., Iz Germanii. RB 1895/5, II, S. $116 f$.

110) A. Kovrov, Iz Germani1. RB 1896/5, II, S. 58.

111) Vgl. z.B. A.K., Iz Berlina. RB 1894/10, II, S.132.

112) Vgl. A. Kovrov, Iz Germani1. RB 1895/11, II, S. 125 .

("Bis jetzt bildet Berlin mit seiner Kunst noch das SchluBlicht..." Ebenda.)

113) Vgl. A.K., Iz Germanii. RB 1895/5, II, S. 118. 
3. Die Preuben

Alle negativen Eigenschaften, die dem Deutschen Keiche von ausländischen Beobachtern, insbesondere im RB, zugeschrieben werden, sind im PreuBen, vorzüglich in seinem Frototyp, dem Junker, verkörpert. DaB man diesem zur Hegemonie im Reich verholfen hat, sähen allmählich auch die übrigen deutschen Staaten als Unglück an. ${ }^{114}$

Der Junker habe seinen EinfluB und seine Macht in der Gesellschaft behalten, obwohl sich im Laufe des 1y. Jahrhunderts ein millionenschweres Grobbürgertun gebildet habe 115 - dieser Geldadel kam gegen den Geburtsadel nicht an.

So sei Preußen ein Junkerstaat geblieben mit geradezu ungeheuerlich anmutenden Relikten aus dem Feudalisinus des iittelalters. ${ }^{116}$

Stuitze dieses feudalismus sei das berüchtigte Dreiklassenwahlrecht, "das in der Geschichte nicht seinesgleichen findet", es begründe die Herrschaft der Feudalen über die Masse der preubischen Bevölkerung und (indirekt nit Hilfe des preuBischen Landtags) über das Deutsche Reich. ${ }^{117}$

114) Vgl. A. Kovrov. Iz Germanii. RB 1897/6, II, S.83. Besonders seit Anfang der neunziger Jahre sehe man in Deutscnland in der preubischen reaktion in zunehmendem Maße eine Bedronung für die Einheit des Reiches. Ebenda.

115) Vgl. Reus., Iz Germanii. RB 1903/7, II, j. 98.

116) Vgl. Reus, Gospoda junkery. RB 1904/11, II,

S. 98-127 passim.; Reus, Iz Germanii.

$\mathrm{RB} 1903 / 7$, II, S. 78-123 passim.; und

V.T., Chronika zagraničnoj žizni. RB 1894/3, II, S. $80 f$.

117) Vgl. Reus, Gospoda junkery. a.a.0., S. 102; und V.T., Chronika zagraniénoj žizni. RB 1894/3, II, S. 80; siehe auch: S. Južakov, Politika.

RB $1901 / 5$, II, S. $141 \mathrm{f}$. 
Den preuBischen Landtag könne man sowohl als eine Idylle "agrarischer Selbstzufriedenheit" bezeichnen als auch ebenso treffend "Geldsackparlament" nennen, denn in ihm säBen Junker und Kapitalisten innig vereint. ${ }^{118}$

Die Zusammensetzung dieses Landtags wesentlich zu ändern, sei unmöglich, denn der Wähler stimme nicht geheim ab, setze also seine materielle Existenz aufs Spiel, wenn er nicht so wähle, wie sein Herr es will. Und dieser wolle seine Herrschaft erhalten, die er mit dem echten Deutschtum gleichsetze. Daher fordere der Junker von seinen armen Rnechten, mutig und offen inr deutsches Herz zu zeigen. 119

Im übrigen garantiere die Zusammensetzung der ersten preubischen Kammer des "Herrenhauses" den Absolutismus der patrimonialen Herren. Darüber hinaus sei die Herrschaft der Feudalen uberall spurbar, in der Armee und der Verwaltung, vom Minister bis zum Ortsgendarm. ${ }^{120}$

So erklärten sich die Erleichterungen, welche den Junkern zugestanden worden seien, in der Besteuerung, in besonderen Frachttarifen für

118) Vgl. A.K., Iz Germanii. RB 1895/2, II, S. $123 f$.

119) Vgl. Reus, Gospoda junkery. a.a.0., S. 103; und Reus, I z Germanii. RB 1903/7, II, S. $84 f$., wo es wörtlich heiBt: "Wenn der deutsche Wichel ein ehrenhafter Bürger ist, dann soll er doch mittels offener Wahlen sein echtdeutsches, offenes und mutikes Herz zeigen' schreit der ... deutsche Junker und wirft eine Arbeiterfamilie auf die StraBe, weil das Familienoberhaupt politische Ehrenhaftigkeit gezeigt hat und nicht einen Konservativen, sondern einen Liberalen gewählt hat."

120) Vgl. Reus, Gospoda junkery. a.a.0., S. 103-106. 
agrarische Produkte und in Einfuhrzöllen zur Stütung der einheimischen Erzeugerpreise. Infolgedessen könnten sie "in unserer Zeit" noch leben wie im 17. Jahrhundert. Hinzu kimen noch die "Iiebesgaben" der "Regierung, z.B. der Ponds zur Förderung des Deutschtums in den von Polen bewohnten preuBischen Provinzen, welcher den "bedüftigen" Gutsbesitzern viele lillionen eingebracht und den Wert ihrer Güter auf Kosten des Staates vervielfacht habe. 121

"Hinter den Mauern seiner unter Naturschutz stehenden Güter kann das ... Junkertum in aller Ruhe die Traditionen bewahren, die es als Erbe von den mittelalterlichen Raubrittern ubernommen hat, von den Französlingen und sittlich verderbten Höflingen aus der Zeit des Absolutismus und schlieBlich von den zwar nicht adeligen, aber trotzdem ebenbürtigen hohen Tieren der Finanzwelt, die in die austrocknenden Adern der Feudalwirtschaft den goldenen Strahl der industriellen Ausbeutung und der Bankbetrügereien fließen ließen. Und alle diese angeborenen Eigenschaften und selbsterworbenen Schätze können nicht nur völlig sicher in den Junkerhorsten bewahrt werden, sondern spielen eine einflubreiche Rolle bei der Gestaltung des preuBischen 'Allgemeinwohls'. Auf sie ist die merkwirdige preubische Vertretung unter tbergehung und ohne Einverständnis des Volkes gegründet, von

121 ) Vgl. Reus, Gospoda junkery. a.a.0., S. $106 \mathrm{f}$. 2.B.: Heil Blamarck die Agrarier für sich gewinnen wollte, habe er deren wirtschaftliche Wacht durch die künstliche Verteuerung des Getreides mittels Einfuhrzöllen gestärkt. Vgl. V.G. Jarockij, Obezpecenie narodnago prodovol'otvija v svjazi s chlébnoju promyslennost ju.

RB $1892 / 3, I, S .134$. 
ihnen ist die von den Junkern ausgehende preußische Bürokratie durchdrungen, mit ihrer kastenhaften Verschlossenheit und ihrer Veracutung für die bürgerlichen 'Kunaillen'; von ihrem hochmütigen Geist und ihrer groben Eigennützigkeit ist die Ideologie des preußischen Konservatismus durchsetzt, der hinter schall und uppigen fhrasen rohe politische juacht und Kastenexklusivität verbirgt." 122

"Glaube", "Monarchie" und "Volkstuin", so laute die Devise der Junker und damit auch der konservativen Parte1. Diese Begriffe, die in früheren Zeiten einen hohen ethischen iert gehabt hätten, seien von den preulischen Junkern völlig ihres ursprünglichen Sinnes beraubt worden und dienten nur der Verschleierung ihrer eigennützigen Nachenschaften.

Reus zitiert aus dem "Ratgeber für die Konservativen im Deutschen Reich" (Leipzig, 1903), der offiziell von den Führern der konservativen Partei herausgegeben worden war. Hier sei die Rede von "höchster Achtung des Christentums und der Erhaltung des christlichen Glaubens im deutschen Volk" als einem der "höchsten Ziele" dieser Partei. Dann würden weitere pugenden der Konservativen aufgezält: "Auf Grund dessen, daB wir Christen sind, sind wir national", "Weil wir Christen sind, sind wir dem König und der Verfassung treu", "weil wir Christen sind, lieben wir das Volk... Letzteres zeigt sich an der gerechten Aufmerksamkeit allen Interessen des Ganzen und der Individuen gegenüber."123

122) Vgl. Reus, Gospoda junkery. a.a.0., s. $107 \mathrm{f}$. 123) Ebenda, S. $109 f$. 
$\mathrm{DaB}$ es sich bei diesem parteigebundenen, nationalistischen Christentum der Junker nur um Heuchelei und Bauernfanterei handele, liege klar auf der Hand. So sei beispielsweise inre Theorie vom christlichen staat gleichzeitig eine antisemitische Theorie. ${ }^{124}$ Das Christentum erweise sich für sie in jeglicher Beziehung als sehr nützlich, wenn es darum gehe, mit nochtönenden Phrasen ihre rein politischen Absichten $z u$ bemänteln.

In iirklichkeit have der Junker nämlich nur ein einziges Interesse: er möchte ein festes, geregeltes Einkommen haben, das ihm die wöglichkeit gibt, gemäß seiner Devise "fein, vornenm und standesgenäß" zu leben. Er wolle sein Schloß erhalten, reisen und seinen Sohn in ein teures Corps schicken. ${ }^{125}$

Ein echter Junker arbeite jedoch nicht: Arbeit këme für ihn einer Ernieùrigung gleich. ${ }^{126}$ Auf Grund seines Lebenswandels sei er auch inmer weniEer in der Lage, seine eigene Angelegenheit, nämlich die Landwirtschaft, richtig zu führen. Zudem verstehe er von der praktischen Landwirtschaft überhaupt wenig, außer von Pferden und Reiten. Deshalb sei sein Lieblingsinstrument auch die Peitsche, die er nicht selten auch seine Dienerschaft spüren lasse. Unfiahig, seine wirtschaftliche Position selbst zu erhalten, setze er jedoch als selbstverständlich voraus, daß es für das Volk eine Ehre sein müsse, seinen Lebensstandard zu ermöglichen. ${ }^{127}$

124) Vgl. Reus, Iz Germanii. RB 1903/7, II, S. 100.

125) Ebenda, S. 99; und Reus, Gospoda junkery, a.a.0., S. 110.

126) Vgl. Reus, Iz Germanii. RB 1903/7, II, S. 98.

127) Vgl. A. Kovrov, Iz Germanii. RB 1896/11, II, S. 13of.; und A. Kovrov, Bor'ba partij iz-za chlëbnych pošlin $v$ Germanii. RB 1901/11, II, s. 111 f. 
Die Zeiten hätten sich indes geändert. Der Junker hasse daher das kapitalistische Heute, welches das "Volk" so entscheidend beeinflusse. Das goldene zeitalter sei zu seinem Kummer vorbe:, das Zeitalter, als die "Leute" noch aufrichtig daran glaubten, sie seien nur dazu geschaffen worden, um dem Herrn im Himmel und mehr noch dem auf Erden zu dienen und für ihn zu schuften. Aber - so träumten diese Agrarier - geblieben se: der deutsche Glaube und die deutsche Treue - und aus diesen ewigen Tugenden des Deutschen Wichel ein gutes Geschäft zu machen, sei ihr ville, denn dadurch könnten sie sich die iittel verschaffen, um das erstrebenswerte "echt christlic.e" und "echt adelige" Leben zu führen. 128

Die Nächstenliebe dieser preuBischen Christen zu ihren nächsten Untergebenen, den Landarbeitern, zeige sich so: sie liessen sie unter noch traurigeren Bedingungen vegetieren als die beklagenswerten Industriearbeiter, zahlten innen weit weniger, verweigerten ihnen den zutritt zur gesetzlichen Krankenversicherung, gewährten ihnen nur einen geringfügigen Unfallversicherungsschutz und versuchten, sie ganz allgemein wieder auf den Status von Leibeigenen herabzudrücken. iler kontraktwidrig die Arbeit einstelle, werde schwer bestraft, manchmal auf Grund von veralteten Vorschriften aus der Zeit Priedrichs des Großen. Und noch schlimmer: die Junker drückten den Hungerlohn der Häher und Drescher noch dadurch, daB sie billige Arbeitskräfte aus Italien oder noch billigere aus den

128) Vgl. Reus, Gospoda junkery. a.a.0., S. $110 f$. 
Zuchthäusern und den Kasernen heranzogen! 129

Gegen ihre Gegner, die sozialistischen Arbeiter, hetzten die Junker die Organe der Regierung; polizeiliche und gerichtliche Pressionen seien an der Tagesordnung. 130

Wenn auch die Landarbeiter von dem Bazillus des Sozialismus noch nicht angesteckt seien, sähen die Junker doch in seiner Verbreitung bei den Industriearbeitern eine riesige Gefahr. Sie warnten daher den "gläubigen Michel" vor dem Ungeheuer Sozialdemokratie, das sie mit dem Antichrist gleicnsetzten - die Sozialisten wirden (wie in der gottlosen französischen Revolution von 1789) Gott und den König (also die himmlische und die irdische Stutze des preußischen Junkertums!) abschaffen. 131

In ihrem Kampf gegen den Sozialismus miBorauchten die Feudalen den Begriff "Volkstum", der im Nunde der Junker genau so verdreht worden sei wie die Sätze des Evangeliums. Ihr Patriotismus sei lediglich eine "Spekulation auf das deutsche Nationalgefül", ihre ziele seien kastengebunden. In der

129) Vgl. Reus, Gospoda junkery. a.a.0., S. $115 f$. Ahnlich auch: A. Kovrov, Iz Germanii. RB $1896 / 11$, S. 132-135.

Hier wird besonders auf die unglaublichen iviBstände in Ostpreußen hingewiesen, infolgederen sich die Landarbeiter in großen Scharen aus der Obhut inrer Herren entfernten und in die Industriegeblete des westlichen preuBen oder anderer Teile Deutschlands abwanderten, oder aber ihr Gluck in der Erigration ins Ausland suchten. (Besonders ins Gewicht falle die diassenemigration nach Amerika. Vgl. V.T., Chronika zagraniznoj žizni. RB 1894/3, II, S. 8off.)

130) Vgl. Reus, Gospoda junkery. a.a.0., S. 119.

131) Ebenda, S. $117 f$. 
smee 132 stünden ihnen die offiziersstellen offen und diese garantierten den Nachfainen der aittelalterlichen kaubritter winkomen und Ordenssegen ohne geistige I.ihe. Daher das große Interesse des Adels, die armee $z$ vergrößern und immer wehr von sich abhänig zu machen. Dazu wüsse der Patriotismus der iassen angeheizt werden aber das patriotische progranin der konservativen bestene eigentlich nur aus drei jorten: "Gewehre, Gewehre, Gewehre".

Is wiusse nimlich durch die Furcht vor auseren Feinden und den $\mathrm{Ha}$ auf innere die liebe zur Heimat genahrt werden, - dauit notivierten die Junker ihren intisenitismus, inre Bekämpfun $\dot{\theta}^{\circ}$ der jozialdemokraten, inre Germanisierungspolitik gegenüber den rolen, D.nen ura Branzosen innerhalb aer deutsciuen Grenzen. 133 Die "Preuben" nielten sich even für aie lräger der kultur und blickten auf inre Nicibarn herab, insbesondere auf die kussen, die in ihren dugen nichts als "ililue" seien. 134

Im übrizen sei dieser "deutsche" Patriotismus der Osteloier verhaltnismässiô neu, der preubiscine Charakter sei darunter vesteckt, für die junker sei der deutsche Kaiser in wesentlicnen der preubiscine hönig. 135

132) Jesonders bei der Garde, aer Kuvallerie und anderen feudalen keg̈imentern - ganz $z u$ scnweijen vo:n 1. Garderefiment zu Fub, de:: "vornenusten Pegiment der Christeniseit".

133) Vgl. Keus, Iz Germanii. RB 1903/7, II, S. 101-104.

134) VËl. Reus, Gospoda junkery. a.a.c., j. 121-127

135) VEl. Reus, Iz Germanii. KB 1903/7, II, S. 104 . 
Vie stehen die Junker zu ihrem König? lach außen dienten sie ihn und achteten seinen ililen und den der Köniclichen Regierung; wenn diese aber gegen die Interessen der Junker handele, dann verweigerten sie der Regierung die Gefolgschaft. Als Beispiel diene die Vorlage uber den Bau des jittellandkanals, der ihnen aus wirtschaftlichen Gründen nicht genenm war. 2weimal, 1899 und 1901, brachten sie ihn zu Fall, andererseits setzten sie 1903 die Erhöhung der Getreidezölle durch. $136 \mathrm{a}$

"Die preußischen Junker haben die Staatsgewalt in inre Hande gerissen und aus dem lionarchen ein Instrument ihrer engstirnigen, habsüchtigen Interessen gemacht. Is besteht kein Zweifel, daß die heform aes preußiscnen Klassenparlaments und die Beseitigung der die !lassen beleidigenden PrivileGien die Frage ist, von der das weitere Schicksal Preußens und seine Rolle in der kulturellen Bewegung der Gegenwart abhängt." 137

Durch den Preußen präsentiert sich das Preußen als ein militaristischer und zueleich bürokratischer Staat, eben ein polizeistaat. Oben regieren die Junker und die aus deren kreisen hervorgegangenen

136) Siehe hierzu auch Adelbert v. Chamisso, Nachtwächterlied, 1826, Strophe 3:

"Hört, inr Herrn, so soll es werden: Gott im Himmel, wir auf Erden, Und der König absolut, irenn er unsern Willen tut, Lobt die Jesuiten!"

(ïobei es hier vielleicht "Hochfeudalen" statt "Jesuiten" heissen sollte.)

1368)Vgl. Reus, Iz Germanii. RB 1903/7, II, S. 104 .

137) Vigl. Reus, Gospoda junkery, a.a.0., s. 127. 
hohen Beamten roh und hochmütig, ${ }^{138}$ unten trampeln und schlagen die Hacken zusammen die Polizisten, sprühend vor Diensteifer, bis in die pommerschen Knochen vom preubischen Geist durchdrungen. Beide Typen seien ideale Preußen, die einen treten, die anderen ducken sich willig und bedingungslos unter deren stiefel. 139

Dieser fast jesuitisch anmutende Kadaveryehorsam werde seit den siegreichen Kriegen in den preußischen Schulen, den Kasernen des Geistes, gelehrt ${ }^{140}$ und damit wurden der milltärische Instinirt geweckt und jene kriegerischen Talente gezüchtet, die den Preußen den fragwürdigen Ruf der "Eroberer" verschafft haben. Tatsächlich seien sie im Erobern ideister, aber sie könnten sich nicht die Sympathien der Eroberten - man denke an die ElsaßLothringer - erwerben, dazu seien inre sonstigen Eigenschaften zu abstoßend. 141

Leider breite sich Preußens Gloriateist bereits über die Elbe und den liain hinweg aus: Sogar in Bayern dringe der "seelenlose Bürokratismus" in alle Bereiche der Verwaltung, und in den Kasernen herrsche bereits ein rüder Ton, der an Preußens fernsten Osten erinnere. 142

138) Vgl. A. Kovrov, Iz Germanii. KB 1896/11, II, S. 131 ;

A.K., Iz Berlina. RB 1894/10, II, S. 140; A.K., Iz Germanii. RB 1895/2, II, S. 120.

139) Vgl. Reus, Krolic'e pravo. KB 1904/10, II, S. 45-47;

A.K., Iz Berlina. RB 1894/10, II, S. 139.

140) Vgl. V.T., Chronika zagranicnoj żizni. RB 1894/6, II, S. $144 f$.

141) Vgl. A.K., Iz Berlina, RB 1894/10, II, S. 139:; siehe auch A.K., Iz Germanii. RB 1895/2, II, S. 128.

142) Vgl. A. Kovrov, Iz Germanii. RB 1896/12, II, S. 79. 
Natürlich merke das der deutsche kulturell hochstehende Süden mit großer Besorgnis. Er wehre sich in zunehmendem Maße gegen Preußen und seinen verhaBten iilitarismus, da er zu Recht fürchten müsse, dab weitere Verstärkungen des Heeres, wie sie beispielsweise von Preußen durch die Militärvorlage von $1892 / 93$ geplant waren, zur Vernichtung der letzten Reste seiner Unabhängigkeit führen würden. 143

Nit einem Satz: Der Preuße habe "mit eiserner Hand" den "friedlichen deutschen Michel" in den Griff bekommen ${ }^{144}$ - und dafür an entscheidender Stelle mitverantwortlich sei Preußens "größter Junker" ${ }^{145}$ : Otto von Bismarck.

143) Vgl. V.T., Chronika zagranienoj žizni. $R B$ 1893/5, II, S. $99 f$.

144) Vgl. Reus, Michel' pod ruz'em. (Pis'mo iz Germanii). RB $1903 / 11$, II, S. 165.

145) Vgl. A. Kovrov, Iz Germanii. RB 1896/11, II, S. 130 . 


\section{Das Deutsche Keich}

\section{Persönlicnkeiten}

a) Bismarck

Das Deutsche Reich von 1871, in dieser Forn gegrüdet von Bismarck und von inm rund 20 Jahre lang geführt, war durch den Sieg über Frankreich zur stärksten Iandmacht in Europa geworden und damit in der dawuls politisch maßgebenden ilelt. -

Die Nachbarn betrachteten dieses keich vielleicht mit Respekt, mehr aber mit líibtrauen, Abneigung und ingst - und diese Gefuhle konzentrierten sich auf den "Eisernen Kunzler", der bis zu seiner Entlassung die Folitik des Reiches lenkte und bis $z u$ seinem rod - und selbst daruber hinaus - das Idol des deutschen Bürgers war.

Das RB fürchtete und haBte Bismarck, dies gent aus allen Artikeln hervor, die sich mit seiner Person und seinen außen- und innenpolitischen Liaßnainmen befassen.

In den Jahren vor 1888 erschienen keine derartigen Artikel; der erste Auslandsbericht ist in der Dezembernuwner 1887 abgedruckt, befaBt sich aber nicht mit dew Deutschen Reich. Am ergiebigsten für die Ansichten des $\mathrm{RB}$ über Bisuarck sind àie Jahrgänge 1888, 1889 und 1890, die einzigen, die zwischen 1880 und 1892 Berichte uber Deutschlanc enthalten, und gleichzeitig die letzten Jahre der Amtszeit des keichskanzlers umfassen; ferner die Jahrgänge 1892, 1893 und 1894, sowie besonders 1898 (Bismarcks Tod). 
In der radikalen Ablehnung Bismarcks und des von inm geschaffenen keiches stimmten die liftarbeiter des RB völlig mit N.K. Michajlovskij übere in. Dessen Antipathie gegen Deutschland fußte auf seiner frihen Ablehnung der Ideen Hegels, als denen der "Berliner Staatsphilosophie" und wurde durch persönliche Erlebnisse im Sommer 1870 intensiviert.

Mit dem deutschen Anmarsch auf Paris im Herbst und Winter 1870 nahm das Gespenst von Bismarcks Deutschland, das Iuir Michajlovskij in krassem Gegensatz zum Deutschland Lessings und Kants stand, für ihn furchterregende Proportionen an.'

Im Februar 1871 schrieb er einen Artikel "Graf Bismarckn ${ }^{2}$, der wegen der Popularität seines Verfassers ziemlichen Eindruck auf die Leser machte, ein Artikel, welcher deutlich seine wachsende Deutschfeindlichkeit erkennen IieB.

Es sei zunächst kurz geschildert, was dem RB in diesen Jahren bis zum Tode Bismarcks erwähnenswert, verdächtig, herausfordernd an seinen Worten und Taten und der Reaktion des deutschen Bürgers erschienen ist; am Schluß soll näher auf die grobe Analyse S.N. Južakovs vom August $1898^{3}$ eingegangen werden.

1) $\mathrm{Vgl}_{\mathrm{gl}}$. James H. Billington, Mikhailovsky and Russian Populism. Oxford, 1958, S. $71 \mathrm{f}$.

2) Vgl. Socinenija N.K. Michajlovskago. Bd. 6, $\mathrm{SPb}, 1897$, S. 71-112.

3) S.N. Juźakov, Politika. RB 1898/8, II, S. 214-229. Für die Intensität und Starrheit des RB-Bildes von Bismarck spricht u.a. die Tatsache, daB Južakov zweieinhalb Jahre später im Rahmen einer Untersuchung über die politische Evolution der einzelnen Länder Europas in neunzehnten Jahrhundert sinngemäb und teilweise sogar wörtlich (!) sein Urteil über die historische Kolle Bismarcks wiederholte. Vgl. S. Južakov, Politika. RB 1901/2, II, S. 124-147. 
Die ersten Auslandsberichte über Deutschland erschienen im "Dreikaiserjahr" 1888.

Dis Regierungszeit Kaiser Friedrich III. wird im $\mathrm{RB}$ als eine der hellsten Seiten der deutschen Geschichte beurteilt; die neunundneunzig Tage hätten die Welt auf die Höglichkeit der Existenz eines anderen Deutschland hingewiesen, eines kulturellen Deutschland, das stolz auf seine Wissenschaft, seine Kunst und seine Philosophie ist anders als das des kriegerischen und standig intrigierenden Deutschland (wobei zu ergänzen ist: Bismarckscher Prägung). 4

Bismarck habe in dieser zeit das Fähnlein nach dem Winde gedreht. Als sein ubliches ianöver, den jeweiligen Herrscher gefügig zu machen, nämlich die Rücktrittsdrohung nichts mehr fruchtete, wurde er plötzlich anglophil in der Hoffnung, damit dem Kaiser und vor allem seiner Gattin, der fruheren Princess Royal, gefällig zu sein. Aber kaum sei Friedrich gestorben, als Bismarck hinterlistig die Maske fallen lie $B$ und England von oben herab und feindselig zu behandeln begann. 5

Als Heinrich Geffken (1830-1896), einer der Ratgeber des Kronprinzen Friedrich Wilhelm (des nachmaligen Kaiser Friedrich), Teile von dessen Tagebuch in der Oktobernummer 1888 der "Deutschen Rundschau" veröffentlichte, ${ }^{6}$ wird dessen Inhalt

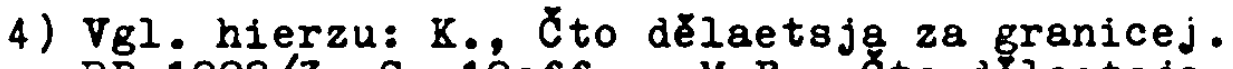
RB 1888/3, S. $180 f f$; - M.F., Cto délaetsja za granice j. RB 1888/10, S. 154ff; - M.F. C to délaetsja za granicej.RB 1888/12, $193 f f$.

5) Vgl. M.F., Cto delaětsja za granicej. $R B$ 1888/10, S. 155 .

6) Geffken wurde auf Bismarcks Veranlassung wegen Landesverrats angeklagt, 1889 aber außer Verfolgung gesetzt. 
vom $R B$ im wesentlichen dazu verwendet, um befriedigt zu notieren, daB sich die Aureole, welche In- und susland um den angeblichen Reichsg̈rüder Bismarck gewoben habe, verfluchtige; uan sähe ein, der ianzler sei keineswegs "der Kopf" gewesen und alle anderen nichts als seine Verkzeuge.

Die ganze Politik Bismarcks werde durch das Tagebuch entschleiert, danach ware er weder weitsichtig planend noch in der Lage, die Vorteile einer bestimmten politischen Konstellation $z u$ erkennen. Er eigne sich vielmehr fremde Gedanken und seien sie selbst verbrecherisch - an, und vergesse im Bedarfsfall sowohl diese wie seine eigenen.

Im Tagebuch Friedrichs fände der Kenner das bestätigt, was man $z$ wiscien den liebedienerischen Zeilen des Bimarckbiographen Moritz Busch bei kritischer Durchsicht schon habe feststellen können: Bismarck habe an eine wirkliche, an eine echte Einigung Deutschlands sogar während der Belagerung von Paris noch nicht gedacht. Erst als König Ludwig von Bayern, zusammen mit dem preubischen Kronprinzen, diese Einigung unter der Voraussetzung betrieben habe, da $B$ alle deutschen Staaten gleichberechtigt sein sollten, schaltete sich Bismarck, der "preubische Intrigant", ein und brachte es fertig, statt des erträumten, grandiosen Reiches eine Art vergröBertes Preußen zu schaffen mit dem Reichstag als Dekoration und inm selbst wie eh und je als ilajordomus.?

7) Vgl. M.P., Čto délaetsja za granicej. RB 1888/10, S. 153-158. (Es sei daran erinnert, daß das böse ifort über den liajordomus Bismarck mit dazu beigetragen hat, daB Wilhelm II. sich von seinem ersten Kanzler trennte.) 
In die an sich liberale deutsche Verfassung nämlich sei das reaktionäre Elewent lediglich durch die פxistenz der "unverantivortlichen und unkontrollierten iuacht des kanzlers" eincebracht worden. 8

Schon 1888 unterstellte das KB Bismarck eigennützige lotive bei der deutschen schutzzollpolitik, durch welche sich kuBland wirtschaftich am meisten getroffen fülte, - Bismarck sei selbst Grundbesitzer und daher nützten ihm die zölle persönlich. 9

Daß die Getreidezölle das Hand arm machen, sei inm fleicn. Ebenso sei er nicht aus einem idealen Prinzip gegen Stöcker ${ }^{10}$ und die Antisemiten, sondern weil sein Bankier der Jude Bleicinröder ist. Bisiarck sei eben kein echter deutscher Patriot, der von nationaler Einigung und kultureller Entfaltung seines Vaterlandes träumt, sondern eher ein preußischer Diplomat, dessen Ideal die völlige Unteroranung nicht nur aller Deutschen, sondern auch aller Europäer unter die eigennützige preubische Politik sei.

Eigentlich dürfe wan in Bezug auf Bismarck überhaupt nicht das ilort "Ideal" verwenden; denn dieser "Preuße von kopf bis Fuß" sei ein kalter Rechner, auf sein persönliches Interesse bedacht, wortbrüchig, falls der Augenblick es erfordere - er verwirkliche

8) Vgl. K.F., Čto dělaetsja za granicej. RB $1888 / 12$, S. 194 .

9) Vgl. Li.P., Čto dêlaetsja za granicej. RB $1888 / 10$, S. 154 .

10) Adolf Stöcker, 1835-1909, Hof- und jomprediger in Berlin bis 1890, KidA, LidR, Antisemit aus wirtschaftlich-sozialen, nicht aus Rassengründen; 1878 Grïder der Christlich-Sozialen Partei. 
mit einem Wort ganz die beruinmte Satire wachiavelis. 11

Der iame liachiavelli taucht wiederholt in Verbindung init Bismarck auf, wobei dieser beim Vergleich durch das RB - man nöchte sagen: selbstverständich - den Kürzeren zieht:

"In der Tat war die Politik Bismarcks ganz auf seinen in der Geschichte beispiellosen Wachiavellismus gegründet. kian tut Bisnarck jedoch zu hohe Ehre an, wenn wan inn bit liachiavelli verGleicht: Letzterer war ein großer Patriot und schrieb Satiren, die von Dummköpfen für bare ifünze genommen wurden und dann durch Fürst Biswarck in Leben konkrete Gestalt annahmen." 12

Der Vergleich setzt sich in nüchsten Jahrgang fort: "Das Gesyenst des heutigen iachiavelli, des allgegenwärtigen Bismarck" wird für fast alle politischen Unruhen in Europa verantwortlich gemacht: "Dieser l.ensch hat einen solcnen Schrecken und einen solchen $\mathrm{HaB}$ auf die deutsche Herrschaft, die keinerlei Grenzen bei der Erreichung ihrer Ziele kennt, hervorgerufen, daß die Deutschen noch viele Jahre lang auf ihrem Rücken die Folgen seiner eisernen Politik, d.h. der Politik mit der unmoralischen Regel: 'Das Ziel heiligt die littel' 13

11) VGI. H.F., Čto dělaetsja za granicej. $\mathrm{RB} 1888 / 10$, S. 153 f.

12) Vgl. iu. r.., Čto dělaetsja za granicej. $\mathrm{RB} 1888 / 12$, is. 195 .

13) Ohne auf die umfan die Beschuldigung Blaise Pascals einzugehen, der Zweck oder das Ziel heilige die littel sei die laxime der Jesuiten, sei darauf hingewiesen, daB bereits 130 Jahre vor Pascal Niccolo ijachiavelli geschrieben hat: "iJenn ihn (= den klugen Staatsgründer, in diesem Fall-Romulus) auch die Tat anklagt, so muB ihn der Erfolg doch entschuldigen" (Discorsi sopra la prima deca di Tito Livio, 1531). 
spüren werden." 14

Blsmarck hat damit das deutsche Volk korrumpiert, meint das RB:

Er habe immer nur an den Erfolg gedacht und nicht etwa daran, ob er der Nation schaden wirde. Dadurch habe er sowohl in politischen Sphären als auch in den Volksmassen das Gefühl dafür zerstört, was man tun kann, und was nicht. Sein Prinzip das ziel helligt die ilittel - sel allgemeine Losung geworden. 15

Im gleichen Jahre 1889 wird vom RB "bewiesen", daB alles, was wirklich gut an der Nationalbewegung von 1848 war, nicht der Politik von "Blut und Eisen" 16

14) Vgl. N.N., ¿to délaetsja za granicej. RB $1889 / 2$, S. 199.

15) Vgl an Chronika zagranicnoj žizni. RB 1890/8, S. 160 .

16) Der zum diffamierenden Schlagwort gewordene Ausspruch Blsnarcks von "Blut und Eisen" ist zum ersten Mal in einer Abendsitzung der Budgetkommission des preuBischen Abgeordnetenhauses am 30.9.1862 gefalien, damals sagte Bismarck: "... nicht durch Reden und Majoritätsbeschlüse werden die groben Pragen der Zeit entschieden das lst der grobe Fehler von 1848 und 1849 gewesen sondern durch Bisen und Blut." (Die politischen Reden des Fürsten Bismarck, hrg. von Horst Kohl, Bd. II: Die Reden des Minlsterprësidenten von B18narck-Schönhausen im Preubischen Land tage 1862-1865. Stuttgart, 1892, S. 30.)

Dazu erklkrte er in der sitzung des Abgeordnetenhauses vom 28.1 .1886 ausdrucklich:

"Ich kann nicht dafur, das ich demals nicht verstanden worden bin;... Es handelte sich um militärische Pragen, und 1ch hatte gesagt: Legt eine moglichst starke militärische kraft, mit anderen Worten möglichst viel Blut und Eisen in die Hand des Königs von Preußen, dann wird er die Politik machen können, die Ihr winscht; mit Reden und Schütenfesten und Iledern macht sie sich nicht, sie macht sich nur durch 'Blut und Bisen'". (Die politischen Reden des Fursten Bismarck, hrg. von Horst Bohl, Bd. XI: Die Reden des Ministerpräsidenten und Reichskanzlers Pürsten von B1smarck im Preubischen Landtage und im Deutschen Relchatage 1885-1886. Stuttgart, 1894, S. 419.) Diese öffentliche Brläuterung seines Ausspruchs hat das RB nicht zur Kenntnis genommen. 
zugeschrieben werden darf, die von preubischen Diplomaten und Strategen praktiziert wurde, sondern vielmehr den Ideen der. Republikaner und Demokraten, dieser "glühenden Nationalkämpfer". Sie seien die echten Einiger Deutschlands gewesen, und wenn nicht "die eiserne Hand Preußens" die Früchte fremder Arbeit ausgenutzt hätte, dann wäre diese Nationalbewegung zu einer hellen Seite in der deutschen Geschichte geworden.

Es gebe nämich zwei Sorten von Nationalismus: Einmal den Nationalismus Wilhelm Tells und Garibaldis, der die schwachen und unterdrückten Nationalitäten befreien wolle und daher fortschrittlich sei, und den Nationalismus Bismarcks und Moltkes. Der Nationalismus dieser beiden Politiker sei kämpferisch, halte das eigene Volk für das beste der Welt, sei roh, vorurteilsbeladen und engstirnig. Er unterstelle der Nation räuberische Instinkte und Fünsche; dieser Expansionsdrang sei indessen letzten Endes doch nur einzelnen Persönlichkeiten von Nutzen.

Jedenfalls besitze dieser Nationalismus keinerlei Ideale. Daran seien die Preußen schon immer arm gewesen, dafir hätten sie mit bemerkenswertem Geschlck fremde Ideen übernommen und für ihre ziele genutzt. (Naturlich ist auch hier wieder "der Preuße Bismarck" gemeint). 17

Ähnlich auch Michajlovskij, wenn er schreibt, dab "dieses große und geeinte Deutschland", dieses

17) Vgl. M. Pilippov, Zto délaetsja $2 a$ granicej. $\mathrm{RB} 1889 / 5 / 6$ (Mai und Juni in einer Numner), S. $341 \mathrm{ff}$. 
"von Bismarck hervorgebrachte Deutschland", nichts mit dem Traum der deutschen Patrioten der vierziger Jahre Gemein habe. 18

Den vermutlich aus "Blut und Eisen" abgeleiteten Beinamen "Eiserner Kanzler" für Bismarck wird einmal vom RB in "Eiserner Attila" umgerandelt und die Deutschen mit den Hunnen verglichen. 19 Entsprungen war der "Eiserne Attila" zweifellos der damaligen Furcht in RuBland und in Frankreich vor dem deutschen Militarismus, dem Dreibund und einem von diesem entfesselten Krieg. 20

Verantwortlich für alle Unruhen in Europa sei Bismarck, wofur folgendes 2 itat kennzeichnend ist: "In der letzten zeit ist der berühmte Satz 'cherchez la femme' in grober Mode, wenn man den

18) Vgl. N. üichajlovskij, Literatura i żiń. $\mathrm{KB} 1894 / 8$, II, S. 170 .

19) Vgl. N.N., Cto dèlaetsja za granicej. RB $1889 / 2$, S. 203. -.-

Also mehr als zehn Jahre vor Wilhelms II unbesonnener Rhetorik vom 27.7.1900 in Bremerhaven: "Pardon wird nicht gegeben. Gefangene werden nicht gemacht... iie vor tausend Jahren die hunnen unter ihrem König Etzel sich einen Namen gemacht,... so möge der Name Deutscher in China auf tausend Jahre durch Euch in einer hieise bestätigt werden, dab niemals wieder ein Chinese es wagt, einen Deutschen auch nur scheel anzusehen." Zit. nach Erich Eyck, Das persönliche Regiment Wilhelms II. Politische Geschichte des Deutschen Kaiserreiches von 1890 bis 1914. Erlenbach-Zürich, 1948, S. 272. In Anmerkung 42, ebenda, bezieht sich Eyck auf Band II, S. 210 der "Reden Wilhelms II.... nach der Keciam-Ausgabe" (S. 787). Line Nachprüfung der $0 . a$. Ausgabe ergab, dab der Text der Rede, die in inrem lortlaut ohnehin umstritten ist (vgl. ReclamAusgabe Bd. II, Anm. S. $211 \mathrm{f}$.), bei Eyck von dem Wortlaut der in der Reclam-Ausgabe enthaltenen Rede abweicht.

20) Daß diese Angst vor dem deutschen Militarismus, dem Dreibund und dem Krieg in den achtziger Jahren besonders in Prankreich und RuBland wirklich sehr akut war, ist aus den letzten Jahrgängen des RB in den achtziger Jahren deutlich zu ersehen: Vgl. z.B. M.F., Cto délaetsja za granicej. RB $1888 / 12$, S. $189 f f_{1}$, und N.N., Eto délaetsja za granicej. KB 1889/1, S. $201 \mathrm{ff}$. 
Grund irgendeines Ereignisses erklären will... iian könnte diesen Satz richtiger in 'sucht Bismarck mit seinem lilitarismus und seiner Frankophobie' umwandeln." 21

Folglich wird Bismarcks Entlassung am 18.3.1890 mit Freuden begrübt und kommentiert ${ }^{22}$ und vilhelm II. (damals!) gelobt: Bismarcks Entlassung sei ein Zeichen "tiefer politischer Weisheit" des jungen Kaisers, dieser habe erkannt, daß Bismarck der lionarchie geschadet habe, wie die letzten Wahlen ja deutlich bewiesen hätten. ${ }^{23}$ עoch die Angst, Bismarck könne wieder auf seinen posten zurückkehren, setzte bald darauf ein, genährt durch das ungeheure Ansehen, das der fürst ${ }^{24}$ bei den tiassen der deutschen Bürger genoß, una verdrängte die kurze freude des $R B$ bald.

Bismarck wurde auch im Ruhestand als eine beständige, latente Gefahr angesehen. wan traute dem "alten Löwen" 25 nicht und befürchtete, er könne vielleicht doch wieder an die kacht gelangen. Als beunrunigendes Moment galt, wie gesagt, die Verehrung, die Bismarck nach wie vor von der deutschen Bevölkerung dargebracht wurde, die Aureole des Begründers der deutschen Einheit, die ihn unschwebte und inm Achtung und Dankbarkeit einbrachte. Nach Ansicht des $R B$ ist das deutsche Volk in dieser Hinsicht naiv und die Popularität des Kanzlers deshalb so gefährlich, weil sie noch

21) Vgl. N.N., Čto dělaetsja za granicej. RB 1889/2, S. 203, 207.

22) Vgl. an., Chronika zagraničnoj Žizni. RB 1890/4, S. 149-152.

23) Ebenda, S. 150.

24) Den ihm bei der Entlassung verliehenen Titel eines Herzogs von Lauenburg hat Bismarck nie benutzt.

25) Vgl. V.T., Chronika zagraniěnoj žizni. RB $1892 / 6$, II, S. 42 . 
lange jegliche Unwahrheit heiligen wird. 26

Unmutig verfolgt das RB die Huldigungen, die Bismarck immer wieder von der Bevölkerung dargebracht werden. Es berichtet von einer glanzvollen Geburtstagsfeier des "Eisernen Kanzlers" in Friedrichsruh, anläBlich deren er von einer "riesigen wenge" gefeiert und durch "zahllose Gratulationen" geehrt worden sei, wodurch sich nach Meinung des Berichterstatters "lautstark der allgemeine : Yunsch ausdrückte, daB er wieder an die Lacht zurückkehren solle."27

Ganz ausführlich wurde die Reise dargestellt, die der "Siserne Kanzler" nach Wien unternahm, um an der Hochzeit seines Sohnes Herbert mit der Tochter Larguerite des ungarischen lagnaten Graf Hoyos teilzunehmen. Die 2 wischenstationen (Berlin, Dresden, Niunchen und andere Städte) habe er nur eingelegt "mit dem Ziel, seine Popularität aufzuwärmen". Lit Besorgnis wird dieser "Triumphzug eines Volkstribunen, wenn nicht gar eines gefährlichen Agitators * verfolgt. Riesige Menschenmengen begruibten in Berlin den 'neuen Wallenstein" oder den "neuen Belisar" (beide Feldherren fielen bekanntlich bei ihren Kaisern in Ungnade - diese Bezeichnungen des Füroten hat das RB vermutlich dem Kladderadatsch entnommen), die Sachsen und Bayern "völlis vergessend, dab sie dank Bismarck ihre Selbständigkeit verloren hatten, bemiinten sich, ihm auf jede

26) Vgl. hierzu: V.T., Chronika zagraniĕnoj žizni. $\mathrm{RB} 1892 / 6$, II, S. 51 . V.T., Chronika zagranižnoj zizni. RB $1893 / 5$, II, S. $97 f$. S. Juzakov, Politika. RB 1898/8, II, S. 216. S. Južakov, Politika. RB 1901/2, II, S. 146.

27) Vgl. V.T., Chronika zagranienoj zizni. RB 1892/2, II, S. 107. 
Heise $z u$ beweisen, daß sie ihm für die Einigung Deutschlands dankbar sind." Auch in "dem einst von ihm besiegten "Wien" wurden ihm aufsehenerregende und glanzvolle Ovationen dargebracht. Fazit: "Die Volksmassen bringen ihm ein heiBes Hohlwollen entgegen, ungeachtet der Tatsache, daB er sich niemals um das Wohl des Volkes gekümrnert hat." 28

Es lag nahe, den entmachteten Kanzler mit dem englischen liberalen Politiker William S. Gladstone (1809-1898) zu vergleichen, der zwischen 1868 und 1894 viermal an der Spitze der Regierung stand, dessen drittes Ministerium 1886 gestürzt worden war, und der dumals (1892) ebenfalls erwartete, zurückgerufen zu werden.

Dieser Vergleich ist sehr aufschlubreich für die Wurzel der negativen Beurteilung Bismarcks. Gladstone, der von den Willen zu einer christlich-humanitären staatsfiunrung durchdrungen war und jeglichen politischen Machiavellismus ablehnte, muBte der politischen Uberzeugung der Narodniki des $R B$ näherstehen als Bismarck, dessen überragende Größe übrigens anerkannt wird: "... es ist schwer, sich eine passendere Bezeichnung für diese Titanen der gegenwärtigen bedeutung̈slosen und jeder GröBe entbehrenden Epoche vorzustellen, als alte löwen. Beide sind sie im Kampfe alt geworden, beide setzen den Kampf fort und strecken die Waffen nicht, beide stehen in unerreichbarer Höne inmitten der sie umgebenden Politiker und Lianner des öffentlichen Lebens; beide haben jetzt alles auf eine Karte gesetzt und beschlossen, sich,

28) Vgl. V.T., Chronika zagraniènoj žizni. RB $1892 / 6$, II, S. $42 f ., 46-48$. 
koste es was es wolle, die innen aus den kijnden geglittene :.acht zurückzuverschaffen."29

(Nämlich Bismarck durch seine keise nach ilien, Gladstone durch seine iahlkampasne).

Doch "es fibt nichts Geneinsimes zwiscilen den Persönlichkeiten des volkstümlichen ilillian und des eisernen Kanzlers... Siner von diesen alten Iöwen ist ein besiegter, witender Iöwe, der, obwohl er sich priysisch in Freiheit befindet, doch in einem moralischen käfig sitzt nach langen Jahren uneingeschränkter iacht, die nur der kufgabe gewidmet waren, seine Heimat und die ganze lelt im Käfig $z u$ halten. Im Gegensatz dazu beschützte der andere löwe secinzig Jihre lang die i'reineit seines Volkes und aller Nationalitäten, und jetzt, im Alter, spannt er seine letzten kräfe an, un den Kafig $z u$ öffnen, in welchell seine liation seit Jahrhunderten sch:lacintet. Der erste hundelte in:er und handelt ois heute aus persönlichen, ehrgeizigen, diktatorischen botiven, und uer zweite hatte und hut als Ziel nur das Wohl des Volkes; der eine stellt einen werswïdioen snacironismus dar, när.lich die ت̈rscheinun wajordomus im neunzehnten Juhrhundert, und der zweite ist oie lebendige Verkörperung eines wohltuenoen Bindnisses der besten Kräte der VerganEenheit mit der hellen iorgenröte der Zuisunft." 30

Zur Befriedigung des $\mathrm{KB}$ ist es dem preußischen alten Iöwen nicht gelungen, seinen Käfig zu öffnen, das Geriicht, "der nach iriedrichsrun Verbannte"

29) VGl. V.T., Chronika zagraniŁ̌noj žizni. RB $1892 / 6$, II, S. 42.

30) Ebenàa, S. 43 . 
werde zum Vorsitzenden des itajtirats ernannt, hatte sich nicht bewahrineitet. Denn die keise des eisernen kanzlers "führte $z u$ einer skandalösen Polenik zwisclien den offiziellen kaiserlicisen presseorsanen und den Bisi.larckzeitungen, die nicht nur für den in Ungnade gefallenen Diktator die Rückkchr an die Niacht zunichte machte, sondern den Absrund, der zwischen inn und seinem enemaligen kaiserlichen schüler gähnt, noch mehr verbreiterte." 31

Auch in der Opposition galt Bismarck dem $k B$ als befärlich, weil seine lieinung in weiten creisen immer noch großes Gewicht besitze, und er solut die ..ötichkeit habe, besonders in Krisenzeiten seinen sinfluib geltend $z u$ machen.

Jid dus $K B$ dem cremali $i_{\xi}$ en Kanzler bei allem, was er tut, skrupelloses iachtstreben unterstellt, widmet es den stellungnahmen und inmischunësversuchen Bismarcks groBe Aufmerksankeit, z.B. dem Kampf uri die Heeresvorlage von 1892/1893.

Bismarck sei gegen die Heeresvorlage wie prinzipiell gegen alle kaßnahmen seiner Nachfolger. ir inalte sie für nutzlos in militärischer Hinsicht und fïr unaöglich in diplomatischer und finanzieiler Bezieisung. Ein An riffskrieg seitens Kublands und jrankreicis (mit dieser Zweifrontenbedrohung Deutschlands wotivierte Caprivi die Notwendigkeit einer verstärkten Heeresvermehrung) erschiene inm nisht aktuell.

Zu einer damaligen, von inm zitierten sußerung Bismarcks:

31) Ebenda. 
"Es wäre äuBerst betfüblich, wenn der Reichstag die Frage der Heeresvorlage unter dem Druck des persönlichen Willens des Herrschers löste; das wird das Prestige der Volksvertretung untergraben und den Verdacht verstärken, dab für ihn suprema lex nicht salus publica ist, sondern regis voluntas", bemerkt das KB ironisch:

"Diese Vorte klingen bedeutsam aus dem Liunde eines bienschen, der selbst einmal eiren nartnäckigen Kampf mit dem Parlament gefuhrt hat wegen der Erhöhung der militärischen Kräfte Preußens." 32

Zugleich mit seiner Ablehnung der Heeresvorlage habe Bismarck zur Freundschaft mit RuBland geraten. Das RB glaubt weder das Eine noch das Andere: "lian darf der Aufrichtigkeit des einstigen Eisernen Kanzlers sowohl bei seiner Verteidigung der freundschaftichen Beziehungen Deutschlands zu RuBland als auch bei seinem Widerstand gegen die Heeresvorlage natürlich nicht trauen, weil das eine wie das andere nur ein Vorwand sein kann, sich die jiacht zurückzug̈ewinnen, um danach wieder als der fruhere Anhänger der Theorie von Feuer und Eisen 33 auftreten zu können." 34

32) Vgl. V.T., Chronika zagraničnoj žizni. RB $1893 / 2$, II, S. 76 .

33) "Feuer und Eisen" steht hier, nicht wie sonst "Blut und Eisen". Diese Floskel hatte Bismarck auch einmal gebraucht: in einem Brief, datiert "Petersburg den 12. Mai 1859" schrieb er an den Minister Schleinitz: "... wir früber oder später ferro et igni werdon heilen miissen,..." (Bismarcks Briefwechsel mit dem rinister Preiherrn von Schleinitz 1858-1861. Stuttgart und Berlin, 1905, S. 18.) Hierbei wird er aber kaum an brennende Häuser und klirrende Waffen gedacht haben, vielmehr an die Gnome des Hippokrates: "Quod medicamenta non sanant, sanat ferrum, quod ferrum non sanat, sanat ignis (quod ignis non sanat, sanat more). Bismarck hat vielieicht den Spruch als Motto von Schillers Räubern kennengelernt (mit quae statt quod und ohne den eingeklammerten SchluB).

34) Ebenda, S. 77. 
Ahnlich ungläubig steht das RB der Äuberung Bismarcks gegenüber, nicht am Wahlkampf teilzunehmen, von dessen Ausgang doch seiner Ansicht nach das weitere Schicksal des Reichs abhängt. 35

"Diese Entschlossenheit Bismarcks, nicht an Wahlkampf teilzunehmen, wenn er sie nur nicht in der letzten hilnute ändert, ist fast der einzige Trumpf in den Händen der Regierung bei dem von ihr begonnenen, gefährlichen Spiel, 36 umso mehr, als der ehemalige Eiserne Kanzler in letzter Zeit seine Ansichten sehr stark geändert hat." 37

Wahrscheinlich mit dem Ziel, die eigene Besorgnis, und zugleich die der leser zu beschwichtigen, bringt das $R B$ mit Vorliebe Berichte über den fortschreitenden Alterungsproze $B$ Bismarcks. (Die Berichte stützen sich auf Zeitungs- und Augenzeugenberichte und sind in ihrer Absicht ziemlich durchsichtig.)

"Was den einstmals schrecklichen Eisernen Kanzler selbst angeht, so denkt er anscheinend nicht mehr an eine Rückkehr an die Lacht... Nach Aussagen von Personen, die inn kurzlich gesehen haben, ist er sehr gealtert und heruntergekommen, so da $B^{\circ}$ nur die von früherem feurigen Glanz erfullten Augen an den alten Bismarck erinnern, dessen Gęsicht,

35) Vgl. V.T., Chronika zagraniěnoj žizni. RB $1893 / 5$, II, S. 101.

36) Die Wahlen, von denen hier die Rede ist, fanden im Juni 1893 statt, im Zusammenhang mit der Krise un die Heeresvorlage, die eine Auflösung des Reichstags im liai 1893 und Neumahlen zur Folge hatte. Im Juli wäre die Heeresvorlage auch abgelehnt worden, mit 185:181 Stimmen, wenn die 19 polnischen Abgeordneten sich der Stimme enthalten hätten, statt die Regierung zu unterstützen.

37) Ebenda, S. 98. 
von tiefen Runzeln zerfurcht, jetzt deutliche Spuren physischer leiden und eines sciweren seelischen Kummers trägt: und nach den :lorten seiner Zeitungen wird er, da er am politischen Geschehen des Landes weiter nicht meinr direkt teilnimrt, in Zukunft nur aus der perne die Vercinderungen im Schicksal des Vaterlands uit Trauer und Besorgnis verfolgen, ungeachtet dessen, ob er Anerkennung oder Undankbarkeit, Gnade oder Ungnide findet." 38

In. Januar 1894, als die vom RB seit Jahren gefüchtete Versöhnung nun wirklich in greifbarer Naihe war, formuliert das $R B$ seine Anjst und seine Befüchtungen ganz konkret (vorher imer nur zwischen den zeilen, wern auch ieutlich wahrnennbar).

Es geht hier um die berihut gewordene Flasche "Steinberger Cabinet", die dilinelu dem Exkanzler am 22. Januar durch den Flügeladjutanten von Moltke zusamen mit einew handschriftlichen Brief wit Glückwïnschen zur Genesung von einer Grippe überbringen lieb. Bismarck sei so gerührt durch diese unerwartete Gnade gewesen, dal er unverzijglich seine Absicht kundgetan habe, nach Berlir zu fanren, un den Kaiser seines Dunkes zu versichern.

"ilie die Telegraphenbüros versiciern, hat dieses Ereignis einen Gevaltigen Eindruck in parlailentskreisen gewacht, und in der l'at, wenn die sussönnung zwischen wilhelm und Bismarck zustandekonmt, und wenn sie auch aurch eine Flasche alten ieins

38) Vgl. V.T., Chronika zagraničnoj žizni. $\mathrm{KB} 1893 / 5$, II, S. 98 . Siehe auch V.T., Chronika zagraničnoj žizni. RB 1893/10, II, S. $79 f$. 
verursacht wäre, so kann diese l'atsache bei dem t.. omentanen Durcheinander in Deutschland ernste Folgen haben; aber natürlich ist eine Rückkehr zur dasuligen Bismarckisuus, d.h. zun Systen von iisen und Feuer, jetzt völlig unaenkbar." 39

Als die Versöhnung dann vollzogen war, aber "glücklicherweise" nicht die befürchteten politischen Konsequenzen zur Folge hatte, zeigte sich das $R B$ wieder beruhigter:

"Hie VersöhnunE des deutschen Kaisers mit Bismarck ist eher eine interessante Seite in der Geschichte dieser beiden bemerkenswerten persönlichkeiten als ein herausragendes Faktun der gegenwärtigen rolitik, da sich bis jetzt ihre politische Bedeutung noch nicht geklurt hat. ... Vier Jahre hartnäckieen kampfes sind vergangen, seit Bismarck mit den iorten 'Le roi me reverra' den Hof verlassen hat, und nun haben sich diese ilorte wörtlich bewahrheitet... Wie oft hat nicht Wilhels bei passenden und nicht passenden Gelegenheiten wiederholt, dab er die Unbeugsamkeit des Alten brechen werde, aber der Alte fuhr stur und sogar frech fort, iliderstand gegen den berüchtigten neuen Kurs $z u$ leisten, und schlieblich ging Hilhelm nach Canossa und beugte sich dem früheren kanzler.

Velche irwigung auch immer seine Handlungen in diesem Zusamennang geleitet haben mag, ob es der ilunsch war, seine erschuitterte Popularität wiederherzustellen, oder die Notwendigkeit, in der gegenwirtigen kritischen liinute die Hilfe des Schöpfers des deutschen Reiches in Anspruch zu

39) Vgl. V.T., Chronika zagranižnoj žizni. $\mathrm{KB} 1894,1$, II, S. 141 . 
nehmen, auf jeden Pall hat er sich - einmal zu einem solchen Schritt entschlossen - nicht mehr geschont und seinem Widersacher einen vollkommenen sieg bereitet.

Naturlich hatte diese ganze Geschichte der Versöhnung von Lehrer und Schuller auch einen komischen Anstrich, weil sie mit der tbersendung einer Flasche Wein begann und mit dem Geschenk eines grauen Uniformmantels endete. Aber die wenigen Stunden, die Bismarck in Berlin verbrachte,... entschädigten ihn völlig für die ganze Bitterkeit der Acht. $" 40$

"Hiermit endete die Bpisode der beruhmten Versöhnung. Aller Wahrscheinlichkeit nach hat Bismarck verstanden, daB sein sieg fruchtlos bleiben und nicht zu seiner Ruckkehr an die liacht führen wird, da er, von Berlin fortfahrend, ... auf die Bemerkung einer ihn begruBenden Persönlichkeit, daB er wirklich ein eiserner Mensch sei, antwortete: 'Ja, ich bin eisern, aber gerostet'. Oowohl sein Sohn, Graf Herbert, dem hinzufügte: 'Und Doktor Schwenninger kümmert sich um die Entrostung'. Aber wenn man die Worte Bismarcks nicht auf seine Gesundheit anwendet, sondern auf seine politische Lage, dann ist der Biserne Kanzler in der Tat gerostet, und ungeachtet seines letztlichen Siegs im Kampf mit Wilhelm ist es in der jetzigen zeit unmöglich, die vergangenen Tage des 'Blsmarckismus' zurückzuholen. " 41

Nach dieser "Versöhnung" aber schwindet beim RB die Besorgnis, der nun Achtzigjährige werde noch

40) Vgl. V.T., Chronika zagranienoj zizni. RB $1894 / 2, S .121$.

41) Ebenda, S. 122. 
einmal die Zügel in die liand nehmen; man wendet sich nun wehr allgemeinen würdigungen und Rückblicken zu:

1895, in schwülstigem und übersteigertem Stil: "Das Bismarcksystem war das System der finadenlosen Opferung aller Seiten der Kultur auf dem Altar der Staatlichkeit, ihrer äußeren stärke und inneren Allmacht. Diese tberentwicklung der Staatlichkeit, die so gefährlich für die Zukunft des Landes ist, wie jede einseitige Entwicklung, war zwar für Preußen notwendig, um die Einigung Deutschlands und die Vorrangstellung in Europa zu erreichen. Das System der tberentwicklung der staatlichkeit wurde indes auch nach der Einigung fortgesetzt, indem es mehr und mehr die hohe geistige Kultur Deutschlands verdrehte und degradierte, und mehr und mehr das geistige, religiöse, materielle und gesellschaftliche Leben dem alleinigen Götzen der staatlichen lacht unterordnete. $" 42$

In der Zeit von 1871-1890, der Hegemonie BismarckDeutschlands in Europa, seien die gemeinsamen europäischen Interessen vergessen worden, weil sich die sogenannte Realpolitik, also die Politik der materialistischen nationalen Interessen, von Berlin aus uber Europa ausgebreitet habe. Erst durch das russisch-französische Abkommen seien europäische Interessen wieder erwacht.

Bismarcks Fall und die Kronstadter Visite der französischen Plotte im Jahr 1890 hätten praktisch das Ende der deutschen Hegemonie in Europa bedeutet,

42) Vgl. S. Južakov, 1894 god. (Iz sovremennoj chroniki). RB 1895/1, II, S. 212. 
die das europaische kecht verletzt und die allgeweine jicherheit gefahrdet nabe. ${ }^{43}$

Und 1897: Bismurck nabe das allgemeine Vahlrecht daulu ausgenutzt, seine pläne durcirzusetzen und dabei vor keinem iattel zurückgeschreckt, das volk zu betriugen una unter jruck zu setzen:

Schon bald nach dem allgemeinen siegestaumel über die Franzosen habe Bisinarck gemerkt, daß er nicht auf eine inm gefügige Lehrheit im Reichstag rechnen und daB nur ein Appell ans Volk - im Stil des napoleonischen Plebiszits - ihm helfen könne. Es sei wohlbekannt, was er unter eineas Appell ans Volk verstand und ait welchen liitteln er die jrfullung seines Planes vorbereitete: Seine iuittelsminner malten "das rote Gespenst eines angeblich drohenden Umsturzes" an die iland. "Die käuflichen Schreiberlinge aes ersten hanzlers und die vor inm liebedienernden Parteien verängstigten das Volk dernaken mit den fingierten Schrecken der kevolution, dall Bismarck sich 1878 zur Auflösunt des leichstag entschließen konnte: bei den herrschenden weiben l'errur konnte von freiheit der neuen iahlen keine kede sein."

Die neue Zusamuensetzung des keichstag nuch den iahlen bezeicinnete das KB als "Frodukt der Angst". Lit einem solchen keichstag wäre es nicht schwer gewesen, die Annahme der gegen die Sozialisten gerichteten Gesetze zu erreichen.

Nach den nächsten iahlen von 1884 habe Bisinarck wieder nicht die feste kegierungsmehrheit besessen und sei gezwungen gewesen, sich etwas lieues

$43 \mathrm{Vgl}$. S. Južakov, Dnevnik žurnalista. $\mathrm{RB}$ 1897/8, II, S. 120-131. 
für eine ginstigere Verteilung der Parteimandate auszudenken. "Dazu war es notwendig, die Wänlermasse wieder in einen solchen unzurechnungsfähigen zustand zu bringen, bei dem sie vor Angst den Kopf und inr gesundes Urtejlsvermögen verlieren würde." Aufs Neue das "Spiel mit dem roten Gespenst" zu versuchen, sei zu riskant gewesen, weil sich immer größere Teile der deutschen Gesellschaft auf die Seite der Unterdrückten und Verfolgten schlugen. Daher blieb nur noch das andere schreckliche Gespenst - das Phantom eines Krieges.

Einige drohende Bemerkungen des Kanzlers an die Adresse von Paris schürten dort die erforderliche kriegeriscne Stimmung, danach brauchten sich blOB noch die Journalisten des "Reptilienfonds" (die käufliche Presse $)^{44}$ und die erfahrene Bismarckbürokratie ans Werk zu machen.

Bismarck habe unbedingt das Septennat, die Heeresvermehrung für sieben Jahre, durchdruicken wollen, er habe also den Keichstag aufgelöst und Neuwahlen anberaumt. Sein "Apparat" arbeitete auf vollen Touren, um die Wähler einzunebeln und ihnen vorzugaukeln, die Franzosen näherten sich schon der deutschen Grenze.

Alles dies wurde geschildert, "um eine Vorstellung von diesem Kreuzzug der iüge, des Betruges und jeglicher Gaunerei zu geben, der einmalig in den

44 ) jchon 1893 schrieb das $R B$, Bismarck habe lange ïber den sogenannten ielfenfonds verfiugt, der aus Einkünften des konfiszierten Besitzes des Hauses Hannover bestand. Hit diesem Geld wurde die "berüchtigte, liebedienernde Presse des Eisernen Kanzlers" bezahlt. "lít diesem Geld kaufte Bismarck alle Leute, die er brauchte." Vgl. V.T., Chronika zagranižnoj Žizni. RB $1893 / 1$, II, ì. 91. 
Annalen des jungen Keiches ist."

Bismarcks Plan sei gelungen, im Pebruar 1887 hube er die Wehrheit für sein jeptennat erhalten. 45

Als 1898 der so gehaßte "Iiserne Kanzler" für immer die Augen schloB, schrieb S. Južakov im gleichen Jahr (und 1901 nochmals) eine große Retrospektive, aus der größere Teile hier folgen.

"Die Figur des 'Großen' Napoleon, der uns ins 19. Jahrnundert hineingefuhrt hat, und die Figur des 'Großen' Bismarck, mit dem die Galerie der Staatsmänner dieses Jahrhunderts endet, lehren uns ... am besten die Kehrseite dieser großen Epoche verstehen; sie zeigen nackt und schonunislos den gegenwärtigen zivilisierten Menschen und seine Leiden und Erniedrigungen. Der Vergleich zwischen Napoleon und Bismarck, zwischen den blutigen Taten des einen und der grausamen Tätigkeit des anderen, $z$ wischen der Verwüstung der europäischen Nenschheit am Anfang und ihrer Verwistung am Ende des Jahrhunderts, dieser Vergleich drängt sich von selbst auf vor dem frischen Grab des ersten deutschen Kanzlers.

Sind etwa llapoleon und Biswarck wirklich die gröbten Staatsmänner des ausgehenden Jahrhunderts? Ist es möglich, daß wir wahrhaftig die Epoche erlebt haben, in der Alexander von Nakedonien an die Stelle des Genius Perikles tritt, und die Größe eines Julius Cäsar die Größe des Gracchen vergessen macht? Betrachten wir diese beiden

45) Vgl. A. Kovrov, Iz Germanii. RB 1897/3, II, S. 135-137. 
unheilsträchtigen Gestalten unseres Jahrhunderts etwas näher!" 46

Bismarck hinterlasse seinem Vaterland ein schweres Erbe:

"Solche Leute wie Napoleon und Bismarck kommen der ganzen Menschheit teuer zu stehen, aber am teuersten ihrem heibgeliebten Vaterland. Die Pranzosen konnten bereits die Bilanz der 'wertvollen' Taten ihres großen Napoleon ziehen, den Deutschen steht diese Aufgabe noch bevor. Es gibt große Leute, die von ihren Zeitgenossen nicht anerkannt, aber von den Nachfahren gepriesen werden, welche ihr Gewissen damit beschwichtigen, daB sie ihnen uppige Mausoleen errichten. Aber es gibt auch eine andere Sorte von großen Leuten, vor denen sich die Zeitgenossen verbeugen, die aber bei den Nachkommen Entsetzen und Empörung hervorrufen. Napoleon und Bismarck gehören natiurlich nicht zur ersten Sorte". ${ }^{47}$

Das Urtell uber Napoleon habe die "schonungslose historische Logik" bereits gefällt; und was Bismarck angehe, so werde das "menschliche Gericht" uber ihn noch fruher urteilen als uber die einzelnen Ereignisse. ${ }^{48}$

Welches sind denn die "groBen" Taten Bismarcks auf dem Gebiet der AuBenpolitik?

"Der Sieg Deutschlands uber Frankreich, der Sieg Preußens uber Osterreich, die Zerstörung der

46) Vgl. S. Južakov, Politika. RB 1898/8, II, S. 215, ebenso: S. Južakov, Politika. RB 1901/2, II, S. 141 .

47) Vgl. S. Južakov, Politika. RB 1898/8, II, S. 2281.

48) Vgl. S. Južakov, Politika. RB 1901/2, II, S. 141. 
russisch-preubischen Freundschat't und die irrichtung des Dreibunds."

Jas Hauptwerk Bismarcks sei der sieg uber Frankreich gewesen, der die Deutschen für eine Einigung unter preubischer Vorherrschaft begeistert und Deutschland die Führung̈srolle in Luropa verschafft habe.

Nicht die französisch-aeutsche Feindschaft, die ja schon seit fünf Jahrliunderten bestehe, wird Biswarck zu Lusten gelegt, auch die schwäche des "jeinmerlichen Regimes" des "kleinen" Napoleon (III.) sei nicht auf Bismarck zuriickzuführen, ebenso wenig habe er die preubische Nilitärorganisation begründet.

Das Vierk Bismarcks habe vielmehr darin bestanden, in einem günstigen Augenblick obige für einen Sieg so vorteilhafte Kombination auszunutzen und danach aus dem sieg Vorteile zu ziehen. Und die Erfüllung dieser Aufgabe nabe ihm nach binung der beutschen ein Anrecht auf Dankbarkeit seitens des Vaterlands und auf allgemeine Anerkennling seiner Gröie gesichert.

Aber wie sehe die ifirklichkeit aus? Er habe in der Tat die günstige Kombination für den sieg über Frankreich ausgenutzt, doch, selbst wenn dieser Sieg für das deutsche Volk notmendig war, habe es ihn ja auch teuer genus erkauft.

ifelchen Gewinn hat Bismarck nun aus dem sieg gezogen? Fr begründete das Reich mit dem preuBiscinen König an der Spitze. GewiB, aber er konnte gar nicht anders handeln, denn bereits 1849 nabe das Frankfurter Farlament dies so beschlossen, und seit der Niederlage Ósterreichs 1866 wurde "das Reich" zum Traum der überwiegenden lehrheit des deutschen Volkes. Es wäre daher übertrieben, 
die Verwirklichung dieses Traums als die Tat Bismarcks hinzustellen.

Dafür waren "die Einverleibung von Elsaß-Lothringen, das Zurückhalten des dänischen Schleswig, die funf Milliarden Kontribution und eine Reihe weiterer Versuche zur Erniedrigung und Zerstörung Frankreichs" seine wirklichen Taten; sie waren die Form, in welche er den deutschen Sieg ummünzte. Seitdem erschöpfen die unmäßigen Summen für die Aufrüstung die Finanzen beider Länder.

Bismarck habe nicht verstanden, welch schwerwiegende historische Verantwortung er Deutschland aufbürdete, als er ElsaB-Lothringen annektierte. 49 Er habe seine Größe darin gesehen, die Grenzen des Reichs nicht dort zu setzen, wo das BewuBtsein, ein Deutscher zu sein, aufhört, sondern weitere Landstriche darüber hinaus zu erwerben. Gleich vielen "großen" Deutschen und Franzosen vor ihm habe er die einfache Wahrheit nicht begriffen, daB "die Grenze zwischen zwei benachbarten mächtigen und zivilisierten Nationen nur auf Grund der Wunsche der Grenzbevolkerung festgesetzt werden kann, da alles andere ungerecht und unbeständig ist."

"Pünf Jahrhunderte lang zahlten Deutsche wie Franzosen bitter für diese 'GröBe' ihrer staatsmänner. Bismarck ist der Richtung seiner großen Vorgänger treu geblieben." Er habe am Ende des neunzehnten Jahrhunderts die Politik Karls V. wiederholt; aber etwas, das zur Zeit Karls V. verzeihlich war, sei kaum verzeihlich in der

49) Es wird geflissentlich übersehen, daß sich Bismarck in dieser Frage erst nach langem Sträuben den Forderungen der Militärs fügte. 
Epoche Gladstones und Garibaldis, in welcher Bismarck lebte und wirkte.

Bismarck habe dem neuen Deutschland nämlich dadurch sehr geschadet; denn ein mächtiger Feind an der Westgrenze, bere1t, jede erfolgversprechende Kombination für einen erneuten Kampf auszunutzen, sei eine schwere Belastung für das Reich. Diese lähme seine gesamte Kraft und hindere es daran, Vorteile aus seiner Macht zu ziehen. Die Großmächte Europas kennten diese schwache Seite der deutschen Größe, die bewirke, daß die Interessen Deutschlands weit weniger anerkannt und zufriedengestellt werden, als es thm seiner sachtstellung entsprechend gebühre.

Die Deutschen erlitten fortwährend, von Janr zu Jahr, uberall, in allen füf Erdtellen, in allen Sphären des historischen Lebens und der historischen Tätigkeit Verluste dank dieser "großen Tat" Bismarcks.

Andere Völker wie die Engländer, Amerikaner und Russen zögen inre Vortelle daraus. 50

Vor dem Sieg über Frankreich hatte Preußen Osterreich besiegt, und auch hier habe es an Bismarck gelegen, daraus alle notwendigen Vorteile für Preußen zu ziehen und darauf das neue Gebäude der zukünftigen Größe Deutschlands zu errichten.

Wie habe nun dieser "gefeierte Genius des deutschen Volkes" seine Aufgabe verstanden und erfült? Während er nach dem Sieg über Frankreich die deutschen Grenzen uber die Grenzen deutschen

50) Vgl. S. Južakov, Politika. RB 1898/8, II, S. 215-218; und S. Južakov, Politika. RB 1901/2, II, S. 141-143. 
Nationalbewußtseins hinaus verlegte, schloß er nach dem Sieg über österreich mit einem Federstrich acht Nillionen "österreichische Deutsche" aus Deutschland aus.

"Auf der einen Seite Franzosen, Yolen und Dänen in die $\mathrm{Zahl}$ der Deutschen einzubeziehen und dadurch ihr nationales Bewulstsein zu vergewaltigen, und auf der anderen Seite die Osterreicher aus der Zahl der Deutschen auszuschließen, wodurch ihr nationales BewuBtsein ebenso schmerzlich vergewaltigt wurde - mag ... zwar als Widerspruch erscheinen, jedoch nicht in wien und nicht in Berlin."

In beiden Hauptstäden hatte man stets weniger die Idee einer einzigen deutschen Nation, als die Idee einer österreichischen oder preußischen staatlichen Organisation vor Augen: die Österreicher träumten davon, die Preußen auszuschließen, den Preußen hingegen gelang es, die Österreicher auszuschließen. Bismarck sei auch hier nur Handlanger der Tradition, er habe weder vermocht, gröBer als sein Jahrhundert $2 u$ werden noch auch nur auf gleicher Stufe mit ihm zu stehen.

Seine beiden sogenannten großen Taten (insofern sie seinem Einflub und seiner Führung zugeschrieben werden können), hätten in Wirklichkeit die gewaltigen erzielten Ergebnisse nur verdorben, in einem ungünstigen und gefährlichen, ja unpatriotischen Sinne.

Der Einwand sei zwar nicht von der Hand zu weisen, daß ein Anschluß des Vielvölkerstaates OsterreichUngarn nicht gangbar gewesen sei; aber die damals immerhin winkende Möglichkeit, in Mitteleuropa ein Reich mit 100 Millionen Deutschen zu errichten, habe Bismarck nicht ergriffen. 
Man nehme zwar an, daß er um die Interessen der deutschen Nation besorgt war. Bei einer Uberprüfung stelle sich indes heraus, daß er entweder davon nichts verstanden hat, oder sie den Interessen der preußischen Staatsorganisation und denen der preuBischen Dynastie untergeordnet hat.

"Österreich aus Deutschland ausschließen und Elsaß-Lothringen einbeziehen - das waren zwei große Taten des berünten Preußen, der soeben seine dräuenden Augen geschlossen hat."

Diese sich widersprechenden Taten seien ebenso gefärlich für die zukunft wie unvorteilhaft für die gegenwärtige deutsche Nation. Denn sie werde nicht nur ständig vom ilesten her bedroht, sondern verliere im Suidosten immer tnehr ihre früher unbestrittene Führungsrolle. Für beides könnten sich die Deutschen bei ihrem troßen Kanzler bedanken. 51

Die Politik Bismarcks in der Orientfrage und seine Rolle beim Berliner Kongress (1878) hätten die traditionelle preußisch-russische Freundschaft zerstört. Bismarck habe für eine weitere Abkühlung durch die Kampagne gegen russische Wertpapiere, den $2011 \mathrm{krieg}$ und andere Taten gesorgt. Dadurch sei Schritt für Schritt das französisch-russische Bündnis vorbereitet worden, das der politischen Vorherrschaft Deutschlands in Europa ein Ende setzte. Die französisch-russische Kombination, "die so wenig der historischen Vergangenheit entspricht", sei nur möglich geworden durch Bismarcks

51) Vgl. J. Južakov, Politika. RB 1898/8, II, S. 218-221; und ders., Poilitika. RB 1901/2, II, S. 143. 
Politik, die standig Paris und Petersburg unvernunftig provozierte. Die französisch-russische Kombination sei auf jeden Fall sehr ungünstig Iür Deutschland, auch dafür könne es sich bei seinem großen hanzler bedanken. Sogar der Dreibund, "die gelungenste politische Tat Bismarcks", hebe die für die Deutschen unangenehme Bedeutung des Iranzösisch-russischen Bündnisses nicht auf, sondern schwäche sie höchstens ab. 52

Demnach ist Bismarck in den Augen der Narodniki ein Versager, was seine Außenpolitik betrifft, aber auch sein Hauptverdienst nach innen, die keichsgründung, wollen sie nicht anerkennen und versuchen alles, inm diese Aureole des Begründers der deutschen Einheit zu nehmen.

Die Einigung Deutschlands sei nicht Bismarcks ilerk, ebenso wenig wie Preußens Sieg über österreich. Das eine wie das andere sei schon eine ausgereifte politische Frucht gewesen, als Bismarck die Leitung der Geschicke Preußens und Deutschlands übernahm. Sogar die wesentlichen Grundzüge der Form der Einigung waren schon durch die Geschichte entschieden und waren nicht mehr viel zu verändern. Bismarck konnte nur noch einige Korrekturen vornehmen und dann den Kurs für das neue Schiff festsetzen.

Die deutsche Einigung sei schon lange der Traum des deutschen Volkes gewesen, wenn auch die Gegensätze zwischen den Stämmen, den Konfessionen und den Dynastien neben den Intrigen des Auslandes seine Verwirklichung lange verhindert hätten.

52) Vgl. J. Južakov, Politika. $\mathrm{KB} 1898 / 8$, II, S. 221; und ders., Politika. RB 1901/2, II, S. 143. 
Auf geistigem Gebiete kam das Reich zustande durch die großen deutschen Dichter, Denker, Gelehrten und Kunstler un die Wende des 18./19. Jahrhunderts. "Lessing, Goethe, Schiller, Kant, Pichte, Hegel, Humboldt, Grimm, Mozart, Beethoven gehörten nicht den Franken oder Sachsen, den Schwaben oder Thüringern noch den Iutheranern, Reformierten oder Katholiken, noch den Habsburgern, Welfen oder Hohenzollern. Sie gehörten den Deutschen; sie waren die Wüde, der Stolz und die Stärke ganz Deutschlands. Vor der Stärke und dem Ruhm dieser gesamtdeutschen Kultur verflogen die Stammes- und Glaubensantagonismen: die deutschen Stämme verschmolzen in eine deutsche $\mathrm{Na-}$ tion. Danach war die politische Einigung nur noch eine Prage der Zeit, und zwar der allernächsten Zeit."

Bereits in den vierziger Jahren naben die süddeutschen Staaten auf Initiative des wirttembergischen Ministers Wangenheim den Versuch zur Einigung gemacht, aber PreuBen und Osterreich haben sie verhindert. Den zweiten Versuch in den stürmischen Jahren 1848-1849 hat Osterreich gestört; dem dritten Versuch im Jahre 1863 stand PreuBen entgegen, das damals bereits von Bismarck geleitet wurde.

Es stellte sich somit heraus, daB zuletzt der Wettstreit der Habsburger und Hohenzollern der einzige Hemmschuh für die Einigung Deutschlands war. Eine der beiden streitenden Dynastien mußte die Oberhand gewinnen, damit die Deutschen ihre so lang gewinschte Einigung endlich bekommen konnten. Bismarck hat viel für den Sieg der Hohenzollern getan. Damit hat er sich um die Hohenzollern sehr verdient gemacht, aber auch um Deutschland? Dieses häte sich doch genau so gut unter dem Zepter Franz-Josefs vereinigen können. 
In diesem Falle hätte man den heute von allen vergessenen österreichischen Staatsminister Schmerling als den groBon Einiger angesehen. Der Sieg bei Königogrätz habe jedoch nicht Schmerling grOB gemacht, sondern Bismarck, der allerdings zu dem Sieg nicht im geringsten beigetragen habe.

So ist die Einigung Deutschlands, der Bismarck 1863 noch ilderstand entgegengesetzt hatte, mit seiner Unterstuitzung verwirklicht worden.

Die Einigung Deutschlands sei also nicht das Werk Blsmarcks, wohl aber die Vornerrscnuft der Hohenzollern und damit die politische Bedeutung der preuBischen Aristokratie und der preuBischen Bürokratie.

Die Einigung Deutschlands, die Wahrung der Autonomie der einzelnen Länder, die gemelnsame Regierung in Gestalt eines Bundesrats und das gesamtdeutsche Parlament - all das se1 nicht das Werk Bismarcks. Dies alles sei bereits 1849 in Prankfurt geplant und (ebenfalls in Frankfurt) 1863 zum zweiten Mal bestätigt und von allen deutschen Regierungen, außer der preubischen, angenommen worden. Die Einigung Deutschlands und die Grundlagen Pür seine Organisation seien ohne Bismarck geschaffen worden. Er habe sie nur modifiziert und für seine eigenen Ideen ungeformt.

Diese Umformungen bestünden im wesentlichen darin, daB, wie bereits zusgefuhrt, unter den Hohenzollern nicht alle Deutschen vereinigt wurden, - die Deutsch-Osterreicher, Ifechtensteiner, Luxemburger, blieben drauben - dab ferner elne Anzahl deutscher Dynastien und ihre Staaten von Preußen geschluckt wurden - Hannover, Hessen-Kassel, Nassau, 
Frankfurt -, daß Preußens Osten ("die polnischen Provinzen"), früher außerhalb des Deutschen Bundes, nun dem Reich einverleibt wurden, ebenso wie das annektierte Elsaß-Lothringen. Ferner sei die Armee und die neue Flotte unter preubische Hegemonie gekommen (der König von Preußen war als Kalser Oberbefehlshaber aller deutschen Truppen im Kriegsfall - und, auBer in Bayern, auch im Frieden). Schlieblich habe Bismarck als letzte Modifikation das allgemeine Wahlrecht für den Reichstag eingefüht. Letzteres werde von der Geschichte dem Kanzler zwar als Verdienst angerechnet, diese Einstellung beruht aber nach dem $\mathrm{RB}$ auf einem MiBverständnis. 53

Er habe nämlich das allgemeine Wahlrecht nicht etwa aus liebe zum Volk eingefüht, sondern es sei inm wie alles, was er tat, nur Mittel zum Zweck gewesen:

"Bismarck kalkulierte mit seinem starken Verstand die Bedeutung der Volksmasse bei der Festigung der Einheit (richtig) ein, obwohl seiner gänzlich herrscherischen Natur die Volkssouveränität fremd und unsympathisch war." 54

Nach der Einigung habe Bismarck zwanzig Jahre lang an der Spitze der Regierung gestanden. Der alte Kaiser vertraute seinem Kanzler bedingungslos, und die Reichstage waren dem Willen des "allmächtigen Halbgottes des neuen Deutschland" gehorsam.

53) Vgl. S. Južakov, Politika. $\mathrm{RB} 1898 / 8$, S. 222-226; und ders., Poitika, RB 1901/2, S. 125f., 129, 143 .

54) Vgl. Gr. Br - v., Iz Germanii. RB $1898 / 6$, II, S. 137 . 
Wohin habe nun dieser große llann sein "gehorsames vaterland" geführt?

Die Organisation des Reichs sei unter seinem Regime geschwächt worden, genau so wie die deutsche Wacht durch seine "miBlungene AuBenpolitik", und in der Innenpolitik sei es sehr schwer, wirklich große Taten zur Verherrlichung des Toten zu finden.

Bismarck sei zwanzig Jahre lang rastlos tätig gewesen, um seine Pläne zu realisieren, nämlich alle seine Gegner - zugleich die der preuBischen Junkerkaste - zu vernichten, oder wenigstens zu "zähmen" - die katholische Kirche, die "Welfen", die Polen, die Dänen, die Elsab-Lothringer, die "Sozis" und auch Männer aus den eigenen Kreisen, wenn sie nicht sklavisch das taten, was der Kanzler wiuschte (Anspielung auf den Arnimparagraphen).

Dieses "Bacchanal der Bezähmung" habe die ganzen zwanzlg Jahre des Bismarckregimes angedauert.

Bismarcks Politik hatte groBen Erfolg und endete mit einem Fiasko, das daraus ersichtlich wird, wenn man die Zusaminensetzung des ersten Reichstags (1871) und des letzten unter Bismarck (1890) vergleicht. 'Obwohl er unermuidich die Klerikalen, Sozialisten, Autonomisten und fremden volker unterdruickt und dabei keine Mittel gescheut hatte, besaßen alle die von ihm "Feinde Deutschlands" genannten Gruppen im Jahre 1890 nicht mehr 101 Sitze wie 1871, sondern 179, also fast $80 \%$ mehr. Des Fürsten Scheitern liege also klar auf der Hand. 55

55) Vgl. S. Južakov, Politika. $\mathrm{RB} 1898 / 8$, II, S. 226-228; ders., Politika, RB 1901/2, II, S. 144-146. 
Als "der Alte vom Sachsenwald" nach Jahren der Entmachtung am 30. Juli 1898 für immer von der Bühne der Weltgeschichte abtrat, betonte auch das Ausland die GröBe des verstorbenen Staatsmannes. So wildigten führende Organe der russischen Presse, 2.B. "Moskovskie Vedomosti", "Russkij Vestnik", "Vestnik Evropy" und der "Graźdanin" die Verdienste Bismarcks. 56

Gemäß dem Wort des Weisen Cheilon, das in der freien lateinischen tbersetzung "De mortuis nil nisi bene" 57 so häufig zitiert wird, fand auch das "Novoe Vremja" einige anerkennende Worte.

Nicht so das RB, aus dessen Nachruf der gleiche unversöhnliche $\mathrm{HaB}$ spricht wie in den vergangenen Jahren. Aus dem Nachruf von S.N. Južakov seien einige charakteristische Passagen zitiert:

"'Le rol me reverra', sagte Bismarck, als er 1890 das Kanzlerpalais verlieB... 'Le roi me reverra', das war eine ernste Drohung aus dem Mund eines 80 unerbittlich rachsulchtigen und in seinen Mitteln nicht wählerischen Menschen, als den die Geschichte Bismarck kennt. Wilhelm II. konnte alles furchten und mubte auf alles vorbereitet sein. Den altersschwachen Diplomaten hat seine Sehergabe indes getrogen, und er verbrachte acht lange Jahre in politischer zurückgezogenheit, beständig frondierend

56) Vgl. Georg v. Rauch, Streiflichter zum russischen Deutschlandbilde des 19. Jahrhunderts. In: Jahrbucher für Geschichte Osteuropas, NP $12 / 1964$, S. $37 f$.

57) Der Ausspruch bedeutet ja nicht, daß man uber die Toten "nur Gutes" reden solite (dann müBte "bona" statt "bene" dastehen), sondern nur "in guter Weise", nicht schmöhend; denn Tote können sich nicht wehren. 
und vergeblich auf die herbeigesehnte stunde der Vergeltung und des Triumphes wartend... Die Stunde der letzten Abrechnung mit einem sündigen Leben schlug früher, und der eiserne Kanzler nahm seine unbefriedigte Rachsucht, seine Hoffnungen auf Kevanche, mit ins Grab." 58

"Ich wollte eigentlich noch einige Worte über das persönliche Leben Bismarcks sagen, ... wie es vor einem frischen Grab üblich ist. Unsere historische Charakteristik ist jedoch sehr umfangreich geworden, so daß für einen biographischen Uberblick wenig Platz bleibt. Aber um es genau zu sagen, liebe Leser, Sie haben dabei auch wenig verloren. Das persönliche ieben dieses 'Blut-undEisen-Menschen' ähnelt sehr seinen Taten. Unüberwindicher, nichts verzeihender Haß, grausame Rachsucht ohne den geringsten Lichtblick fuillen dieses lange, stürmische Leben an. Weder Anwandlungen von GroBmut noch Opferbereitschaft, weder erhabene Ideale noch moralische Interessen, sondern statt dessen ein alles zerstörender Wille, ein weitblickender, durchdringender Verstand, eine seltene Kühnheit der Pläne - so war diese bemerkenswerte Persönlichkeit, die durch ihre Tätigkeit die zweite Hälfe des neunzehnten Jahrhunderts geprägt hat." 59

So findet das RB, wenn auch widerstrebend, ganz zum SchluB noch ein kleines anerkennendes ifort über"diese bemerkenswerte Persönlichkeit" und

58) Vgl. S.N. Južakov, Politika. RB 1898/8, II, S. 214 .

59) Ebenda, S. 229. 
deren scharfen Intellekt. 60

60) Bemerkenswert ist, dais das $R B$ in seinem Haß schärfer sah als der Durchschnittsdeutsche und $d a b$ es in seinen Urteilen sich denen manches großen deutschen Zeitgenossen näherte; z.B. schrieb der politische Schriftsteller Konstantin Frantz (1817-1891), der als Anhänger des Traums von einem groben mitteleuropäischen Staatenbund in der Bismarckschen Reichsgründung nur ein Provisorium sah, über Bismarck:

"Bei hoher Tatkraft und seltenem Talent der Wache bewegt er sich leider in einem beschränkten Ideenkreis."

(In einem Brief an den Rassenforscher Ludwig Schemann vom 3.1.1888, zitiert nach Eugen Stamm, Konstantin Frantz. 1857-66. Stuttgart, 1930, S. 141.)

Und Friedrich Nietzsche (1844-1900) meinte (Fröhliche Wissenschaft, II, 104 , Vom Klange der deutschen Sprache, 1882) hellsichtig: "Fast in jeder Rede des ersten deutschen Staatsmannes .... ist ein Akzent, den das $\mathrm{Ohr}$ des Ausländers mit Widerwillen zurückweist: aber die Deutschen ertragen ihn, sie ertragen sich selber."

Siehe auch Hans-Günter Zmarzlik, Das Bismarckbild der Deutschen - gestern und heute. Freiburg, o.J. (Vortrag, gehalten am 24. November 1965 im Studium Generale der Universität Freiburg i.Br.). 
b) Wilhelm II.

Da Wilhelm II. den Fürsten Bismarck entlassen hatte, der dem $R B$ so verhabt war, wird der inonarch (zunächst) einerseits gelobt: "energisch und im höchsten Grad vital", 61 ein Mann, dem man große Sympathien entgegenbringt, 62 andererseits bedauert, weil er ein schweres Erbe antrete und die Folgen der verderblichen Politik Bismarcks tragen müsse: "Die Fehler vieler Jahrzehnte zu korrigieren ist schwer, und wenn es dem jungen, edlen Wilhelm II. nicht gelingt, sie auszumerzen, so wird man ihm die Schuld geben - so kurzsichtig und naiv ist bis heute die kienschheit. ${ }^{63}$

Die Entlassung Bismarcks wird als "Ergebnis staatsmännischer Weisheit" des Kaisers und seiner Umgebung gewertet, ${ }^{64}$ desgleichen die Einberufung zur 1. Internationalen Arbeiterschutzkonferenz nach Berlin - das RB nimmt an, dab der junge Kaiser sich zu einer demokratischen Volkspolitik entschlossen habe, er bringe der Lage der Arbeiterklasse Mitgefühl und Verständnis entgegen. 65

61) Vgl, an., Chronika zagraniěnoj žizni. $\mathrm{KB} 1890 / 4$, S. 149 .

62) Vgl. an., Chronika zagranıžnoj žizni. RB $1890 / 4$, S. $149-152$; und an., Chronika zagraničnoj žizni. RB 1890/8, S. 158-173.

63) Vgl, an., Chronika zagranienoj žizni. RB 1890/4, S. $149 f$., ähnlich auch: an., Chronika zagraniěnoj žizni. RB $1890 / 8$, S. 162 .

64) Vgl. an., Chronika zagraniěnoj žizni. RB $1890 / 4$, S. 150 .

65) Vgl. an., Chronika zagraniěnoj žizni. $\mathrm{RB} 1890 / 8, \mathrm{~S}$. 170-173. 
Knapp zwel Jahre opäter war der positive Elndruck völl1g verflogen. Dabel ist festzuhalten, daB das $R B$ bel aller Kritik dem Kalser Verständnis entgegenbringt und seine Unbesonnenheiten aus selnem Charakter zu erklären versucht - sehr Im Gegensatz zu der konzessionslosen Ablehnung Bismarcks. Dies wird im folgenden an Hand einiger wurdigungen des Kalsers durch das RB dargestellt, we1l diese des Wesentliche bringen, so des auf die hunderte von Bemerkungen im $R B$ uber die jeweils aktuelien Reden und Taten Wilhelms II. nicht eingegangen zu werden braucht.

In der Januarnummer 1892 he1Bt es ruckblickend: "Der junge deutsche Kalser regiert Insgesamt dreielnhalb Jahre, aber in dieser kurzen zeit hat ein solch auBergewöhnlicher Umschwung in Deutschland stattgefunden, daB man es uberhaupt nicht wiedererkennen kann. Selne gestrige und heutige Lege wird völlig durch die Yersönlichkeiten seines gestrigen und heutigen Beherrschers verkörpert; damals Blsmerck, jetzt ilhelm II. Damals zeigten sich Herrocher und Land als feste, stabile, unerschutterliche, elserne Kolosse; Jetzt gärt alles, alles schwant, alles wackelt, sowohl in dem unausgeglichenen, nervösen, jungen Puhrer, als auch in dem Start, dessen Geschicke zu leiten Ihn das Schicksal bestimmt hat. Naturlich bewelot die Tatsache, das eln elserner KOlOB so schnell geoturzt und ein anderer zerschlagen werden konnte, wie trügerisch die Gröbe und die Macht belder waren, wie schwankend und undurchfiuhrbar in unserer leit die furohteinflöBende Theorie 'Peuer und Bisen' lat, und we unsicher solche Grundlagen fur den Bau elnes Startsgebäudes sind, das sich als auf Sand errichtet erwlesen hat. Aber wenn die 
Arbeit Bismarcks, die doch so lange gepriesen wurde und so imposant erschlen, elgentlich nur eine trügerische Luftsplegelung war, als was erwelst slch dann die fleberhafte, hastige, nervöse Tät1gke1t seines Nachfolgers?

Um auf diese Prage antrorten zu können, muß man zuä̈chst die persönlichen E1genarten des jungen Kaisers erklären und dann die Bilane der tatsachlichen Ergebnisse selner kurzen, aber sehr bedeutsamen Leltung des von Blsmarck errichteten Deutschen Relches ziehen.

Wilhelm II. Lat Jung. Die Jugend erklärt seine Regsamke1t, selne Hast, sein allzu groBes Selbstberubtsein und seine Redseligke1t. Er lst oft krank, die Krankhe1t verleiht seinen Handlungen einen nervösen, widersprüchlichen, oft unverständlichen Charakter; und das Hohenzollernblut gibt inm latelnische Variationen des beruhmten Satzes Ludrigs XIV. ein: 'l'etat c'est mo1' - 'Sic volo sic jubeol' - 'Sit pro ratione voluntas!' 'Suprema lex regle voluntagl', die als einziger Leitfaden in dem buntgemlachten, verschledenartigen Labyrinth seiner Rederitis und Geschäfigkeit dienen.

Wenn man allein diese drei Elemente im Chararter des neuen Deutschen Kalsers berücksichtigt, dann kann man elne Menge merkwirdiger, unbegrelflicher und sich offensichtlich widersprechender Pakten in seinem kurzen, aber so viele dramatische Tendepunkte enthal tenden zwelunddre1Bigjährigen Leben verstehen." 66

66) Vgl. V.T., Chronika zagrantznoj zizn1. RB 1892/1, II, S. 1641 . 
Wilhelm II. habe in unzähligen Reden und Toasten als die Hauptprobleme der Zeit die Arbeiterund die Schulfrage bezeichnet, die Arbeiter muißten vor Willkür geschützt werden, es müsse ferner für den gymnasialen Unterricht ein neues Programm entworfen werden. Er sei, so töne er, fest entschlossen, den Frieden zu bewahren, auch im Inneren - vermutlich sei der Nationalliberale Miquel deswegen zum Finanzminister berufen worden, um durch Steuerreformen die Lage der armen Volksschichten zu erleichtern. 67

"Alle diese vielversprechenden Ansätze schienen von einer tatsächlichen Ausrichtung ... des Staatsgchiffes nach vorne auf dem Weg des Fortschritts zu sprechen, und die Deutschen, die, befreit von dem Albtraum Bismarck, aufatmeten, der sie so lange bedrückt hatte, glaubten, daß für sie endlich eine neue Ära angebrochen sei, dab ein neuer Wind wehe.

Aber es vergingen zwe 1 Jahre nach dem Abschied Bismarcks und der selbständigen leitung des Landes durch Wilhelm - sein neuer Kanzler, General Caprivi und die von ihm oft ausgewechselten Minister sind nur blinde Ausfürende seines Willens ${ }^{68}$ - und die Resultate der mit solchem Lärm und Aufaehen an die groBe Glocke gehängten Reformen sind gleich Null." 69

67) Ebenda, S. 165f.

68) tber die Reichskanzler Caprivi, Hohenlohe und Bülow wird während ihrer Amtszeit 1mmer wieder in konkretem Zusammenhang in den politischen Auslandschroniken und speziellen Deutachlandkorrespondenzen berichtet, jedoch bleiben sie im Vergleich zu Bismarck und auch Wilhelm II. farblos.

69) Ebenda, S. 166. Siehe auch V.T., Chronika zagraniěnoj żizni. RB $1893 / 2$, II, S. 70 . 
Wilhelm habe die Arbeiter enttäuscht, die Sozialdemokraten wuirden trotz dem Erlöschen der einschlägigen Gesetze weiter verfolgt, die Nahrungsmittel seien nicht billiger geworden, denn die "verheerenden und verhaBten" Getreidezölle würden im Interesse der Grobgrundbesitzer weiter erhoben, die Armut nehme immer bedrohlichere Formen an. In Wilhelms Friedensbeteuerungen mischten sich kriegerische Fanfarentöne einerseits, andererseits dominiere sein "Gottesgnadentum" immer mehr: er spreche uber seine täglichen Gebete für das Wohl des ihm vom Herrn übergebenen Reichs, uber seine heilige Verpflichtung als PreuBischer König und summus episcopus, uber die Verbreitung des christlichen Geistes zu wachen, über seine feste Absicht, die von Gott stamende hohenzollersche Berufung zu erfuillen und darüber nur dem Himmel Rechenschaft abzulegen. 70

Das $R B$ weist auf seinen Ausspruch hin, dab er nur zwel Parteien kenne: die für ihn und die gegen ihn, ferner auf seine Drohung, alle zu zerschmettern, die sich inm widersetzen, 71 und läbt dann die Ansprache des Kaisers im Brandenburgischen Provinziallandtag (24. Feb. 1892) im Auszug folgen, in der er alle mit seiner kegierung unzufriedenen Deutschen auffordert, den deutschen Staub von den Füen $2 u$ schütteln und die mit den bekannten Worten schlieBt:

"Brandenburger, $2 u$ Großem sind wir noch bestimmt, und herrlichen Tagen fiuhre I ch euch noch entgegen..." 72

70) Vgl. V.T., Chronika zagraniěnoj žizni. KB $1892 / 1$, II, S. $166 f$.

71) Ebenda, S. 167.

72) Ebenda, S. 168. 
Antulufend an die in dieser Rede enthaltenen Worte von seinem Kurs, welcher der richtige sei, und Wilhelms Telegramm nach Bismarcks Entlassung ("Der Kurs bleibt der alte, und nun Volldampe voraus") stellt das $R B$ fest, daB dies tatsächlich der Fall sel: Bismarcks Theorien von "Blut und Eisen" und von der Kraft, die Recht schafft, herrschten weiter, nur unter dem Mäntelchen liberaler Worte, und die reaktionäre kichtung sei um einen neuen 2 ug, nämlich den mystisch-klerikalen, bereichert worden. Der Kurs blelbe der alte, das Startsachiff werde aber, im Gegensatz zu fruher, von einem jungen, kranken steuermann gelenkt und schwanke und schlingere nach allen Selten. 73

Das KB schreibt von einem Ohrenleiden Wilhelms, das sich gefährlich verschlimmern könne, da der KrankheitoprozeB im Schädelinneren ablaufe, und scheint anzunehmen, dab der Kaiser nicht ganz normal se1:

"Was die Jugend Wilhelms angeht, 60 sprudelt sie nur so, ungeachtet seiner Krankheit; und gerade wegen dieser Krankheit äußert sie sich in den merkwirdigsten und kuriosesten Pormen. Seine fleberhafte Tätigkeit scheint vollig ohne Wahl und MaB zu sein. Mit der gleichen Energie reitet er nachts durch die Straßen Berlins, mit dem Ziel, in der einen oder anderen Kaserne Aufregung hervorzurufen, oder jagt in den verschiedenen Teiler seines Reichs. ... Mit dem gleichen Peuereifer stellt er Projekte für pseudo-soziale Reformen zusammen, hält er Gottesdienst auf Deck seines Schiffes ab, ... läBt er mystische Predigten abdrucken, weist er die offiziere darauf hin, daf sie schlecht tanzen, organisiert er auf dem Hof-

73) Ebenda. 
ball selbst ein Menuett und schreibt das Iibretto für eln neues Ballett, entwirft er das Schnittmuster für elnen neuen Militärmantel, führt er eine Inspektion in den Hofküchen durch, was nlcht ein elnziger preubischer könlg vorher tat, ..."

Jedenfalls gerate Deutschland dank selner "orig1nellen Regierung" in Immer stärkere Gärung. Minister, Parteien, Armee - alle Schichten seien unzufrieden. 74

Dieses 1892 gezelchnete B1ld des impulsiven Deutschen Kalsers bleibt während des gesamten hier betrachteten Ze1traums prakt1sch unverändert, es kommen nur noch zusätzliche Pinselstriche, verursacht durch die jeweiligen Ereigntsse, hinzu.

Im Jahre 1899 wird Wilhelms "Streben nach dem Romantischen und Außergewöhnlichen" abgehandelt, das er schon als Kronprinz gezelgt habe. 75

In der Hohenzollerndynastie gebe es zwel prägnante Typen: "Der elne Typ wird repräsentiert durch die starken Charaktere, die Preußen und seine Hegemonle geschaffen haben, und die weder Träumere1 noch Unschlüesigke1t, noch Mitleld kennen." Zu diesen Hohenzollern rechnet das RB auch den Ballenstedter Albrecht den Bären (1100-1170), Im übrigen den Großen Kurfüsten, die Könige Priedrich Wilhelm I. und Priedrich II., sowle Kalser Vilhelm I., "Ieute von Blut und Elsen, die geradlinis auf das ziel zugehen, kelne Rechtfertigung dafur suchen und sich nicht scheuen, unterwegs alles zu erdrücken..."

74) Ebenda, S. $168 f$.

75) Vgl. S. Južakov, Praviteli 1 vlast1teli sovremennoj evropy. Sbornik zurnala "Russkoe Bogatstro". a.a.0., S. 434 . 
Der andere Typ werde repräsentiert von den Königen Friedrich I., Friedrich Wilhelm III., Friedrich ilihelm IV. und Kaiser Friedrich III. alle meist gut und hochheriig, voll Streben nach Großem und Erhabenem, jedoch unentschlossen und schwankend - in den Augen ihrer Verwandten vom Blut-und-Eisen-Typ "unpraktische Romantiker". 76

nilhelm II. ist einer der kennzeichnendsten und vollendetsten Vertreter des Typs der unpraktischen Romantiker, die sich stets mit großen Plänen tragen, doch unfähig sind, sie durchzuführen". Leider habe er sich als Voroild nicht einen seiner romantischen Vorfahren gewählt, sondern Friedrich II., Wilhelm I. - und Bismarck. Wilhelm II., "empfindsam für alles Erhabene und Schöne", ein "Ritter des Wortes", wollte also iuenschen nacheifern, die sich nie an gegebene Versprechen hielten und gelacht hätten bei der Prage, ob das Erhabene und Schöne ihre politiscuen Entscheidungen beeinflussen könne. 77

Daher sei Hilhelms "Realpolitik" zum Scheitern verurteilt, "er hat viel angefangen, aber bis jetzt nichts vollendet, weder in der Innen- noch in der Außenpolitik"."78

Als Beispiele für seine AuBenpolitik werden die schwankende Haltung des Kaisers in der Dreibundfrage, beim kolonialen Wetteifer der mächte und im Burenkrieg angefüht. Ganz besonders wird die ablehnende Haltung dieses "groBherzigen und wei $B$ Gott nicht blutgierigen" Herrschers gegenüber der

76) Ebenda, S. $435 f$.

77) Ebenda, S. $436 f$.

78) Ebenda, S. 437. 
Haager Abrüstungskonferenz mit Kopfschütteln registriert. 79

Im Inneren habe Wilhelm die Arbeiter erst beschützt, dann bekämpft, desgleichen die Polen, - die Agrarier zunächst angegriffen, dann protegiert. "Wilhelm hat nirgends etwas erreicht und nur eine einzige groBe Tat vollbracht, namlich die Entlassung Bismarcks." 80

Die "merkwürdigen und kuriosen Fauxpas", mit denen Wilhelm im Laufe seiner Regierungszeit Deutschland und die gesamte übrige Welt immer wieder in Erstaunen versetzte, seine "unerwarteten, scharfen Kurswechsel", seine besondere Vorliebe, bei allen passenden und unpassenden Anläßen bombastische Reden $z$ u halten, seine dauernde Reiserei durci Deutschland und ins Ausland, seine unersättliche Leidenschaft für Paraden, Eröffnungen und Bankette, sein Wunsch, immer und überall an erster Stelle zu stehen, und schlieblich sein Anspruch, nicht nur Kaiser, sondern darüber hinaus Komponist, Prediger, Feldherr, Maler, Schiffebauer und Kapellmeister zu sein - alles Dinge, uber die das $\mathrm{HB}$ in seinen monatlichen Auslandschroniken regelmäBig und detailliert im jeweils konkreten zusammenhang, teils fassungslos, teils tadelnd

79) Ebenda, S. $437 f$.

80) Ebenda, S. 438. 
berlchtet, 81 - all das fuhrte dazu, daB man den Deutschen Kaiser in vielen Gesellschaftskreisen nicht mehr ernst nahm.

Ungeachtet der heftigen Kritik, die das RB immer wieder sowohl am persönlichen Verhalten wie an der Innen- und AuBenpolitik Wilhelms II. Ubt, versucht es doch (wenn auch kelne Rehabilitierung, denn die Kritik bleibt bestehen), zumindest eine Erklärung für das Verhalten des Kalsers zu finden, welche Mitgefuhl, sogar bisweilen Sympathie für den Mengchen Wilhelm erkennen läBt. 82

Das RB hält die satirische Darstellung des Deutschen Kaigers, wie sie damals in vielen (tellwelse bösartigen) deutschen Karikaturen zum Ausdruck kam, für ungerecht. Selner Ansicht nach lst dieser "bemerkenswerte Vertreter der Romantik" eher elne tragische alg eine komische Gestalt.

Kalser Wilhelm lebt - so das RB - völl1g auBerhalb der Welt der geschichtlichen Wirklichkeit. Die Historie wird bel ihm durch Mythos und Legende

81) Vgl. hierzu u.a.:

V.T., Chronika zagranienoj zizni. RB 1892/2, II, S. $103 f f$. V.T., Chronika zagranilnoj zizni. RB 1892/3, II, S. 289 .

V.T., Chronika zagrantenoj zizni. RB $1893 / 2$, II, S. 76 .

V.T., Chronika zagraniznoj zizni. RB 1893/5, II, S. 92, $95 f f$.

V.T. Chronika zagranicnoj ziznt. $\mathrm{RB}$ 1894/1, II, S. 1401 .

A. Kovrov, Iz German11. RB 1897/2, II, S. 90f. S.H. Juzakov, Politika. RB 1901/4, II, S. 167. S.I. Južakov, Pol1t1ka. RB 1902/2, II, S. 122, 26 . Reus, Vil'gei'm II. (Pis'mo iz Germanil). $\mathrm{RB} 1904 / 1$, II, S. 106, 123, $125 f$.

82) Vgl. Reus, Vil'gel'm II. (P1s'mo 12 Germanii). $\mathrm{RB} 1904 / 1$, II, S. 106-138. -

Dieser Artikei soll im folgenden in verkürzter Porm referiert werden. 
ersetzt. ( 5.107 ) Seine Tragik liege darin, dab seine Anspriche, die auf seiner Bewunderung vergangener Epochen basierten, der veränderten Realität seiner Reglerungazeit widersprechen. Die schöne Legende diene thm als poetische Grundlage, auf die er seine gesamte Staatslehre aufbaue, und naturlich auch sein politisches Dogma von der kelserlichen und königlichen Macht. (S. 111)

Er fuble sich als absoluter Monarch ("von Gottes Gnaden") und sei doch in Wirklichkeit nur konstitutioneller Herrscher: Absolutismus als Theorie und ein konstitutionelles Regime als Praxis daraus resultiere die widerspruchlichke1t in allen seinen von inm noch so aufrichtig und ernstnaft gemeinten Maßnahmen.(S.117f.)

Vergleiche man die stolzen Auseprüche des Kaisers in der Art von: "sic volo, sic jubeo", "suprema lex regis voluntas", mit denen er die Illusion, unumschräntter Herrscher zu seln, darzuetellen pflege, 83 mit seiner wirklichen Stelluag im Relch, so zeige sich, wie bescheiden seine wirkliche Rolle im Vergleich zu seinen autoritären und hochtrabenden Proklamationen iat.

Seine Staatstheorie entbehre eben jeder fartiachen Grundlage, denn sie sel nur ein romentisches. Luftgebilde.(S. 1191.)

83) Vgl. hierzu z.B. auch: V.T., Chronike zagraniznof ziznt. $\mathrm{RB} i 893 / 2$, II, S. $72 f$. - und Reus, Iz Germanil. RB $1903 / 7$, II, S. 78 . 
Noch einmal zusammengefaßt, 84 seine "poetische" Weltanschauung gipfele in dem Wahn, seine rolitik stehe über den Parteien und über den Klassen. Auf diesen Traum zu verzichten und sich mit der Stellung eines konstitutionellen Königs abzufinden, könne der Romantiker nicnt über sich bringen, und un sich auf dem "überparteilichen" und "über den Klassen stehenden" Sockel zu halten und um "auf den idealistischen Höhen des Dienstes für das allgemeine Honl" zu bleiben, spiele Wilhelm die Kolle eines unumschränkten, allwissenden, unfehlbaren Herrschers. (S. 113-115).

Jedoch sei Wilhelm II. in Wirklichkeit, ohne es zu merken, das Werkzeug eben jener Parteipolitik, die er so energisch verurteile. Aus diesem Grunde protestierten weder die bürgerlichen Liberalen noch die Kadikalen gegen seine Absolutismuspredigten. Sie wübten, daß die vielen keden des Kaisers nur platonisch sind. (S. 121)

Die bürgerlichen Parteien versteckten sich gerade in ihrer Propaganda gegen die Arbeiterpartei hinter der impulsiven Persönlichkeit des Kaisers und versucnten dadurch, ihren zielen einen unschuldigeren Charakter zu geben.

Diese "Parteien der Ordnung" wïten im Grunde ganz genau, daß die wirkliche Macht im Staate in ihren Händen liege. In dieser Beziehung seien für sie die diktatorischen Bestrebungen des Kaisers

84) Die Berzchter des RB haben die Angewohnheit, ihren Lesern die gewonnenen Erkenntnisse doppelt und dreifach in immer neuen Formulierunien einzuhämmern, eine auf die lientalität inres Leserkreises anscheinend besonders zugeschnittene Beeintilussung; um auch dieses zu zeigen, sind nicht alle Wiederholungen gestricnen worden. 
eine GroBe Chance im Parteikampf, und im Grunde schätzten sie die Möglichkeit sehr, immer, falls nötig, das Gespenst des Absolutismus hervorholen zu können, um damit bei Bedarf die bügerliche Diktatur (gemeint ist die "Diktatur der Plutokratie") zu tarnen. (S. 121)

"Sich selbst als absoluter Monarch zu fülen und zu gleicher Zeit zu sehen, wie diese illusorische Allmacht ungestraft in humoristischen Groschenblättchen verspottet wird; auf sich die Aureole der göttlichen Berufung zu fühlen und gleichzeitig nicht imstande $z u$ sein, auch nur eine einzige Maßnahme durchzufuhren, ohne dab im Parlament gleich tausend Einwände, Belehrungen, Kritiken und Spötteleien laut werden; zu wïnschen, persönlich... sein Volk glücklich zu machen und sich davon zu uberzeugen, dab... dessen Vertreter ... keine Dankbarkelt für die angebotenen Wohltaten zeigen, weil sie diese gar nicht als solche betrachten." (S. 122)

Der Kaiser brauche den Wahn, alle seien inm ergeben und beteten ihn an, achteten inn hoch und seien von ihm begeistert, um sich ständig in die lichten Wolken seines "königlichen Märchens" hüllen zu können, die er sich gewoben habe. Kein Wunder, daß er daher am meisten auf die Partei böse sei, die ihm seinen Idealismus zerstören will, die weder seine Romantik, noch seine Mystik, noch seine soziale Berufung anerkennt und das inm aufs höchste verhaßte "Murren" in Volk verursacht, welches inm das Leben in dieser schönsten aller Welten vergiftet, nämlich die SPD. ${ }^{85}$

85) Vgl, auch: A. Kovrov, Iz Germanil. $\mathrm{RB} 1897 / 3$, II, S. 138. 
Dieser Gereiztheit bedienten sich (wie bereits mehrfach gesagtl) die burgerlichen Parteien und machten den Kaiser zum blinden Werkzeug in ihrem Kamp mit den Arbeltern. (S. 122-124).

Die "Parteien der Ordnung" verhielten sich in dieser Hinsicht wesentlich schlauer als die Sozialdemokraten. Sie gingen behutsam mit den romentischen Traumen ihres Kaisers um. Da sie seiner Hilfe gegen ihre politischen Peinde bedurften, bráchten sie es fertig, durch äuberliche Bekenntnisse der Llebe und des Vertrauens seine krankhafte Ägstlichkeit zu beruhigen. Und der Kaiser bedanke sich bisweilen ruhrend bel innen fur diese noffenbarung des thm nahestehenden und verständlichen 'Idealismus'." (S. 122)

Aber diese seine angeblichen Bundesgenossen unterstützten seinen "Idealismus" nur so lange, wie er nicht mit ihren realen Interessen zusammenstobe. Gerade diese Partelen und gesellschaftlichen Gruppen, die er fur seine treuesten Diener halte, bisweilen in der Opposition zu sehen, schmerze inn ungemein. 86

86) Stehe hierzu beispieloweise:

S.I. Južakov, Politike.

RB $1899 / 6$ (9), II, S. 129-132. -

Hier geht es um den Konflikt 2 wischen der preubischen Regierung und dem preubischen Parlament regen des uittellandkanals, der Rhein und Blbe verbinden sollte.

Bei dieser Auseinandersetzung haben die

preus. Konservativen, de sich damit bristen, "1mner die zuverlussigsten Stüzen des Throns" und "die besten Diener des Monarchen" zu sein, nach Nnsicht des $R B$ wieder elnmal inr wahres Gesicht gezeigt: Obwohl sich der Kaiser personlioh fur das Projekt eingesetzt habe und ganz sicher gewesen sel, seine "besten Diener" umstimmen zu konnen, habe die konservative Mehrheit im preubischen Parlament gegen den Willen des Kaisers das Projekt zum Scheitern gebracht. Viele hätten ernsthafte Polgen erwartet, nëmlich diejenigen, die. imer noch an eine "alrtive Bnergien" des Kai-

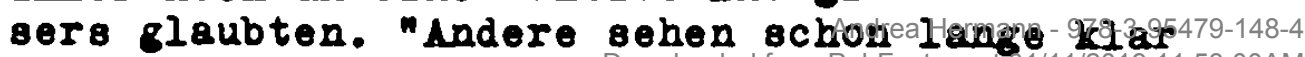


86) Ports.

und wissen, daB man von Wilhelm nichts erwarten kann als Aufwallungen und starke Absichten, ohne daB sie aber ebenso stark in die Tat umgesetzt wirden. Die Agrarier erkennen dies natülich klar und wissen sehr gut, dab ihr Monarch zu der Sorte von Leuten gehört, uber die gesagt wurde, daB sie zwar edle Regungen haben, denen es aber nicht gegeben lat, etwas zu vollenden." (S. 130)

Und naturlion seien die ernsthaften Folgen augeblieben. Der Kaiser ha be auf Anraten seiner Ratgeber nicht das Parlament aufgelobt und die Meinung der Nation befragt, was nach Ansicht des RB sowohl der gesetzliche wie auch der einzig zweckmäbige Ausweg aus dem Konflikt gewesen wäre:

"Aber die Ratgeber Tilhelms haben ihn augenscheinlich gut studiert und vermögen diese unentschlossene und seelisch unsusgeglichene, aber begeisterungsfähige und launische Natur hervorragend zu lenken." (S. 132)

Die Episode um den Mittellandkanal sei in vieler Bezlehung lehrreich: Sie habe die Macht der Agrarier in PreuBen gezeigt und wieder einmal in der Meinung bestärkt, daB sowohl der Charakter wie das Staateverständnis Wilhelms II. den Erfordernissen der schwierigen Lage in Deutschland nicht entsprächen. "Gesetzlichkeit und 2weckmäBigkeit das lot vielleicht zuviel für zweitklassige Politiker". (S. 132)

Ergänzend siehe hierzu auch:

S. Južakov, Politika.

$\mathrm{RB} 1901 / 5$, II, S. 140-144. 
Dem Deutschen Kaiser bleibe daher nur eine Zuflucht, ein einziges wittel, seinem Idealismus widerspruchslos die Zügel scnießen zu lassen namlich die preubisch-deutsche Armee, in die er sein ganzes Vertrauen setze. (S. 127) Hier könne er seinen ganzen Herrschattsanspruch austoben.

Zur Begründung nur ein Beispiel - die "SchieBrede" vor den Potsdamer Rekruten anno 1891, wörtlich im $R B$ zitiert:

"Ihr habt Mir Treue geschworen, und das bedeutet Kinder Meiner Garde - daB inr jetzt Meine Soldaten seid, daB ihr euch Kir mit Leib und jeele verschrieben habt. Für euch gibt es jetzt nur binen Feind - und das ist Mein Feind... es könnte sein, das ich euch befehle, eure eigenen Verwandten zu erschieBen, eure Brüder, sogar eure Eltern,... auch dann müBt ihr keinen Befehl onne Murren ausfüren." 87 (s. 1271..)

Der einzige Bereich, in dem "der kaiserliche Dichter" nicht b $1 O B$ reden, sondern, gemäB der deutschen Verfassung, auch selbständig handeln könne, sei die AuBenpolitik - und auch diese habe inm nur Verdruß gebracht. (S. 128)

Ein "Rittergeist" geht nach Ansicht des $R B$ von den "starken Worten und schönen Bildern" aus, mit denen der Kaiser seine sogenannte Weltpolitik rethorisch garniert, und zwar nicht der Geist einer Jeanne d'Arc oder eines Richard Löwenherz, sondern der eines "weitgehend modernisierten Rittertums." ("Als Staatsoberhaupt kann ich mich nur

87) Vgl. Reus, Vil'gel'm II.a.a.0., S. 106-128. 
über jeden Hanseaten freuen ..., der ins lieer sticht und in der Ferne neue Punkte sucht, in die wir unsere Nägel einschlagen können, um daran unsere "affen aufzunängen"; oder "die Worte 'ich bin ein deutscher Bürger'" müBten allenthalben in der Welt die gleiche Bedeutung erhalten wie früher das stolze "civis komanus sum!", u.i.)(S. 129f.)

Wihrend sich der kaiserliche Romantiker auf dem deutschen Adler über den Ozean schwinge und sein Schwert in die Waage groBer internationaler Entscheidungen werfe, denke er gleichzeitig an Industrie und Handel und an ein warmes Plätzchen für die Deutschen unter den Strahlen der "internationalen Jonne".

Kitter und Krieger vereinten sich hier geschickt mit Geldbörse und Ladentisch, und Wilhelm II. mit dem deutschen Aar nehme die Nission des Führers der Argonauten auf sich:

"Nachdem das kriegerische Reich in Europa alles an sich gerissen hatte, was man nur mit gepanzerter Paust an sich reiBen konnte, streckt es nun seine Krallen iber die Meere aus und predigt

Kreuzzüge im Namen des neuen Kapitalismus". (S. 130) Nicht umsonst habe der Kaiser seine Soldaten bei der Expedition nach China mit den iorten entlassen, kein Pardon zu geben, keine Gefangenen zu machen, "gebraucnt eure iaffen so, dab es für tausend Jahre ausreicht und nicht ein Chinese sich erdreistet, einen Deutschen scheel anzusehen." (S. 130)

"Es bibt nichts Grausameres und Unmenschlicheres als Kriege mit den 2 ielen... der Landeroberung. Und im Interesse der 'Neuen Hanse' kann man nicht umhin, zu bedauern, dab dieses neue Rittertum 'des goldenen 
Vlieses' in Deutschland so spät geboren wurde. Amerika ist bereits entdeckt und besetzt, unter der amerikanischen Sonne sind nicht nur schon alle Plätze vergeben, sondern zudem unter den Schutz der Monroe-Doktrin gestelit. In Afrika ist die Lage für die Heldentaten eines Pizarro ebenfalls unguinstig geworden. Auch in Asien sind die Sonnenplätze fast alle vergeben und Australien kommt nicht in Betracht. Nan muB sich also dort zusammendrängen, wo sowieso schon eine Menge anderer Argonauten sitzen, die der neue Kapltalismus dorthin geführt hat... Um in die Mitte starker und meisterhafter Konkurrenten vorstoßen zu können und ibnen unter der Nase ein Stück Sonnenland oder... Märkte wegzuschnappen, ist eine subtilere Politik notwendig, als das'Rittertum' eines Pizarro und Amerigo Vespucci. Mit der gepanzerten Faust allein kann man hier nichts erreichen,... (sondern nur) durch die Diplomatie der neuen Schule, durch die Politik der realen Interessen." (S. 130f.)

Kaiser Wilhelm jedoch sei $z u$ einer solchen Diplomatie nicht fähig. "Für ihn ist die Diplomatie nur eine Arena für persönliches Heldentum, ebenso wie die Geschichte ein sich ewig ninziehendes Drama darstel1t, in welchem ein unsichtbarer Regisseur in den ersten Rollen fortwährend verschzedene glänzende Könige oder große Eroberer herausstellt." (S. 131)

Da er sich auf der höchsten Höhe der Weltpolitik und in den vordersten Rängen des weltheaters fïhle, gebrauche Wilhelm auch hier Mittel, die eher dem Oberhaupt der katholischen Kirche anstünden, als einem Vertreter imperialistischer Politik.

Wenn er auch in seiner Tneorie sehr schön die "große Berufung der Deutschen jenseits des Ozeans" 
mit den altpreuBischen Erobererinstinkten und den Aufgaben des kapitalistischen Imperialismus verbinden könne, so meine er doch, auf unvorstellbarer Höhe $z w i s c h e n$ den irdischen Staaten und Gott im Himmel zu schweben, und deshalb wolle er vor allem seine Mission als Wächter und Bewahrer der göttlichen Weltordnung unter den Kulturvölkern erfullen. (S. 131)

Wilhelm II. "Diplomatie der persönlichen IIebenswirdigkeiten" (S. 137), selne überschäumenden Lobesreden, mit denen er seine auBenpolitischen Konkurrenten einzulullen versuche, "sein Glaube an die auBergewöhnliche, fast mystische Bedeutung der verschiedensten außerlichen Liebenswürigkeiten, der dekorativen Seite der Macht, der Belohnungen und Auszeichnungen" (S. 133) könnten im Zeitalter der Realpolitik nur MiBtrauen hervorrufen. Diese seine Diplomatie habe nicht nur zu den traurigsten Ergebnissen gefürt, sondern sogar den deutschen Interessen geschadet. 88

88) Vgl. Reus, Vil'gel'm II. a.a.0., S. 128-138. Als klassische Belspiele für die Auswirkungen dieser Diplomatie und für die Unvernunft, Widerspruchlichkeit und Inkonsequenz der AuBenpolitik Wilhelms II. werden immer wieder die Chinaexpedition, bei der Filhelm als der Hauptschuldige am europäischen MiBerfolg bezeichnet wird, sowie die Burenaffäre angeführt, bei der nicht nur die Buren, sondern auch die letzten Konventionen geopfert worden seien: zuerst habe Wilhelm II. sein boruhmtes Telegramm an Krüger gesandt und anschließend den englischen Feldmarschall Roberts, der sich im sudafrikanischen Krieg $2 w e i f e l$ hafte Lorbeeren erworben hätte, mit einem Orden ausgezeichnet. (Vgl. u.a. S. Južakov, Politika. RB $1900 / 12$, II, S. 21 of., und ders., Politika, RB 1901/5, II, S. 144-148.) ----Die Berichter des RB waren nicht nur wiederholungsoüchtig, sondern eifrig bestrebt, das, 
88) Ports.

was sie so oft sagten, genau zu belegen. So stüzte sich beispielsweise auch Reus in dem oben referierten Artikel "Vil'gel'm II." auf deutsche Quellen:

Die zahlreichen Auszüge aus den keden Wilhelms II. zitiert er nach "E. Schröder, cin Tagebuch Kaiser Wilhelms II. Breslau, 1903. Sravn., Reden Kaiser Wilhelms II. in Reclams Universal-Bibliothek".

(Vgl. Reus, Vil'gel'm II. 8.8.0., s. 106). Bei seiner Kritik an Wilhelms "Weltpolitik" wendet er u.a. den Kunstgriff an, "die Deutschen selbst sprechen zu lassen", und zwar erteilt er den "Alldeutschen" das Wort, die, wie er schreibt, eine imperialistische politik zwar sehr befüworten, aber mit der Art und Weise inres Kaisers höchst unzufrieden seien und heftige Kritik an ihm übten. Keus zitiert hier aus "Class, Die Bllanz des neuen Kurses. Vortrag (Flugschriften des alldeutschen Verbandes, Heft 16). Berlin, 1903". (Vgl. Reus, V1l'gel'm II. a.a.0., S. 134). Die Broschüre ist nach seiner Ansicht deshalb so interessant, weil sie nicht etwa aus der sicht der "Feinde der göttlichen Weltordnung" geschrieben sei, sondern von einem "erzpatriotischen" Standpunkt aus. (Ebenda). 
Letztlich sieht das $R B$ in Wilhelm II, und erst recht in seinen Kanzlern Caprivi, Fürst Hohenlohe und v. Bülow nur Epigonen Bismarcks, die "leider" sein Werk fortsetzen, ohne aber Bismarcks Format und Stärke $z u$ besitzen. ${ }^{89}$

89) Vgl. z.B. V.T., Chronika zagraniěnoj žizni. $\mathrm{RB} 1893 / 5$, II, S. 90f.

(Bismarck sei es damals bei seinem Vorhaben, das Septennat durchzusetzen, gelungen, den Papst auf seine Seite zu ziehen, der daraufhin den Klerikalen vorgeschrieben habe, für das Gesetz zu stimen. Wilhelm II. Versuch, anläBlich der Heeresreform von 1892/93 das Gleiche zu tun, sei hingegen gescheitert: "Offensichtlich ging das, was für einen Bismarck möglich war, über die Kräfte seiner Nachfolger." Ebenda, S. 91)

Vgl, auch A.K., Iz Germanii. RB 1895/II, S. 87f. ("Die Ankuindigung 'das Wort hat der Herr Reichskanzler' ruft heute nicht mehr die fruhere Sensation hervor" - Bismarck wird sehr eindrucksvoll beschrieben, Caprivi und besonders Fürst Hohenlohe fallen im Vergleich stark ab.)

Vgl, auch S. Južakov, 1894 god. (Iz sovremennoj chroniki)

RB 1895/1, II, S. 211 f.

(Bismarcks "System der Uberentwicklung der Staatlichkeit" wird scharf kritisiert. Der "neue Kurg" sei indes nicht viel besser gewesen, und der "neueste Kurs" suche ein Bündnis mit den Klerikalen, bemuihe sich aber ansonsten, die Wege Bismarcks fortzusetzen.)

Vgl. auch S. Južakov, Praviteli i vlastiteli sovremennoj Evropy. Sbornik žurnala "Russkoe Bogatstvo". a.a.0., S. 439. ("Caprivi, Hohenlohe, Marschall, Miquel, Bülow - das sind die gleichen prinzipienlosen Nationalisten, mit dem einzigen, aber wesentlichen Unterschied, daB Bismarck und Wilhelm II. originell sind jeder auf seine Weise - und sie (nur) deren Wegen folgen.")

Vgl. auch S. Južakov, Politika. RB 1902/12, II S. 137. - ("Bismarcks unheilvolle Hand ist auch im gegenwärtigen Deutschland in jeder unguten und gegen das Volk gerichteten Sache erkennbar. Kaiser Wilhelm II. und die anderen inn umgebenden Epigonen setzen nur das Werk des großen Bismarck fort.") 


\section{Anonyme Kräfte}

Pur das RB gibt es drei "finstere Kräfte" im neunzehnten Janrhundert, die es fur beherrschend hëlt: den Kapitalismus, den Nationalismus und den Militarismus.90

Die spezifischen Erscheinungsformen dieser Kräfte in den einzelnen europäischen Lëndern werden vom KB detailliert behandelt and analysiert, wobei der Schwerpunkt auf England, Prankreich und Deutschland liegt.

a) Kapital1smus

Im Gegensatz zu den Ansichten der marxistischen Sozialisten (für die der Kapitalismus höchstens verschiedene Entwicklungsotufen aufweist), sahen die"Legalen Narodniki" den Kapitalismus als eine Eracheinung an, die sich in jedem Land ganz eigenständig und nicht miteinander vergleichbar entfaltet.

Deutschland wurde in gewisser Hinsicht als Phänomen angesehen: als eines der europäischen Hauptagrarländer - was es auch noch um die Jahrhuadertwende trotz starker Industrialisierung war - hatte es von 1871 an einen kometenhaften, wirtschaftilchen Aufachwung genommen, und es war inm als vergleichsweise jungem Industriestaat in kurzer zeit gelungen, in die Reihe der wirtschaftlich fuhrenden Nationen Europas (laut RB

90) Vgl. S. Juzakov, Politika.

RB 1900/1, II, S. 206-211, besonders S. 210. 
bisher durch England, Frankreich, Belgien und Holland repräsentiert ${ }^{91}$ ) aufzusteigen und stetig an Macht und Ansehen in der Welt zu gewinnen.

Dieser Wandel in Deutschland erschien dem RB gewaltig: "Aus den Mauern des rückständigen Handwerks und der Begrenzung der Dreifelderwirtschaft mit gemeinsunen Weideplätzen und Frondienst hat Wichel den ireg der kapitalistischen Entwicklung beschritten und sich nicht nur dort behauptet, sondern sogar konkurrenten wie k'ngland geschlagen.... Wichel wurde Kapitalist und spekulant."92

Die Leistung war nach Ansicht des RB jedoch nicht eigenständig, denn Deutschland habe sich sowohl ideell von Frankreich befruchten lassen, als sich auch materiell an inm bereichert: "Die Franzosen gaben Deutschland nicht nur ihre liberalen Ideen, sondern muBten ... (zudem) auch noch gewaltige Kriegsentschädigungen zahlen." 93

Die Geldsummen, die Deutschland am Anfang des Jahrhunderts von Frankreich erhalten habe, hätten den Grundstein fiur den spekulativen Aufschwung gelegt, der 1848 durch den Gold- und Silberstrom aus Kalifornien, Australien und Mexiko weiteren Auftrieb erhalten habe. Seit dieser Zeit habe sich der Kapitalismus in Deutschland, ungeachtet

91) Vgl. z.B. S. Juzakov, Politika. RB 1902/1, II, S. 182. (Im Gegensatz zu den wirtschaftlich rückständigen Ländern: RuBland, Österreich, sowie die Balkan-, Appenninen- und Pyrenäenhalbinsel. cibenda).

92) Vgl. Reus, Pod znamenem kapitalizma. (Pis'mo iz Germanii). KB 1903/6, II, s. 156.

93) Ebenda. 
der ilirtschaitskrisen zwischen 1860 und 1870, bereits gefestigt. ir sei Deutschland in Fleisch und Blut übergegangen und nabe seine beiden Hauptstüzen - die Eisen- und Textilindustrie - begründet. Jetzt nabe nur noch der Zustrom der französischen keparationsmilliarden von $18 / 1 \mathrm{ge-}$ fehlt, um Deutschland endgultig in ein Industrieland umzuwandeln: "Und in der Tat, vorn Jahre 1870 an wird Deutschland schon $z u$ dem, was es jetzt ist: d.u. ein muchtiger Inaustriestaat, der nach kapitalistischer Wirtschaftsform organisiert ist und mit stolzen insprüchen auf die erste rolle und die Herrschaft auf den Weltmarkt trat." 94

Gleichzeitıg bracn ein zügelloses Gründungstieber aus, das sich geradezu in eine Grüdungsmanie hineinsteigerte?

Begünstigt wurde diese intwicklung durch die Verbinaung von Manchesterliberalismus und Darwinismus, die das individualistiscne ixpansionsstreben zum höchsten Gut deklarierte.

Diese sogenannten Gründerjahre, die unter der Bezeichnung "Grjunderstvo" als feststehender Begriff in die russische Terminologie eingegangen sind, werden vom RB scharfstens kritisiert. Auf die "Siegesschreie" seien auf Kosten der reichen französischen Ausbeute die "Honigjahre" des nunmehr geeinten Reiches gefolgt, die sich durch "wilden Eifer", "empörende Wirtschafterei mit den

94) Ebenda, S. $157 f$.

95) Slehe hierzu aus der zeitgenössischen deutschen Iiteratur Kudolph lieyer, Politische Gründer und die Corruption in Deutschland. Leipzig, 1877, und viaximilian iiuller-Jakusch, jo waren die Gründer jahre. Duisseldorf, 1957. 
französischen Milliarden" und "schamlose Begeisterung für das goldene Kalb" ausgezeichnet hätten. 96 Lit dem sieg der kapitalistischen ivtschaitsform habe sich nicht nur in ökonomischer Hinsicht ein totaler Umschwunb vollzö̈en, sondern bleicineitig habe der "materialistische, individualistische Liberalisinus" völliö die Oberhand über den "theokratischen spiritualismus" der alten wirtschaft gewonnen und eine radikale veränderung in der "Sphare des staatlichen Denkens" stattgefunden. 97

Die "Ara des bürgerlichen Iiberalismus" hatte die absolute Herrschaft der "Philisterbürokratie" abgelöst, 98 die Industriemassen traten immer mehr in den Vordergrund - die moderne Industrie- und "Klassengesellschaft" war entstanden.

Ein wichtiger Aspekt für die Narodniki des $\mathrm{KB}$ waren die Auswirkungen der "kapitalistischen Diktatur"99 auf das Individuum, das ihrer Ansicht nach zuin Opfer der industriellen Evolution wurde.

Der harte Daseinskampf lieb den Altruismus dem Egoismus weichen, an die stelle von Individualismus und Heroismus trat die liassenschablone, die alle Lebensbereiche erfaßte. Der "estestvennyj Zelověk", dieser "Natur- und Verstandesmensch", der einzig und allein von "abstrakten Leidenschaften"gelenkt wird, denen alles Originelle und Fersönliche fehlt, der nur nach der allen gemeinsamen

y6) Vgl. A.K., I z Germanii. KB 1895/9, II, S. 133; und A. Kovrov, Iz Germanii. KB $1891 / 2,1 I$, S. 87 .

y7) Vgl. Keus, Pod znamenem kapitalızma. a.a.0., S. 158 .

98) Vgl. ebenda, S. 171.

99) Ebenda, S. 184. 
"Logik des elementaren Rationalismus" denkt und mit allen im "bellum omnium contra omnes" kämpft, um für sich den allen gemeinsamen Wunsch nach einem angenehmen Leben $z u$ verwirklichen - dieser "estestvennyj Člověk" ist nach Ansicht des RB der traurige Prototyp der kapitalistischen Kultur. 100

Der Kapitalismus als Ganzes, als Organisation, hat seiner lieinung nach die Persönlichkeit unterdrückt, er hat aus dem Menschen einen "technischen Apparat", eine "lebendige idaschine" gemacht, der nur noch die Funktion eines kleinen Kädchens im großen Getriebe zu erfullen hat.

Der Kapitalismus verlangt vom arbeitenden Wenschen als höchste Haxime, ganz gleich, ob auf den Gebiete der Technik oder der Wissenschaft, Spezialisierung bis zur Vollendung und äuBerste Anpassungsfähigkeit - eine "Tugend", die nach Ansicht des RB "erstaunlich gut" mit dem typioch deutschen Charakterzug, die "kleine Sache" (malen'koe delo) zu idealisieren, ${ }^{101}$ übereinstimmt, und daher aus dem zeitgenössischen Deutschen den "vollendeten Teilmenschen" macht, der seinerseits wieder so gut zu der "mechanischen Organisation der modernen Wirtschaftsstruktur" paßt. 102

Pür die "Legalen Narodniki", die als Anhänger der "subjektiven Methode" Michajlovskijs die menschliche Persönlichkeit in den Mittelpunkt inres Fortschrittsbegriffs stellten und die "objektiven" Gesetze des sozialen Darwinismus, den Kampf aller

100) Vgl. ebenda, S. 179.

101) iöglicherweise schwebten dem KB Heinrich Seidels Erzählungen von Leberecht Hühnchen (1882, 1888, 1889) vor.

102) $\mathrm{Vgl}$. ebenda, S. $181 \mathrm{f}$. 
gegen alle, strikt ablehnten, entbehrte der Fortschrittsmechanismus der kapitalistischen Produktion jeglicher ethischen Substanz.

Dieses ethisch-moralische Moment war für die Narodniki des RB jedoch nur ein (wenn auch ein wesentlicher) Aspekt der vielen negativen Auswirkungen des Kapitalismus. binen ebenso tiefgreifenden Einflub ubte dieses system inrer Ansicht nach auf die wirtschaftiche und soziale Ordnung uiberhaupt aus. Als ein Symptom für diese Auswirkungen betracntete das RB etwa die deutsche Schutzzollpolitik. Zunächst einmal bedeutete Deutschlands Wende vom Wirtscnaitsliberalismus zum Neumerkantilismus, die Bismarck im Jahre 1879 mit den ersten Schutzzollen für Landwirtschaft und Industrie vollzogen hatte, für RuBland empfindliche wirtschaftliche EinbuBen.

Die diesbeziglichen wirtschaftichen Differenzen zwischen den beiden GroBmächten, die ihren Höhepunkt 1894 in einem kurzen, aber heftigen 201lkrieg erreichten, anschlieBend zwar im Rahmen der Handelsvertragspolitik Caprivis vorübergehend abgeschwächt wurden, sich aber durch Bülows Zolltarif erneut verschärften, trugen nicht wenig dazu bei, daB sich das Deutschlandbild der russischen Offentlichke1t ganz allgemein gegen Ende des 19. Jahrhunderts und nach der Jahrhundertwende zunehmend negativierte.

In den Augen des RB war die deutsche Schutzzollpolitik nichts anderes als ein Eingriff des Staates zu Gunsten der kapitalistischen Grobbourgeoisie und der feudalistischen Landjunker unter dem Tarnmantel angeblicher nationaler Interessen und zum Nachteil für die sozial schwachen Schichten. 
Die siegreiche Rolle der besitzenden Klassen im Kampf um die Wirtschaftsgüter spiegelte gleichzeitig inre immense politische lacht im deutschen Staate wieder. Aus reinen Klasseninteressen wichen die liberalen Parteien immer häufiger von den Prinzipien des Liberalismus $a b$ und näherten sich mehr und mehr dem Standpunkt der rechten Agrarier. Besonders deutlich wurde dies in inrer Haltung bei der Auseinandersetzung um die zollerhöhung für landwirtschaftliche Produkte in den Jahren 1901/1902, die das RB als endgültigen Verrat an der liberalea Idee und als Todesurteil des deutschen bürgerlichen Liberalismus ansah. 103

Als Reaktion auf die Verelendung der liassen wegen der Benachteiligung durch die herrschenden nationalliberalen und reaktionären Kreise gewann die

103) Diese Auseinandersetzung wird im RB unfangreich und detailliert behandelt. Die wichtigsten Positionen werden in folgenden Artikeln wiedergegeben:

an., Chronika vnutrennej zizni.

RB 1893/8, II, S. $129 f$.

an. Chronika vnutrennej zizni.

RB $1893 / 10$, II, S. 91-96.

an., Chronika vnutrennej žizni.

RB 1893/11, II, S. 109-112.

an., Chronika vnutrennej żizni.

RB 1894/2, II, S. 125-142.

V.T. Chronika zagranicnoj žizni.

$\mathrm{RB} 1894 / 2$, II, S. $105 \mathrm{f}, 108 \mathrm{f}$.

A. Kovrov, Bor'ba partij iz-za chlěbnych pošlin

$v$ Germanii. RB 1901/11, II, S. 75-112.

S.N. Južakov, Politika.

RB 1902/1, II, S. 182-187.

S.N. Južakov, Politika.

RB 1902/10, II, S. 155-157.

S.N. Južakov, Politika.

KB 1902/12, II, S. 134-140.

S.N. Južakov, Politika.

RB 1903/6, II, S. 100-106.

Reus, Pod znamenem kapitalizma.,

a.a.0., S. 190-197. 
deutsche Sozialdemokratie an Einfluß. Für das RB steht der Aufschwung der SPD mit der zunehmenden Richtungsänderung der liberalen Kräfte in ursächlichem Zusammenhang. Sie sahen in der sozialdemokratischen Bewegung den Nachfolger und Erben der ursprünglichen liberalen Idee. ${ }^{104}$

Die Narodniki des RB nahmen die deutsche Sozialdemokratie zwar nicht so vorbehaltslos zum Vorbild wie die meisten russischen Sozialdemokraten, aber dennoch nötigte sie ihnen groBe Hochachtung und eine durchwegs positive Bewertung ab. Sie bewunderten an ihr die organisatorische Disziplin, die sie (auch an anderer Stelle) als typisch deutsches Charakteristikum bezeichnen. 105

Der groBe Unterschied zwischen der deutschen Sozialdemokratie und dem revolutionären liarxismus wurde aucn im Pesthalten der SPD an der Legalität gesehen.

Die Tatsache, daß die deutsche Sozialdemokratie eben keine umstürzlerische Bewegung war, sondern daB sie auf friedlichem Wege Verbesserungen für die Arbeiterschaft erreichen wollte, war nach seinung des RB auch den bürgerlichen Parteien in Deutschland wohlbekannt. Da diese jedoch nur die "bürgerliche Diktatur" im Auge hatten, fochten sie weiter gegen die Sozialdemokratie, um in ihr einen Sündenbock zu haben. ${ }^{106}$

104) Vgl. beispielsweise Reus, Pod znamenem kapitalizma. a.a.0., s. 196; und Reus, Iz Germanii. RB 1903/7, II, S. 121.

105) Vgl. etwa folgende sehr markante Aussage: an., Chronika zagraniðnoj żizni. RB 1890/8, S. 163ff., oder Nikolaj-on, Teorija trudovoj stoimosti $i$ nékotorye iz eja kritikov. RB 1902/2, I, S. $50 f$.

106) Vgl. Reus, Vil'gel'm II. a.a.0., S, 121, $126 f$; ähnlich auch schon M.M. Filippov, Cto délaetsja zagranicej. KB 1888/2, S. 123-134, 
Von dem zunehmenden EinfluB der SPD in Deutschland, der aus ibren wachsenden Stimmenzugewinnen bei den Reichstagswahlen besonders ab dem Jahre 1890 ersichtlich war, versprachen sich die Narodniki des RB fur das zwanzigste Jahrhundert weitere Verbesserungen der kapitalistischen Mängelerscheinungen und ein graduelles Abklingen des Nationalismus und Militarismus in Deutschland. 107

Das für die deutsche Sozialdemokratie so uberaus gunstige Wahlergebnis von 1903 (das gunstigste im gesamten untersuchten Zeitabschnitt) komment1erten sie mit folgenden Worten:

"Das Urteil des Volkes ist gesprochen. Unter allen Parteien ist durch Volksabstimmung eine an die erste Stelle gesetzt worden. In dem starken, monarchistischen Staat hat sich die Sozialdemokratie als stärkste Partei erwiesen. Aber diese Partei verfolgt keine revolutionären oder enggefaBtklassengebundenen Ziele. Sie hat sich die Verwirklichung der gröBten Aufgaben bezüglich deg Wohlergehens des Volkes zur Aufgabe gemacht..."108

Das RB interessierte sich für sämtliche Praktiken der fortschrittlicheren Iänder Europas, die irgendwie auf die russischen Verhälnisse nutzbringend angewandt werden konnten. Daher schenkten sie auch ihre besondere Aufmerksamke1t der sozialen Gesetzgebung und den Sozialreformen Bismarcks und seiner Nachfolger.

Sie sahen darin nicht das "non plus ultra", sondern betrachteten sie, wie alle ausländischen Vorlagen, nur als Denkoodell zur Entwicklung eigener sozialer

107) Vgl. S. Južakor, Politika. RB 1900/1, II, S. $209 f f$.

108) Vgl. Reus, Iz Germanil. RB $1903 / 7$, II, S. 124 . 
Reformvorschläge. Die deutsche Sozialpolitik erschien ihnen zwar, gemessen an den horrenden Summen, die der deutsche Staat für Aufrüstungszwecke ausgab, als lächerlich geringfügig und aucn in manch anderer Hinsicht als noch unzureichend, dennoch war sie in ihren Augen, wenn auch nicht das beste denkbare, so doch immerhin das beste zur Zeit existierende Modell in Europa. ${ }^{109}$

Ein weiteres Interessenfeld bot ihnen das deutsche Kredit- und Genossenschaftswesen, das seine entscheidenden Impulse durch schulze-Delitzsch und raiffeisen erhalten hatte und auf den gewerblichen Mittelstand und die bäuerIicne Bevölkerung ausgerichtet war. Auf diesem Gebiete empfanden sie

109) Vgl. nierzu:

M.M. Pilippov, Čto délaetsja za granicej. $\mathrm{KB} 1888 / 2$, s. 130 . M.F., Cto délaetsja za granicej. RB 1888/12, S. $199 f$. an., Novy ja knigl. KB 1893/8, 1 , S. 65-67. S.N. Juzakov, Ministerstvo zemledélija. RB 1893/10, II, S. 31 . V.T., Chronika zagranicnoj žizni. RB 1894/2, II, S. 114-117. A.K., I z Germanii. RB 1895/5, II, S. 108-111. an., Noryja knigi. RB 1895/19, II, S. 76-79. A. Kovrov, Iz Germanif. $\mathrm{RB} 1895 / 11$, II, S. 136-139. G.B. Iollos, Ocerki zakonodatel'stva o trude $v$ Germanil. I. Bor'ba za fabričnye zakony. RB 1898/3, I, S. 84-122, ders., Ozerki zakonodatel'stva o trude v Germanii. II. Reforma $1891 \mathrm{~g}$. I nynésnee sostojanie fabridnago zakonodatel'stva. RB 1898/5, I, S. 162-194. ders., Ocerk zakonodatel'stva o trude v Germanil; (Okončanie). RB 1898/12, I, S. 176-201. an., Novyja knigi. RB 1903/9, II, S. 39-42. Michail Berenstam, Juridiceskija konsul'tacii $\checkmark$ Rossii i rabodie sekretariaty v Germanil. $\mathrm{RB} 1903 / 3$, II, S. $1-33$. M. Lunc, Raboḋij vopros i fabricnoe zakonodatel'stro v Rossil. RB 1904/4, I, S. 147, 149-154. 
Deutschland als absolutes Vorbild. 110

b) Nationalismus

Parallel zur Ausbildung des Kapitalismus auf wirtschaftlichem Gebiet entwickelte sich in Europa in der zweiten Hälfte des neunzehnten Jarrhunderts auf ideologischem Gebiet ein neuartiger Nationalismus, der sich in seinen geistigen Grundlagen weitgehend vom humanitäen, liberalen Nationalismus Herders und der Romantik unterschied, und den man heute nach Charles liaurras als "integralen Nationalismus" bezeichnet. 111

Das RB beklagt an diesem neuartigen Nationalismus, für den "der ethnisch homogene, souveräne Nationalstaat zum unbestrittenen politischen Höchstwert avancierte" 112 , das völlige Fehlen eines übergeordneten Leitprinzips, wie es der Europagedanke in der ersten Hälte des neunzennten Jahrinunderts gewesen war. 113

110) Vgl. hierzu u.a.: in. Gercenštejn, Central'nye sojuzy i kreditnye banki dija melkich kreditnych učreždenij $v$ Germanii. RB 1898/11, II, S. 97-110;

und M.F., I.G., Cto dělaetsja za granicej. RB $1889 / 3$, S. 222-225.

111) Vgl. hierzu Eugen Lemberg, Geschichte des Nationalismus in Europa. Stuttgart, 1950, S. 267-306.

112) Vgl. Günther stökl, Die deutsch-russischen Beziehungen in der Geschichte. in: Österreichische Osthefte. 13/1971, H. 3, S. 196.

113) Vgl. z.B. S.N. Južakov, Politika. KB 1902/1, II, S. $179 f$. 
In dieser neuen Epoche eines prinzipienlosen Nationalismus dominierten nach Ansicht des $R B$ allein die eigenen, selbstsüchtigen nationalen Begierden; auch die Gruppierung der europäischen Machte sei das ausschliebliche Produkt engstirniger nationaler Interessen.

Ler Imperialismus habe den Impuls für die englisch-amerikanische Annüherung geliefert; das konservative, monarchische Rubland und das demokratische, republikanische Frankreich hätten sich verbuindet, um ihre Ziele vor den eigennützigen Plänen des Dreibunds zu schützen, und der Dreibund schlieblich, dessen Gründung das Protramm persönlicher Interessen verbündeter liüchte geradezu proklamiert habe, sei das Produkt des deutschen Chauvinismus der Bismarckzeit. 114

Das $R B$ macht Deutschland dafür verantwortlich, dem Nationalismus in Europa den letzten, aber entscheidenden Anstob gegeben und inn dadurch zum endgültigen Durchbruch verholfen $z u$ haben: "jer absolute Triumph des Nationalismus in Deutschland, verbunden mit den ungeheueren Erfolgen dieses Staates, hat dazu geführt, dab Europa sich endguiltig selbst, d.h. als Ganzes, vergab, und nicht die Solidarität herausstellte, sondern isolierte Interessen einzelner Staaten und Nationen; Staaten, die doch eine einneitliche Kulturgruppe bilden, die eng zusummengenalten wird durcn ein komplizlertes Netz von Interessen, Ideen, Bestrebungen, Hofinungen und Gefanren." 115

114) Vgl. S.N. Južakov, Politika. RB 1902/1, II, S. 179-181; und S.N. Južakov, Politika. RB 1899/1, II, S. 101.

115) Vgl. S.N. Južakov, Politika. RB $1902 / 1$, II, S. 180 . 
Durch den Sieg über Frankreich hatte die deutsche nationale Bewegung inr Ziel, den deutschen bachtstaat, erreicht; das dadurch ausgelöste ubersteigerte Erfolgsbewubtsein fand beim nachbarlichen kuBland ganz allgemein und beim RB im speziellen eine negative Resonanz, die sich treffend mit Benedetto Croces Feststellung umschreiben läbt, seit 1870 sei das "Sedanlacheln" nicht mehr vom Angesicht des deutschen Bürgers gewichen. ${ }^{116}$

Besonderen AnstoB beim RB erregten die juhrlichen Sedanfeiern, die dazu bestimmt seien, die Erinnerung an vergangene militärische Erfolge wachzuhalten und in der jungen Generation neuen Chauvinismus zu erzeugen. 117

Nationalismus werde auch in den deutschen Schulen, besonders den höheren, gezüchtet: Sie seien vor allem patriotisch, und das deutsche pädagogische Ideal bestehe darin, "um jeden Preis ... Kenschen heranzuziehen, die uberzeugt sind von ihrer geistigen Uberlegenheit, die beseelt sind von dem absoluten Glauben an die hohe Bestimmung inres Vaterlandes und bereit, tapfer für deren Verwirklichung zu kämpfen, überall da, wo sich dafür eine Gelegenheit bietet". 118

Die Idee einer einheitlichen Menschneit rangiere dabei ebenso auf dem zweiten platz wie die Vermittlung von Wissen und die Entwicklung des Verstandes: "Deutschland braucht disziplinierte kiassen

116) Vgl. Benedetto Croce, Geschichte Europas im 19. Jahrhundert. Stuttgart 1950, j. 303.

117) Vgl. A.K., Iz Berlina. RB 1894/10, II, S. 137-139, und

A.K., Iz Germanii. $\mathrm{KB} 1895 / 9$, II, S. 119-126.

118) Vgl an., Novyja knigi. RB $1904 / 9$, II, S. 100 . 
von Befehlsempfängern, nicht aber Denker, die sich weiB Gott was ausdenken könnten." 119

"Einem mittelalterlichen Magier gleich gibt Deutschland für Jugend und physische Kraft seine Seele hin. Nur ein Kult der Stärke könnte zu dem Gedanken führen, seinem Beispiel zu folgen." 120

Auch die Kunst werde zur Ausbildung chauvinistischer Gefuhle bei den breiten Massen mibbraucht, dies beweise das Vorherrschen eines patriotisch-chauvinistischen Genres auf dem Berliner Kunstmarkt. ${ }^{121}$

Auf überhitzten deutschen Nationalismus stößt das RB ebenfalls in der Iiteratur- und Geschichtswissenschaft, beispielsweise in der "Geschichte der deutschen literatur" der beiden Breslauer Professoren Friedrich Vogt und Max Koch (1897), die 1901 in russischer thersetzung erschien, 122

In der Rezension des RB wird dieses Buch als das zur Zeit letzte Wort der literatur-historischen Forschung in Deutschland bezeichnet, und es wird gesagt, daB "... das ganze Buch vergiftet ist vom Geist des Nationalismus und dazu noch eines militanten, aggressiven und von selbstzufriedenheit und Intoleranz erfülten Nationalismus." 123

119) Ebenda.

120) Ebenda, S. 102 .

121) Vgl. A. Kovrov, Iz Germanii. KB 1895/11, II, S. 125.

122) Das KB gibt in seiner kezension den russischen Titel wie folgt an: "Fogt i Koch. Istorija nèmeckoj literatury. Yer. privatdocenta A.L. Pogodina. Izdanie tovarizcestra 'Prosvěščnie'. SPb. 1901n. (Vgl. an., Novyja knigi. RB 1901/7, II, S. 43.)

123) Ebenda. 
Als äuBerst bezeichnend findet das RB die Tatsache, $d a b$ in dieser umfassenden Iiteraturgeschichte, die jede vergangene oder neuzeitliche Nebensächlichkeit berücksichtige, zum Beispiel die "glänzenden Reden" eines Eugen Richter oder August Bebel nicht erwähnt werden und ein Heinrich Heine nur herabsetzend behandelt wird, die Reden Bismarcks hingegen mit groBem Lob bedacht und als "gewaltiges Denkmal des eisernen Gründers und Fihrers des Reiches in der Geschichte der Iiteratur" herausgestellt werden.

Für das RB liegt dabel klar auf der Hand, daB die Autoren nicht, wie sie behaupten, von den "Bildern und Vergleichen", an denen Bismarcks Reden angeblich so reich seien, gefesselt waren, sondern von der politischen Richtung dieser keden. 124

Das $R B$ rezensiert die russische Ubersetzung der "Geschichte des deutschen Volkes" von Karl Lamprecht, 125 den es als "uberzeugten Nationalisten"

124) $\mathrm{V}_{\text {gl }}$. ebenda, S. 44 Noch weiter in dieser Hinsicht geht nach Ansicht des RB der Literaturhistoriker Berthold Litzmann, der in seinem Buch "Das deutsche Drama in den literarischen Bewegungen der Gegenwart" (1894) die feste tberzeugung geäuBert habe, "daB das Urteil der kommenden Generationen uber jeden Deutschen, der eine mehr oder weniger hervorragende Rolle im literarischen und politischen Leben des letzten Viertels des 19. Jahrhunderts gespielt hat, in bedeutendem liaße von folgendem Kriterium bestimmt sein wird: in wieweit jede dieser zu beurteilenden Personen in der Lage war, die Persönlichkeit Bismarcks, dieses größten staatsmännischen Genies, das Deutschland je hervorgebracht hat, $z u$ verstehen und $z u$ bewerten." (zit. nach: A.K., Iz Germani1. RB 1895/9, II, S. 134; siehe auch S. 133.)

125) Der russische Titel wird wie folgt angegeben: "Istorija Germanskago naroda, Karla Lamprechta. Tom 1. Casti I i II. Perevod s německago $P$. Nikolaeva. Izdanie K.T. Soldatenkova. Lioskva 1394." (Vgl. an., Novyja knigi. RB 1894/8, II, S. 86.) 
vorstellt, 126 und gibt dabei seiner Verwunderung Ausdruck, daß er völlig die Existenz der Slaven ignoriert und die Ansicht vertritt, an Oder, vibe und Weichsel häten von alters her Deutsche gesessen: "Lamprecht, als nationaler Historiker, sieht überall Deutsche und will nicht anerkennen, daß seine 'Ostgermanen' (vostodnye germancy) keine Deutschen waren, sondern Slaven." 127

In Deutschland werde chauvinistische Reklame sogar mit der Tatsache getrieben, dals sich deutsche Produkte in der "Welt groBer Beliebtheit erfreuen und deutsche Wertarbeit überall als Zeugnis deutschen Fleißes, deutscher Qualität und deutscher wacht gelte. 128

Der "Imperialismus" in Europa und Nordamerika, welcher nur den Interessen der plutokratie diene und den neuen Nationalismus hervorgebracht habe, 129 werde in Deutschland dadurch variiert, daB auch noch traditionelle Elemente ihren EinfluB behielten: die "Feudalstruktur", die Dynastie der Hohenzollern, die protestantische Kirche und daraus resultierend "die ... sehr weit verbreitete nationale Exklusivitä". 130

Die Hohenzollerndynastie verstand sich als Verteidiger des Protestantismus; die protestantische

126) Ebenda.

127) Ebenda, S. $87 f$.

128) Vgl. A. Kovrov, Iz Germanii. RB 1896/3, II, S. $106 f$.

129) S.N. Južakov, Politika. RB 1903/12, II, S. $132 \mathrm{fI}$.

130) Ebenda, S. 135. 
Kirche hatte dem preuBischen staat und seinen Zielen $z u$ dienen. Im Gegensatz zum jenseitsbezogenen Katholizismus bemiihe sich der Protestantismus hauptsächlich den Staat und das irdische Leben zu idealisieren. Die preubischen Konservativen erhielten dadurch die Möglichkeit, ihre politischen Ziele (Nationalismus und Antisemitismus) und ihre sozialen Interessen mit der christlichen Idee $z u$ verbrämen und damit $z u$ rechtfertigen. 131

Der deutsche Patriotismus bedeute nicht so sehr die Liebe zum Vaterland, wie vielmehr die Feindschaft gegenuber anderen. 132 Diese Feindschaft 208 sich demnach jeder Nicht-Protestant, jeder Nicht-Preuße zu.

Auch nach Bismarcks "Kulturkampf" bekamen die Katholiken (ebenso wie die Juden und die Polen) den $\mathrm{HaB}$ der deutschen Nationalisten zu spuren. Der Antisemitismus sei in Deutschland etwa gleichzeitig mit der Gründung des Keiches aufgeblüht. 133

Wenn auch der Antisemitismus in Frankreich 134 und sogar in RuBland ${ }^{135}$ kritisiert wurde, verur-

131) Vgl. Reus, Iz Germani1. RB 1903/7, II, S. 97.

132) Vgl. S. Južakov, Praviteli i vlastiteli sovremennoj Evropy. Sbornik zurnala "Russkoe Bogatstron. a.a.0., S. 449.

133) Vgl. M.H. Pilippov, ¿to délaetsja za granicej. RB 1888/11, S. 177f.

134) Vgl. hierzu z.B. E.L., Sovremennyj antisemitizm vo Prancii.

RB 1899/8 (11), II, S. 1-8.

135) Deutschland wurde die Schuld an der Ausbreitung des Antisemitismus in RuBland gegeben! Somit wurde der russische Antisemitismus nicht als Eigenprodukt, sondern als ausländischer Import betrachtet. Vgl. an., Chronika vnutrennej iizni. RB $1894 / 4$, II, S. 123. 
teilte man inn in seiner deutschen Variante besonders scharf, weil er, wie es deutschem Wesen entspreche, institutionalisiert worden war. Die Partei der Antisemiten sei ein typisch deutsches Produkt. Obwohl deren Anhänger nicht zur intellektuellen Elite Deutschlands zahlten und in der politischen Arena niemals eine größere Rolle spielten, wurde inr vom $R B$ doch erstaunlich grobe Beachtung geschenkt. 136

Auch auBerhalb des Ranmens der politischen Partei wurde der Antisemitismus in Deutschland tadelnd beschrieben. Sein lotiv liege in der Unzufriedenheit der konservativen Mittel- und Unterschicht mit ihrer wirtschaftlichen Lage. Das Neidmotiv sei besonders auch bei den Studenten ausgepragt gewesen, da "der jüdische Student sich durch groben fleiß und große Abstinenz auszeichnet und daher leicht bei den Prüfungen seinen germanischen (germanskago) Kommlitonen übertrifft, der viel Zeit auf kneipen, Fechten und die übrigen kierkmale des patriotisch-studentischen Daseins verschwendet natte." 137

Da neben den Juden auch die orthodoxen und katholischen Slaven als Antagonisten der protestantischen Preußen betrachtet wurden, richtete sich der Nationalismus der deutschen keaktionare auch gegen die kussen und die Yolen.

136) Vgl. hierzu M.M. Filippov, Čto dělaetsja za granicej.

KB $1888 / 11 ;$ S. 177-198. -

V. Vodovozov, Antisemitizm v Germanii i predstojašic vybory $v$ rejcnstag. KB 1898/2, I, S. $118-150$.

137) Vgl. A. Kovrov, Iz Germanii. KB $1896 / 2$, II, S. 98 . 
Das $R B$ schildert uusführlich ale teinaselige Haltung der Deutschen gegenüber den in ihrem Machtbereich anzutreffenden Russen, seien es Studenten, Bmigranten oder Besucher. 138

Das negative Bild des preußischen Junker vom Kussen, welches "leider auch in den sogenannten bürgerlichen kreisen" vorherrsche, wird scharf kritisiert. Für diese Leute sei "das russiscre Volk ... so etwas wie eine Herde von Tieren, die keines jener recntlicnen und kulturellen Güter bedürfen, die der Deutsche bei sich zu Hause im Uberfluk in Anspruch nimmt." Pür inn seien die "russiscnen ivilden" "geborene Sklaven, für die es nur eine Tugend gibt - tierische Ergebenheit in inr schicksal und Unterwirfigkeit gegenüber dem 'von den Deutschen' gekommenen Beamten-kulturträger (cinovnik-kul'turtreger)". 139

Selbstverstandich richtete sich die deutsche Slavophobie (wie imner mit dem Antisemitismus verbunden ${ }^{140}$ ) in erster Linie gegen die Polen.

Es sei das Bestreben der preubischen Chauvinisten gewesen, die im preußiscinen Staatsgebiet lebenden Polen völlig zu germanisieren, un (wie in ElsaßLothringen und Nordschleswig) alle Anzeichen einer fremden Nation $z u$ vernichten. 141

138) Vgl. Reus, krolid'e pravo. (Piśmo iz Germanii). KB 1904/10, II, S. $45 f f$.

139) Vgl. Reus, Gospoda junkery. a.d.0., RB $1904 / 11$, II, S. 125. (iiese Feststeilungen stimmen haargenau überein mit den Ansichten der liationalsozialisten uber die "ostischen Untermenscnen".)

140) Vgl, an., Chronika vnutrennej žizni. RB 1894/4, II, S. 123-125; S. Južakov, Politika. RE 1903/11, II, S. 145.

141) Vgl. S.N. Južakov, Politika. RB 1902/9, II, S. 106-109. 
Das polnische Element bilde angeblich eine Gefuhr für das "große und ruhmreiche Deutschland", 142 weswegen die preubischen reaktionäre brutal dagegen vorgingen: "lit den polen verfahren die Führer und Träger des Hakatismus ${ }^{143}$ genauso, wie die Bewohner der Dünen mit den Kaninchen: sie füllen inre köhlen mit Wasser und drängen sie so aus ihren :lohngebieten; nur vergessen die preubischen Hakatisten eines - nicht die Polen kamen zu inren ... nach Freblsen, sondern die Geschichte gab die polniscnen Gebiete unter das deutsche Joch, sie ersticken keine seelenlosen Tiere in ihren Höhlen, sondern verwenden nackte Staatsgewalt gegenuber einer lebendigen und Bewußtsein besitzenden Nation in derem seit Jahrnunderten geheiligten und geliebten Vaterland." 144

Die deutsci-russische Freundschaft, die eine inrer Bindeglieder in der gemeinsamen Unterdrück ing der Polen besaB, wollte das RB nicht auf Kosten der Polen bewaint wissen. ${ }^{145}$

Trotz der negativen Beurteilung Deutschlands sain das $k B$ in inm nicht etwa den Vorkampfer des liationalismus in Europa. Dieser nehme in England und Frankreich fülbar $a b$, daher seien diese Staaten

142) Vgl. Reus, krolid'e pravo. a.a.0., s. 47.

143) Gemeint sind die Mitglieder des Ostmarkenvereins, genannt nach den Anfangsbuchstaben seiner Gründer: $v$. Hansemann, Kennemann, v. Tiedemann.

144) Val. Reus, Krolid'e pravo. a.a.0., s. 79 .

145) Vgl. j.N. južakov, Folitika. KE 1902/9, II, S. 109. 
fortachrittlicher als Deutschland, jedoch nabe der Humanismus noch keine Erfolge in OsterreichUngarn und auf dem Balkan erringen können. So nähmen das Deutsche Keich und Italien eine Mittelstellung ein; in diesen Ländern machten sich bereits Anzeichen einer Opposition bemerkbar, die sich gegen den extremen nationalen Chauvinismus richten. 146

Da das $\mathrm{KB}$ jeglichem ubertriebenen Nationalismus abhold war, lehnte es nicht nur den pangermanismus, sondern mit an Sicherheit grenzender Wahrscheinlichkeit auch den Panslavismus ab, soweit dieser mit der Unterdrückung einer fremden Nationalität verbunden war.

c) Militarismus

Dem deutschen Kapitalismus und dem deutschen Nationalismus gleichermaßen diente nach Neinung des $R B$ der deutsche Militarismus. ${ }^{147}$

Auf Grund seiner Beobachtungen der europëiscien Arena gelangt das RB zu der Ansicht, Deutschland sei "d $i$ e Heimat des Militarismus". ${ }^{148}$

146) Vgl. S. Južakov, Praviteli i vlastiteli sovremennoj Evropy. Sbornik Zurnala "Russkoe Bogatstro". a.a.0., S. 406 f. ders., Politika. RB 1900/1, II, S. 209, siehe auch S. Južakov, Politika. $\mathrm{KB} 1902 / 10$, II, S. $142,144 \mathrm{f}$. ders., Politika. RB 1903/2, II, S. 93.

147) Vgl. S. Južakov, Politika. RB 1900/1, II, S. 209.

148) Vgl. V.T., Chronika zagraniěnoj žizni. RB $1894 / 4$, II, S. 92 . 
Der Aufrüstungstaumel, der Europa in der zweiten Halfte des neunzehnten Jahrhunderts befallen hat, habe seinen "Herd" im "Militärlager" Deutschland. 149

Die Militärbegeisterung des deutschen Bürgertums fuhrt das RB auf den "Rausch" der Siege von 1870/71 zurück, von dem es sich seit dieser zeit nicht mehr habe befreien können: "Wenn ihm auch der Militarismus noch nicht endgullig in Fleisch und Blut ubergegangen ist, so hat er doch zumindest stark auf sein Leben und auf die gesellschaftlichen Verhältnisse abgefärbt ... von außen gesehen hat die deutsche Gesellschaft einen stark militärischen Anstrich." 150

Für die Auffassung in den damaligen bürgerlichen Krelsen zutreffend beobachtet das RB, daB sich "jeder Deutsche, besonders aber der PreuBe, fur einen unglucklichen Menschen hält, wenn er nicht wenigstens den Rang eines Reserveleutnants besitzt." 151

Der Kriegswert des deutschen Soldaten wurde der guten Schulausbildung der Deutschen zugeschrieben. Dadurch, dab im Unterschied $z u$ anderen europälschen Ländern, wo das Analphabetentum noch weit verbreitet war und die Armee mehr zeit darauf verwenden muBte, die Soldaten auch auBermilitärisch auszubilden, die militärische Ausbildung in Preußen ouf einer guten Schulbildung aufbauen konnte und so die Wehrdienstzeit verkuirzt werden konnte, verfügte Deutschland uber eine größere Reserve

149) Vgl. M.M. Filippor, Čto délaetsja za granicej. $\mathrm{RB} 1888 / 2$, S. $127 f$.

150) Vgl. Reus, Michel' pod ruz'em. (Piśmo iz Germani1) RB 1903/11, II, S. 148 .

151) Vgl. A. Bovrov, I z Germanil. RB 1896/11, II, S. 131. 
wohlausgebildeter Soldaten.

Das RB konnte sich der deutschen Behauptung, daB der deutsche Volksschullehrer bei sedan ${ }^{152}$ die Franzosen besiegt habe, nur anschlieben. 153

Da durch diesen Sieg das deutsche Nationalgefihl einen großen Aulscnwung erfahren hatte, erregte seither alles Militärische die grobe Bewunderung der deutschen Konservativen und des liberalen Buirgertums. Der aeutsche bichel erscheint als "geborener Soldat": "so sehr ist hier alles von dem Donner und Getöse jeder nur denkbaren Soldateska erfüllt, mit den grellen Farben der Aufschläge und Uniformen geschmückt, von soldatiscner Haltung und Disziplin, soldatiscner Roheit und Kraft durchdrungen." 154

Am meisten wird das $K B$ von den Militärparaden, die es "preuBisches hilitärballett", 155 eine Art "zweiter Akt von Lohengrin" 156 nennt, von der "erfolgreichen propaganda des kriegspatriotischen Geistes" und der "Dressur" der preußischen Soldaten beeindruckt. Lis beschreibt "das völlig untalbbare Schauspiel der dressierten, federnden Automaten, bei deren Anblick man nicht weiB, woruber man sich mehr wundern soll: darüber, daß die unglückliche, menschliche Natur buchstäblich alles ertragen kann, oder darüber, daß es leute gibt, die hartnäckig

152) Eine Behauptung, die zuerst 1866 nach der Schlacht bei Königsgrätz aufgestellt wurde.

153) Vgl. S. Južakov, Dnevnik žurnalista. RB 1896/6, II, S. 28f ; und

an., Novyja knigi. KB $1904 / 3$, II, S. 33.

154) Vgl. Reus, Michel' pod ruz'em. a.a.0., S. 145.

155) Ebenda, S. 151.

156) A.K., Iz Germanii. RB 1895/1, II, S. 791. 
und bewuBt danach streben, mit solchen Mitteln den Glanz und die Würde der Militäruniform aufrecht zu erhalten." 157

Jedoch beschränkt sich das RB nicht darauf, nur die Äußerlichkeiten des deutschen Militarismus zu kritisieren, sondern es zeigt auch auf, welche immensen Lasten das deutsche Volk tragen mußte, um nach außen hin den Schein "des bewaffneten Friedens" wahren zu können. Hinter den Kulissen des nationalen Glanzes ersticke "das Volk ... unter dem Gewicht der Aufrüstungen und der seine Kräfte ubersteigenden Bürden." "Der deutsche Militarismus verschwendet Millionen von volkseigenem Geld, das unter solcher Anstrengung aller Kräfte das werktätige Volk für den Staat erarbeitet." 158

Daher könne der deutsche Militarismus nur das Werk der Oberschicht sein; "Die angeborene 'kriegerische Ader' der Preußen, inre soldatische Haltung und ihr Militarismus - dies wird mit eiserner Hand dem friedliebenden Michel eingehämmert, unter den Anstrengungen und dem Stöhnen des Volkes wird staatlicher Glanz und Prunk erkauft." 159

Symptomatisch erscheint die Haltung Deutschlands auf der ersten Hager Friedenskonferenz im Jahr 1899, wo es als entschiedener Gegner der Abrüstung

157) Reus, Nichel' pod ruž'em. a.a.0., S. 151

158) Ebenda, S. 155, siehe auch V.T., Chronika zagraničnoj żizni. RB $1894 / 3$, II, S. 80 ; und

A. Kovrov, Iz Germanii.

RB 1896/12, II, S. 79

159) Vgl. Reus, Michel' pod ruź'em. a.a.0., S. 165 . 
auftrat und zwar mit dem Argument, daB für es die Aufrustung keine Belastung, sondern im Gegenteil eine Garantie fü Fortschritt und Keichtum bedeute. 160

In diesem Argument vermeint das $R B$ die Stimme Bismarcks zu vernehmen, der nicht nur wirtschaftliche Gründe gegen eine Abrüstung vorgebracht, sondern im Militärdienst auch eine Einrichtung gesehen hatte, um die Energien und die körperlichen und geistigen Kräfte des Volkes zu entwickeln. Und so sieht das RB die Bismarck zugeschriebene Pormel "Kraft macht Recht" bestätigt, "die fur Jahrhunderte das Denkmal der Barbarel des XIX. Jahrhunderts bleiben wird." 161

Anknüpfend an seine tberzeugung, daB der Willtarismus in Deutschland viele Anhänger in der Oberschicht und im Bürgertum habe und dab somit die "kulturellen Schichten" gegen die objektiven Interessen des Volkes handelten 162 - "der Kapitalismus bedient sich der veralteten Formen militärisch-theatralischer Vorstellungen, um sich damit auberen Glanz und Zauber zu verschaffen und sich selbst mit einer militärisch-romantischen Aureole zu umgeben", 163 - "Deutschland (aber) schlieblich nicht die Türke1" se1, 164 meint das RB für den

160) Vgl. S.N. Južakov, Politika. RB $1899 / 5$ (8), II, S. $162 f$, ders., Praviteli 1 vlastiteli sovremennoj Erropy. Sbornik Zurnala "Russkoe Bogatstro". a.a.0., S. 438 .

161) Vgl. S.N. Južakov, Politika. $\mathrm{HB} 1848 / 9$, II, S. 170 .

162) Vgl. S.N. Juzakov, Praviteli 1 vlastiteli sovremennoj Evropy. Sbornik Zurnala "Russkoe Bogatetro". a.a.0., S. 438.

163) Vgl. Reus, Michel' pod ruz'em. a.a.0., S. 180. $164)$ Ebenda, S. 165. 
Abbau des Militarismus in Deutschland Hoffnungen auf die deutschen Volksvertretungen setzen zu können, in denen die Sozialdemokraten immer mehr an Gewicht gewännen; diese aber führten einen erbitterten Kampf gegen die militaristischen "Spielereien" der Bourgeoisie und hätten gute Aussichten, die diesbezüglichen tberspanntheiten in Deutschland schrittweise abbauen zu helfen. 165

165) Ebenda, S. 166, 181 . -

Siehe auch A.K., Iz Germanii.

RB $1895 / 9$, II, S. $123 f$. 
C. AUSKLAIG: DAS VOLK DEK "DICHTER UND DERKER"

Zusamengefabt läbt sich der Eindruck des $R B$ vom Deutscinen und seinem Reich so unreiken: In einer gar nicht so fernen, aber anscheinend unwiederholbaren Vergangenineit war Rubland der deutschen kultur, besonders seiner Fhilosophie, aber auch seiner Wissenschaft verpflichtet. Die Deutschen waren auf diesen Gebieten die groben Geber, aber auch die groben äittler. ${ }^{1}$

Deutschland wurde damals nicht als politisches Gebilde aufgefabt ${ }^{2}$ (das Römische Reich Delitscher Nation, der Deutsche Bund, ja selbst der Norddeutsche Buna waren dafür $z u$ wenig konturiert), sondern als "die heimat kants, voetnes und Schillers" 3 , kurz als das "Volk der Dichter und Denker". ${ }^{4}$

Naturlich kennt und schätzt das RB auch Persönlicnkelten, die nach der Reichsgründung in Deutschland wirkten, wie die Dramatiker Gerhard Hauptmann ${ }^{5}$ und Hermann Sudermann ${ }^{6}$, die Erzählerin

1) VEl. M. Filippov, Sud'by russkoj filosofii. RB 1894/1, I, S. 114 .

2) Vgl. A.K., Iz Germanii. KB 1895/9, II, S. 133.

3) Vgl. N.K. Lichajlovskij, Literatura i żizh. RB 1900/2, II, S. 145.

4) Vgl. A.K., Iz Germanii. KB 1895/6, II, S. 125;A. Kovrov, Iz Germanii. RB 1896/1, II, J. 130;an., Novyja knigi. KB 1904/3, II, S. 33.

5) Vgl. z.B. A. Kovrov, Iz Germanii. RB $1896 / 1$, II, S. 133-149, oder G. Stil'man, Spory o teorii obnišanija. RB 1900/7, II, S. $124 f$.

6) Vgl. z.B. A.K., Iz Germanii. RB 1895/10, II, S. 181 ; oder an., liovyja knigi. RB 1903/5, II, S. 73-75. 
Liarie v. Ebner-Eschenbach ${ }^{7}$ oder die Philosophen jilhelm Vund ${ }^{8}$, liax Stirner ${ }^{9}$ und Friedrich Nietzsche ${ }^{10}$.

Aber gegenüber der Fülle geistigen Lebens auf allen Gebieten, wie es im "alten" Deutscnland von Königsberg bis Veimar, von Jena bis Tubingen blühte, scheint es sich jetzt nur noch un eine durftige Nachlese zu handeln. Der Ehrentitel "Volk der Dichter und Denker" gilt nicht mehr, die Deutschen können nur von vergangenem, immer mehr verblassendem Ruhm zehren.

Friber stand Michel an der Spitze der europaischen Zivilisation; seinen Ruhmesplatz multe er seit langem an Marianne abtreten, ${ }^{11}$ die an seiner Stelle jetzt die Achtung Europas als Hort der Kultur genießt. Und wem verdankt der Deutsche diesen Abstieg? Seinen Führern, Bismarck und Wilhelm II.

7) Vgl. z.B. A. Kovrov, Iz Germanii. RB 1896/10, II, S. 92 .

8) Vgl. u.a. an., Novyja knigi. RB 1902/11, II,S.53f.

9) Vgl. z.B. N.K. Michajlovskij, Literatura i žizh. RB 1894/11, II, S. 111-128.

10) Vgl. z.B. N.K. inichajlovskij, Literatura i zizh. RB 1894/12, II, S. 84-110; ders., Literatura i žizh. RB 1898/2, II, S. 156, 158-162;

ders., Literatura i žizń. RB 1900/2, II, S. 146, 148f., 158f.;

ders., Literatura i žizh. RB 1903/4, II, S. 76f., 81 . - - -

Dern "Gelehrten" und "Mann des öffentlichen Lebens", Rudolf Virchow, widmete das RB einen Nachruf von 45 Seiten.

(Vgl. V.V. Lunkevit, Rudol'f Virchov. 1821-1902. RB 1902/10, II, S. 54-99), den Juristen Rudolf $v$. Ihering bezeichnete es als "einen der letzten Mohikaner des alten kulturellen Deutschland". (Vgl. V.T., Chronika zagraniðnoj žizni. RB 1892/10, II, S. 78.)

11) Vgl. S.N. Južakov, Praviteli i vlastiteli sovremennoj Evropy. Sbornik žurnala "Russkoe Bogatstro". a.a.0., S. 448 . 
Bismarck hat das "Volk der Philosophen und Träumer" aus diesen ernsten und heiteren Iuftgespinsten gerissen und es mit seiner eisernen Hand in sein neues eisernes und blutiges system gepreBt. 12

Die Menschheit kannte Michel nicht mehr wieder, seit er durch den Kanzler zum PreuBen deformiert worden war. Diese "Verpreußung" des deutschen Menschen seit den Jahren 1866 bis 1871 fuhrte dazu, daß das Land der "Gelehrten und der Dichter" ein Hort des lilitarismus wurde, des "engstirnigen Nationalismus" und der Aggressionspläne nach allen kichtungen der indrose. 13

"Nachdem Deutschland Frankreich ausgepreBt und ausgeplündert hatte, machte es sich sofort an die 'Ausnutzung' und 'Ausstattung' des Landes, an die Verstërkung der Entwicklung von Industrie und Handel, ... mit einem Wort, es stürzte sich in den materielien ProzeB des Lebens und kehrte seinen Philosophen und Dichtern den Rücken zu." 14

In Gleichem Maße, wie sich die intellektuelle Schicht von "materiellen Funktionen" aufsaugen

12) Vgl. Keus, Iz Germanii. KB 1903/7, II, s. 89.

13) Vgl. S.N. Južkov, Politika. RB 1901/9, II, S. 128 .

14) Vgl. V.G. Podarskij, Naša tekušcaja zizh. RB 1902/1, II, S. 170 .

("Die 'ideellen Bestrebungen' des verehrten Deutschen aus der bürgerlichen Intelligencija ... beschränkten sich in der letzten Zeit ausschlieblich auf den Dienst für das militaristische und industrielle Reich, das durch Eisen, Blut und den Schmutz fieberhafter Spekulation gefestigt wurde. Die Arbeiterklasse, auf welche der alte Idealismus Deutschlands überging, befindet sich noch in zu schwieriger materieller Lage, um sich am literarzschen Schafien beteiligen zu können." Ebenda.) 
lieb, verarmte die Iiteratur. Sie fiel der Politik und der Wirtschaft zum Opfer. ${ }^{15}$

Dafür erzielten die Deutschen binnen recht kurzer Zeit im Zuge des wirtschaftlichen Aufschwungs erstaunliche technisch-wissenschaftliche Erfolge. In Gegensatz dazu verkimmerten alle ubrigen Wissenschaftsbereiche, besonders stagnierte die Pailosophie, "die immer so etwas wie ein Privileg des 'Volkes der Denker' war". 16

Sind die Deutschen so inzwischen auch nur noch dem Namen nach "das Volk der Dichter und Denker", 17 so sind sie doch eifrig bestrebt, ihren Ruf als solche zu kultivieren.

Man sagt ihnen eine geradezu "fanatische Ehrfurcht vor ihren Abgöttern" nach. ${ }^{18}$ Sie errichten auf den Gräbern dieser "Dichter und Denker" nicht blOB Kreuze, sondern wundervolle Denkmäler, ganze Dome und Museen. ${ }^{19}$

15) Ebenda, S. $169 f$.

16) Vgl. A.K. Iz Germanif. RB 1895/9, II, S. 129. --Kovrov läßt an anderer Stelle keinen Zweifel daran, wie seiner Meinung nach Deutschlands Bilanz aus seiner 25-jährigen Geschichte als geeintes Reich aussehen wird, wenn es, wie er schreibt, "Rechenschaft ablegen muß nicht nur uber die Erfolge des Militarismus, sondern auch uiber die Erfolge des kulturpolitischen ... und geistigen Leben des Landes". Vgl. A.K., Iz Germani1. RB 1895/8, II, S. $126 f$.

17) Vgl. an., Novyja knigi. RB 1904/3, II, S. 33. -(Dieser Ausdruck wird immer wieder gerne verwendet.)

18) Vgl, an., Novyja knigi. RB 1899/4, II, S. 58.

19) Vgl. A.K., Iz Germani1. RB 1895/6, II, S. 125. (Auch "fertigt man von Schriftstellern noch bei deren Lebzeiten Porträts an und hängt sie in den Nationalgalerien auf". Ebenda.) 
Nach der Primisse des $K B$, dab "das kulturelle Niveau einer Gesellschaft (am besten) an ihrer Beziehung zu ihren Dichtern gemessen werden kann", schneiden die Franzosen besser ab als die Deutschen. 20

Die Franzosen lesen still ihre großen Prosaisten, die Deutschen übertreiben auch darin. Sie begnügen sich namlich nicht mit den "allgemein unerkannten Giganten der deutscnen Literatur", sondern bringen auch solchen Schriftstellern übertriebene liebe entgegen, die nocn nicht einmal "ihren kurm überleben". 21

Zwischen den Zeilen meint man die Frage zu lesen: Ist nicht auch dies ein Symptom für den Niedergang der deutschen Kultur? Denn eins steht für das RB fest: Die Deutschen, "das Volk der Philosophen", sind zum "Volk der Politiker und Geschuftemacher" geworden. 22 Die Denker sind also $z u$ Politikern, die Vichter zu Geschäftemachern herabgesunken.

Die Politiker werden neidvoll bewundert, sie sind so leistungsfähig, sie strotzen von geistiger Energie, sie sind so erstaunlich zäh, sie besitzen eine so ungewöhnliche nervliche Widerstandsfähigkeit - diese ungeheuere "Masse von Verstandsarbeit (mozgovaja rabota)" wird respektroll anerkannt. ${ }^{23}$

20) Vgl.A.G. Gornfel'd, Zabytyj pisatel'. KB 1895/12, I, S. 143.

21) Ebenda.

22) $\mathrm{Vgl}$. Reus, Simplicissimus. a.a.0., s. bo

23) Vgl. A. Kovrov, Iz Germanil. RB $1896 / 8$, II, S. 85 . 
hit leisem Bedauern und spürbarer Verachtung sieht das $\mathrm{KB}$ hingegen die Geschäftemacher an, diese zahlenmäbig viel größere lienge von Halbgebildeten, welche, vor inrem Bierkrug dösend, sich einbilden, frei zu sein, weil sie Erfolg haben, welche Darwin als dem Verkünder des "struggle of life" huldigen und Bismarck als Genie preisen, welche stolz auf das geeinte Reich und die ileltstadt Berlin sind und sich selbstgefällig für den "eisernen kern des Volkes und den Hort der lioral" halten. 24

Demnach deckt sich die lieinung des $\mathrm{KB}$ über das "Volk der Dichter und Denker" mit dem bitteren Urteil, das ein berümter Zeitgenosse, nänlich Friedrich Nietzsche in der "Götzen-Dänmerung" (1889) uber seine Landsleute fälte und das lichajlovskij in seiner Spalte "Literatura $i$ žizh" zitiert hat:

"Die Deutschen - raan hieb sie einst das Volk der Denker: denken sie heute überhaupt noch? Die Deutschen langweilen sich jetzt am Geiste, die Deutschen miBtrauen jetzt dem Geiste, die Politik verschlingt allen Ernst für wirklich geistige Dinge 'Deutschland, Deutschland über alles', ich fürcnte, das war das Ende der deutschen Prilosophie... 'Gibt es deutsche Philosophen? gibt es deutsche Dichter? gibt es gute deutsche Bücher?' - iragt man nich im Ausland. Ich erröte; aber mit der Tapferkeit, die mir auch in verzweifelten Fallen zu eigen ist, antworte ich: 'Ja, Bismarck!" 25

24) Vgl. N.K. Wichajlovskij, Otryvki o religii. $\mathrm{KB} 1901 / 9, \mathrm{I}$, s. 166.

25) Vgl. N.K. Wichajlovskij, siteratura i žizń. $\mathrm{KB} 1894 / 12$, II, j. 84 . Hichajlovskij hat das zitat so getreu ins Russische übertragen, dals die Rückübersetzung ins Deutsche praktisch genau mit dem NietzscheText ubereinstimmt; dieser ist oben angefuhrt. 


\section{LITERATURVERZEICHNIS}

Die in den Exkursen über die deutsche Literatur angefübrten Werke warden in dieses Literaturverzeichnis nicht aufgenomen, da sie eindeutig identifizierbar und leicht zugänlich sind.

\section{Quellen}

Die römischen Ziffern in den Angaben beziehen sich auf die Abteilungen der Nummern (s. S. 3).

Aleksěev L., Počemu vskipel bul'on 1 počemu teper tol'ko my obrašcaem na eto svoe vimanie. $\mathrm{RB}$ $1880 / 12$, II, S. $53-75$.

Annenskij N.F., Chronika vnutrennej žizni. RB 1896/2, II, S. 197 - 221 .

an, Chronika vautrennej ǐizni. RB $1893 / 8$, II, S. $126-142$.

- Chronika vautrennej žizni. RB $1893 / 10$, II, S. 91 - 107 .

- Chronika vnutrennej žizni. RB $1893 / 11, \mathrm{II}$, s. $107-123$.

- Chronika vnutrennej žizni. RB $1894 / 2$, II, S. $125-147$.

- Chronika vnutrennej žizni. RB $1894 / 4$, II, s. $101-128$. 
an., Chronika zagraničnoj žizni. RB $1890 / 4$, S. 149 - 152 .

- Chronika zagraničnoj žizni. RB 1890/8, S. 158 $-173$.

- , Novyja knifi. RB $1893 / 8$, II, S. 55 - 73.

- , Novyja knigi. RB 1894 / 8, II, S. 72 - 92 .

- , Novyja knigi. RB 1895 / 11, II, S. $60-83$.

- Novyja knigi. RB 1898 / 5, II, S. 32 - 60 .

- , Novyja knigi. RB 1899 / 4, II, S. $55-85$.

- , Novyja knigi. RB $1899 / 8$ (11), II, S. 8 - 44.

- Novyja knigi. RB 1901/7, II, S. 31 - 57.

- , Novyja knigi. RB $1902 / 11$, II, S. 44 - 74.

- Novyja knigi. RB 1903 / 5, II, S. 69 - 97.

- , Novyja knigi. RB 1903 / 9, II, S. 32 - 59.

- Novyja knigi. RB 1904 / 3, II, S. 16 - 45.

- , Novyja knigi. RB 1904 / 9, II, S. 85 - 114.

- Russkaja žizh. RB $1880 / 1$, II, S. 78 - 92.

B. G., s. Plechanov.

B. V., s. Bervij-Flerovskij. 
Berenštam Michail, Juridičeskija konsul'tacii v Rossii $i$ rabočie sekretariaty $v$ Germanii. $\mathrm{RB} 1903$ / 3, II, S. 1 - 33.

Bervij-Flerovskij V. V., (Abk.: V. B.), Poèzija i filosofija agronomii. RB $1880 / 5$, I, S. 51 - 101.

B-skij (Fseud.), Něčto o dialektičesion metodě. RB $1895 / 4$, II, S. $44-72$.

Cernov V. M., Po povodu novoj knigi ob ékonomičesxom materializmè. RE $1899 / 9$ (12), I, S. 149 - 183.

- Sub-ektivnyj metod v sociologii i ego filosofskija predposylki. RB 1901 / 7, I, S. 231 - 256;

$R B 1901$ / 8, I, S. 219 - 261;

$\mathrm{RB} 1901 / 10$, I, S. 107 - 156;

RB $1901 / 11$, I, S. 115 - 162;

$\mathrm{RB} 1901 / 12$, I, S. $123-175$.

Černov V. M., Tipy psichologiðeskago i sociologiðeskago monizma. RB 1899 / 1, I, S. $33-69$.

¿ernyj Mi., Zakonoproékt Gejnoe i nexmeckoe obstestvo. $R B 1900 / 4$, II, S. $73-80$.

Daniel'son N. F., S. Nikolaj-on.

F. M., Ċto dělaetsja za Eranicej. RB $1888 / 10$, S. 153 - 158 .

- Čto delluet ja za garicej. is $1886 / 12, \mathrm{~s}$. $189-200$.

- Čto dellaetsja za sranicej. RB $1889 / 3$, S. 212 $-225$. 
Filippov $M_{0} M_{0}$, Čto délaetsja za granicej. RB $1888 / 11$, s. $177-198$.

- Čto dellaetsja za granicej. RB $1888 / 12, \mathrm{~S}$. 123 - 134 .

- Čto délaetsja $2 a$ granicej. RB $1889 / 5-6$, S. 341 - 352 .

- ' 'ud'by russkoj filosofii. $\mathrm{RB} 1894 / 1$, I, S. $86-115$.

Garin N. G., Detstvo Temy. RB 1892 / 1, I, S. 1 - 36.

Gercenttejn M., Central'nje sojuzy i kreditnye banki dlja melkich kreditnych uxrežc̀enij $v$ Germanii. RB 1898 / 11, II, S. 97 - 110.

Gomolickij V., Německie sarlatany. (Piśmo iz Berlina). RB $1900 / 6$, II, S. 129 - 141.

Gornfel'd A.G., Zabytyj pisatel'. RB $1895 / 12$, I, S. $143-180$.

Gr. Bor.-ov (Pseud.), Iz Germanii. RH 1898 / 5, II, S. $104-124$.

- Iz Germanii. RB 1898 / 6, II, S. 137 - 166.

Iollos G. B., Nemeckie remeslenniki. K charakteristike truda $v$ germanskoj promyslennosti. $R B$ 1895 / 6, I, S. $79-122$.

- , Oxerki zakonodatel'stva o trude $v$ vermanii. I. Bofba za fabritnye zakony. RB $1898 / 3$, I, S. $84-122$.

II. Reforma $1891 \mathrm{~g}$. i nyněsnee sostojanie 
fabritnago zakonodatel'stva. RB $1898 / 4$, I, S. 162 - 194 .

(III.) Okoncanie. RB $1898 / 12$, I, S. $176-201$.

Jarockij V. G., Obezpexenie narodnago prodovol'stvije $v$ svjazi s chlebnoju promyrlennostju. RB $1892 / 3$, I, S. $126-157$.

Južakov S. N., Dnevnik zurnalista. RB $1896 / 6$, II, S. $19-42$.

- Dnevnik Zurnalista. RB 1897 / 5, II, S. 122 - 147.

- Dnevnik Zurnalista. RB 1897 / 8, II, S. $106-131$.

- Ministerstvo zemledelija. RB 1893 / 10, II, S. 29 - 40 .

- , Pamjati S. N. Krivenko. RB 1906 / 7, II, S. 181 - 182 .

- Politika. RB 1898 / 8, II, S. $214-235$.

- Politika. RB 1898 / 9, II, S. 161 - 185.

- Politika. RB 1898 / 10, II, S. 147 - 166.

- Politika. RB 1899 / 1, II, S. 100 - 118.

- Politika. RB $1899 / 5$ (8), II, S. 160 - 177.

- Politika. RB 1899 / 6 (9), II, S. 128 - 150.

- Politika. RB 1900 / 1, II, S. 195 - 211. 
Juzakov S. N., Politika. RB 1900 / 3, II, S. 94 - 112.

- Politika. RB 1900 / 12, II, S. 199 - 216.

- Politika. RB $1901 /$ 2, II, S. 124 - 147.

- Politika. RB 1901 / 4, II, S. 156 - 171.

- Politika. RB 1901 / 5, II, S. 140 - 157.

- Politika. RB 1901 / 9, II, S. 120 - 133.

- , Politika. RB 1902 / 1, II, S. 178 - 191.

- Politika. RB 1902 / 2, II, S. 121 - 134.

- Politika. RB 1902 / 9, II, S. 98 - 114.

- Politika. RB 1902 / 10, II, S. 150 - 164.

- Politika. RB 1902 / 12, II, S. 128 - 145.

- Politika. RB 1903 / 2, II, S. 86 - 101.

- Politika. RB 1903 / 6, II, S. 92 - 106.

- Politika. RB 1903 / 11, II, S. 134 - 145.

- Politika. RB 1903 / 12, II, S. 121 - 136.

- Praviteli i vlastiteli sovremennof Evropy. Sbornik Zurnala "Russkoe Bogatstvo" 1899, S. $405-450$.

- 1894 god. (Iz sovremennof chroniki). RB 1895 / 1 , II, S. $186-213$. 
Juzakov S. N., Voprosy ekonomiCeskago razvitija Rossii. RB 1893 / 11, I, S. 202 - 227; $\mathrm{RB} 1893 / 12$, I, S. $210-224$.

K., Čto délaetsja za granicej. RB $1888 / 3, \mathrm{~s}$. $179-186$.

K. A., Iz Berlina. RB 1894 / 10, II, S. 131 - 142.

- Iz Germanii. RB 1895 / 1, II, S. 77 - 93.

- Iz Germanii. RB 1895 / 2, II, S. $117-136$.

- Iz Germanii. RB 1895/ 5, II, S. $103-123$.

- Iz Germanii. RB 1895 / 6, II, S. 104 - 125.

- Iz Germanii. RB 1895 / 8, II, S. 109 - 129.

- Iz Germanii. RB 1895 / 9, II, S. 119 - 134.

- Iz Germanii. RB 1895 / 10, II, S. 172 - 188 .

Kovalevskij Evgraf, V velikom Eercogstve Ljuksembursskom. RB $1892 / 1$, I, S. $67-97$.

Kovrov A., Borba partijiz - za chlebnych poslin $v$ Germanii. RB 1901 / 11, II, S. 75 - 112.

- , Iz Germanii. RB 1895 / 11, II, S. 124 - 139.

- Iz Germanii. RB 1896 / 1, II, So 130 - 149.

- Iz Germanii. RB $1896 / 2$, II, S. 86 - 106. 
Kovrov A., Iz Germanii. RB 1896 / 3, II, S.106 - 126.

- Iz Germanii. RB 1896 / 5, II, S. 58 - 75.

- Iz Germanii. RB 1896 / 6, II, S. 142 - 158.

- Iz Germanii. RB 1896 / 8, II, S. 73 - 86.

- Iz Germanii. RB 1896 / 10, II, S. 84 - 98 .

- Iz Germanii. RB 1896 / 11, II, S. 117 - 135.

- Iz Germanii. RB 1896 / 12, II, S. 75 - 93.

- Iz Germanii. RB 1897 / 2, II, S. 86 - 101.

- Iz Germanii. RB 1897 / 3, II, S. 133 - 142.

- Iz Germanii. RB 1897 / 6, II, S. 83 - 96.

- , Iz Germanii. RB 1897 / 7, II, S. 96 - 107.

Krivenko S. N., Po povodu kul'turnych odinotek. RB $1893 / 12$, II, S. 160 - 192.

Kudrin N., s. Rusanov.

L. E., Sovremennyj antisemitizm vo Francii. RB $1899 / 8$ (11), II, S. 1 - 8 .

Lozinskij Evg., Detskij trud i narodnaja zkola v Germanii. RB 1902 / 12, II, S. 37 - 58.

Luchmanova N. A., Dvadcat' let nazad. BB 1893 / 10 , I, S. $145-170$. 
Lunc M., Rabolij vopros i fabriznoe zakonodatel'stvo v Rossii. RB 1904 / 4, I, S. 146 - 173.

Lunkevic V. V., Rudol'f Virchov. 1821 - 1902. RB 1902 / 10, II, S. 54 - 99.

Michajlovskij N. K., Literatura i zizh. RB $1893 / 4$, II, S. $120-136$.

- Literatura i そizf. RB 1893 / 10, II, S. 108 - 141.

- Literatura i そizf. RB 1894 / 1, II, S. $88-123$.

- Literatura i そizh. RB 1894 / 2, II, S. 148 - 168.

- Literatura i Zizh. RB 1894 / 8, II, S. 151 - 172.

- Literatura 1 Zizf. RB 1894 / 11, II, S. 111 - 131.

- Literatura i Zizh. RB 1894 / 12, II, S. $84-110$.

- Literatura i zizh. RB 1895 / 1, II, S. 124 - 154.

- Literatura i Zizh. RB $1898 / 2$, II, S. 132 - 162.

- Literatura i zizh. RB $1900 / 2$, II, S. 139 - 167.

- Literatura i Zizf. RB 1903 / 4, II, S. 73 - 103.

- Otrgrki ot religii. $\mathrm{RB} 1901$ / 9, I, S. 157 - 180.

N. N., Cto delaetsja $2 a$ granicej. RB $1889 / 1$, s. 201 - 206 .

- Cto délaetsja za granicej. RB $1889 / 2$, s. 197 211. 
Nikolaj - on (Pseud, von Daniel'son N. F.), Apologija vlasti deneg, kak priznak vremeni.

$\mathrm{RB} 1895$ / 1, II, S. 155 - 187;

$\mathrm{RB} 1895$ / 2, II, S. 1 - 34 .

- Čto ze znaxit ékonomiðeskaja neobchodimost'?

$R B 1895$ / 3, II, S. 44 - 58 .

- Nexto ob uslovijach našego chozjajstvennogo razvitija. RB 1894 / 4, II, S. 1 - 34;

$\mathrm{RB} 1894$ / 6, II, S. $86-130$.

- Teorija trudovoj stoimosti i nékotorye iz eja kritikov. RB 1902 / 2, I, S. $31-69$.

Oranskij, s. Zlatovratskij.

Podarskij V. G., Nała tekusłaja Zizh. RB $1902 / 1$, II, S. $142-177$.

- Nasa tekuscaja zizh. RB 1902 / 4, II, S. 92 124.

Plechanov G. V. (Pseud. G. B.), Obscina i eja verrojatnoe budustee. RB $1880 / 1$, II, S. 35 - 55; $\mathrm{RB} 1880 / 2$, II, S. $17-36$.

Ratner M. B., Agrarnjj vopros $v$ evropejskoj literature. $R B 1899$ / 8 (11), I, S. 148 - 179; $R B 1899 / 9$ (12), I, S. $215-247$.

- Pismo v redakciju. RB 1899 / 9 (12), II, S. 195 - 207. 
Reus, Burenoscy. (I2 Germanii). RB 1904 / 3, II, s. $72-96$.

- Gospoda Junkery. Fismo iz Germanii. RB $1904 / 11$, II, S. $98-1 \hat{\imath}$.

- , Iz Germanii. RB 1903 / 7, II, S. 78 - 124.

- Krolic'e pravo. RB $1904 / 10$, II, S. 45 - 79.

- Michel' pod ruz'em. (Piśmo iz Germanii). RB $1903 / 11$, II, S. 145 - 181.

- Nazad k prirodel fismo iz Germanii. RB 1903/ 8, II, S. 131 - 174 .

- Pod znamenem kapitalizme. Pismo iz vermanii. fB $1903 / 6$, II, S. 156 - 197.

- Simplicissimus. Pismo iz Germanii. $\overline{\mathrm{K} B} 1904 / 5$, II, S. $47-76$.

- "Ultra montes!" Pismo iz Germenii. RB 1903/9, II, S. $116-160$.

- Vil'gel'm II. (Piśmo iz Germanii). RB 1904 / 1, II, S. $106-138$.

Rusanov N. S., (Pseud. Kudrin $N_{0}$ ), Na vysotach ob-ektivnoj istiny. $R B 1895 / 5$, II, S. $144-170$.

- Sovremennyja projavlenija kapitalizma $v$ kossii. $\mathrm{RB} 1880$ / 1, I, S. 79 - 108; $R B 1880 / 2$, I, S. $49-88$. 
Štil'man G., Spory o teorii obnistanija. RB 1900 / 7, II, S. $109-131$.

Sukennikov M., Čto ¿̇itajut nëmeckie raborie.

RB 1901 / 6, II, S. 45 - 68 .

T. V., Chronika zagranixnoj Žinni. RB $1892 / 1$, II, ... 1ל\% - 169.

- Chronika zaernničnoj Zizni. RB 1Ega / $\hat{c}$, II, j. $89-107$.

- Chronika zagranienoj Zizni. RB 1892 / 3, II, S. $284-300$.

- Uhronika zagranitnoj zizni. RB 1892 / 6, II, S. $42-51$.

- Chronika zagraniznoj zizni. RE 1892 / 10, II, S. $66-82$.

- Chronika ząraniðnoj Zizni. FB 1893 / 1, II, S. 88 - 99 .

- Chronike zagranixnoj Zizni. RB 1893 / 2, II, s. $123-144$.

- Chronika zacranienoj Zizni. RB 1893 / 5, II, S. 87 - 106 .

- Chronika zagraniznoj Zizni. KB 1893 / 7, II, S. $78-98$.

- Chronike zafranixnoj Zizni. RB 1893 / 10, II, S. $77-90$. 
T. V., Chronika zagranilnoj zizni. RB 1894/1, II, S. 124 - 149 .

- Chronika zagranilnoj Zizni. RB 1894/2, II, S. $101-124$.

- Chronika zagraniznoj zizni. RB 1894 / 3, II, S. $60-88$.

- Chronika zagranixnoj zizni. RB 1894 / 4, II, S. $79-100$.

- Chronika zagranienoj zizni. RB 1894 / 6, II, S. 131 - 155 .

Tolstoj L. N., Derevnja i gorod. RB $1885 / 12$.

- Mnogo - li Celověku zemli nuzno. RB 1886/5.

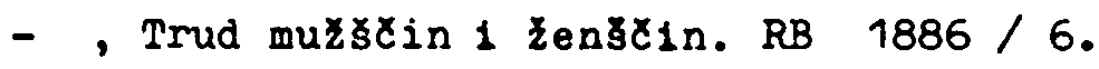

- , Žiuh $\nabla$ gorode. RB 1885/3; RB 1885/4.

V. V., s. Voroncov V. P.

Vejnberg P. I., Novye materialy dlja istorii "Molodoj Germanii". RB 1901 / 9, II, S. 1 - 17; $R B 1901$ / 10, II, S. 1 - 36.

Vodovozov V., Antisemitizm v Germanii i predstojastie vybory $v$ rejchstag. $R B 1898 / 2$, I, S. 118 - 150.

Voroncov V. P. (Abk.: V. V.), Mysli o budustem poměżið'ich chozjajstv. RB $1880 / 10$, I, S. $43-82$. 
Voroncov V. P. (Abk.: V. V.), Popytki obosnovanija

narodnitestva. RB 1892 / 2, I, S. 39 - 63;

$\mathrm{RB} 1892$ / 3, I, S. 68 - 88;

$\mathrm{RB} 1892 / 6, \mathrm{I}, \mathrm{S} .118$ - 148;

$\mathrm{RB} 1892$ / 10, II, S. 1 - 26;

$R B 1892 / 11, I, S .36-52$.

- , V zastitu kapitalistiðeskago pessimizma. RB 1881 / 2, II, S. 1 - 20 .

Zak L. S., Istorizeskif materializm. RB $1895 / 1$, II, S. 1 - 34 .

- Nemeckij krest' janin posle osvoboždenija.

RB 1897 / 10, I, S. 41 - 70;

RB 1897 / 11, I, S. 56 - 88;

RB $1897 / 12, I, S .140-164$.

- , sud'by krest'janskoj obstiny v Germanii.

$\mathrm{RB} 1895$ / 9, I, S. 81 - 113;

$\mathrm{RB} 1895 / 10, \mathrm{I}, \mathrm{S} .137$ - 172;

$R B 1895 / 11, I, S .183-212$.

Zlatovratskif N. N. (Pseud. Oranskij N.), Narodnyj vopros $v$ nasem obscestve i literature.

RB 1880 / 3, II, S. 25 - 48;

$\mathrm{RB} 1880$ / 5, II, S. 1 - 16;

$\mathrm{RB} 1880 / 6$, II, S. $1-20$. 


\section{Sekundärliteratur}

Allport Gordon W., Die Natur des Vorurteils. Köln 1971.

Anfimov A. M., Prusskij put' razvitija kapitalizma $\mathrm{v}$ sel'skom chozjajstve $i$ ego osobennosti $v$ Rossii. In: Voprosy Istorii $7 / 1965, \mathrm{~S}$. $62-76$.

Beltov N., s. Plechanov.

Berezina V. G. u. a., Istorija russkoj zurnalistiki XVIII - XIX vekov. Moskva, 1963.

Berezovskaja ż. J., Literaturno - kriticeskie pozicii zurnala "Russkoe bogatstvo" 1892 1905 g8. In: Iz istorii musskoj zurnalistiki vtoroj poloviny XIX v. Moskva, 1964, S. 62 136.

Beyme Klaus von, Politische Soziologie im zaristischen Rußland. Wiesbaden, 1965 ( = Frankfurter Abhandlungen zur Osteuropäischen Geschichte, Band 1).

Billington James H., The Bolshevik Debt to Russian Populism. In: Occidente, Torino $4 / 1956$, S. $319-327$.

- The Icon and the Axe. An Interpretive History of Russian Culture. London, 1966.

- Mikhailovsky and Russian Populism. Oxford, 1958. 
Bismarck, s. 'politischen Berichte'; 'politischen Reden'.

Bismarcks Briefwechsel mit dem Minister Freiherrn von Schleinitz 1858-1861.

Stuttgart und Berlin, 1905.

Boehlich ernst, Obentraut Johann Michael Elias, Zur Geschichte und Legende des "Deutschen Michel". In: Bausteine. Festschrift für Max koch. Breslau, 1926, S. 283 - 321.

Buldakov V. P., IstoriografiCeskaja problematika

'legal'nogo marksizma'. In: IstoriCeskie zapiski $87 / 1971$, s. $287-333$.

Choros V. G., Narodniteskaja ideologija i marksizm. Moskva, 1972.

Croce Benedetto, Geschichte Europas im 19. Jahrhundert. Stuttgart, 1950.

Dan Theodore, The Origins of Bolshevism. London, 1964.

Deutsch - russische Beziehungen von Bismarck bis zur Gegenwart. Hrsg. Werner Markert. Stuttgart, 1964.

Esin B. I., Russkaja Zuurnalistika $70-80-\mathrm{ch}$ godov XIX veka. Moskva, 1963.

Evgenev - Maksimov V., Iz istorii "Russkago Bogatstva"! In: Russkoe Bogatstvo (Russkija Zapiski) 11-12/ 1917, S. $55-95$.

Eyck Erich, Das persönliche Regiment Wilhelms II. Politische Geschichte des Deutschen Kaiserreiches von 1890 bis 1914. Erlenbach - Zürich, 1948. 
Fischer George, Russian Liberalism. From Gentry to Intelligentsia. Cambridge, Mass., 1958.

Galaktionov A. A., Nikandrov P. F., Ideologi russkogo narodnitestva. Leningrad, 1966.

Gebhardt Bruno, Handbuch der deutschen Geschichte. Bd. 3. Stuttgart, ${ }^{8} 1960$.

Germanskif imperializm i militarizm. Sbornik statej. Moskva, 1965.

Geyer Dietrich, Lenin in der russischen Sozialdemokratie. Die Arbeiterbewegung im Zarenreich als Organisationsproblem der revolutionären Intelligenz 1890 - 1903. Köln, Graz, 1962 ( - Beiträge zur Geschichte Osteuropas, 3).

Grieser Helmut, Die Sowjetpresse über Deutschland in Europa 1922 - 1932. Revision von Versailles und Rapallo - Politik in sowjetischer Sicht. Stuttgart, 1970 ( - Kieler Historische Studien, Band 10 ).

Hauffen Adolf, Geschichte des deutschen Michel. Prag, 1918.

Ivanov - Razumnik, Istorija russkoj ob̧restvennoj mysli. Individualizm $i$ mఈstanstvo $v$ russko $j$ literature i Zizni XIX v. St. Petersburg, 1907.

Kindersley Richard, The First Russian Revisionists. A Study of "Legal Marxism" in Russia. Oxford, 1962. 
Kluge Ernfried Eduard, Die russische revolutionäre Presse in der zweiten jälfte des neunzehnten Jahrhunderts. Zürich, 1948.

Koßmin B. P., Iz istorii revol jucionnoj mysli $v$ Rossii. Izbrannye trudy. Moskva, 1961.

Krivenko S. N., Sobranie sodinenij. Bd. 1. St. Peteroburg, 1911.

Laqueur Walter, Deutschland und Kußland. Berlin, o. J. (1965).

Lampert E., Sons against Fathers. Studies in Russian Radicalism and Revolution. Oxford, 1965.

Lemberg Eugen, Geschichte des Notionalismus in Europa. Stuttgart, 1950.

Lenin Vladimir I., Polnoe sobranie soxinenij. Bd. 1. Moskva, 1958.

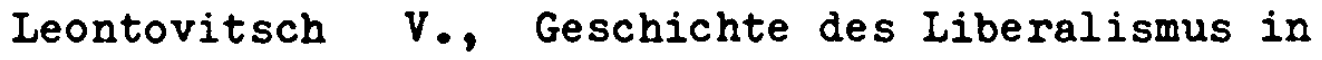
Kußland. Frankfurt/M., 1957.

Letov B. D., Russkoe Bogatstvo. In: Oterki po istorii russkoj Zurnalistiki i kritiki. Bd. 2 . Leningrad, 1965, S. $413-430$.

Marx Karl, Engels Friedrich, Werke. Bd. 37. Berlin / DDR, 1967.

Masaryk T. G., RuBland und Europa. 2 Bde. Jena, 1913. 
Maynard John, Russia in Flux. Before October. Iondon, 21946.

Mendel Arthur P., Dilemmas of Frogress in Tsarist Russia. Legal Marxism and Legal Fopulism. Cambridge, Mass., 1961.

Mentzel Jörg Peter, Pfeiler Wolfgang, Deutschlandbilder. Die Bundesrepublik aus der Sicht der DDR und der Sowjetunion. Dïsseldorf, 1972.

Meyer Rudolph, Politische Gründer und die Corruptior. in Deutschland. Leipzig 1877.

Michajlovskij N. K., Soxinenija N. K. Michajlovskago. 6 Bde. St. Fetersburg, 1897 - 1907.

Miljukov P. H., Vospominanija (1859 - 1917). 2 Bde. New York, 1955.

Müller - Jabusch Maximilian, So waren die GründerJahre. Diisseldorf, 1957.

Neumann Friedrich Wilhelm, Das Bild des Deutschen in russischen Schrifttum. In: Ostdeutsche Wissenschaft VIII / 1961, S. $234-252$.

Nikolaevskij Boris, Delo "iusskneo Logatstva". Iz materialov archiva byvsago Departamenta Policii. In: Russkoe Bogatstvo 1-2-3/1918, S. 85 96.

Nikolaj-on (Pseud, von Daniel'son N. F.), Orerki naseğ poreformennago obకtestvennaco chozjajstva. St. Potersburg, 1893. 
Oberlënder Erwin, Tolstoj und die revolutionëre Bewegung. München, 1965.

Pankoke Eckart, Sociale Bewegung - Sociale Frage - Sociale folitik. Grundfragsn der deutschen Socialwissenschaft im 19. Jahrhundert. Stuttgart, 1970.

Percov F., Literaturnye vospominanija 1890 - 190288 . Hoskva, Leningrad, 1933.

Pfeiler Wolfgene, Das russische Deutschlandbild und das sowjetische Bild von der Bundesrepublik. In: Aus Folitik und Zeitgeschichte $316 / 1972$, S. 3 - 22 .

Pipes Richard, Die russische Intelligentsia. Stuttgart, 1962.

Ylamenatz John, German Marxism and Russian Communism. London, 1954.

Plechanov (Fseud. Beltov $N_{0}$ ), K voprosu o razvitii monistiæeskago vzgljada na istoriju. Otvět $\mathrm{gg}$. Michajlovskomu, Kareevu i komp. St. Petersburg, 1895.

Die politischen Berichte des Fürsten Bismarck aus Petersburg und Faris. 1859 - 1862. Hrse. Ludwig Raschdeu. 2 Bde. Berlin, 1920.

Die politischen Reden des Fürsten Bismarck. Lirsg. Horst Kohl. 14 Bde. Stuttgart, 1892 - 1905. 
Rademacher Carl, Wodan - St. Michael - der deutsche Michel. Köln, 1934.

Radkey Oliver H., The Agrarian Foes of Bolshevism. Promise and Default of the Russian Socialist Revolutionaries - February to October 1917. New York, 21962.

Rauch Georg von, Streiflichter zum russischen Deutschlandbilde des 19. Jabrbunderts. In: Jahrbücher für Geschichte Osteuropas N. F. $12 / 1964$, s. $5-47$.

Sbomik statistiCeskich svedenii po Moskovskoj gubernii. Formy krest'janskago zemlevladenija v Moskovskoj gubernii. Moskva, 1879.

Schapiro Leonard, Rationalism and Nationalism in Russian Nineteenth-Century Political Thought. New Haven, London, 1967.

Scheibert Peter, Von Bakunin zu Lenin. Geschichte der russischen revolutionären Ideologien 1840 1895. Leiden, 1956 (- Studien zur Geschichte Osteuropas, Bd. III).

Schelting Alexander von, Russland und Europa. Bern, 1948.

Schnabel Franz, Deutsche Geschichte im Neunzehnten Jahrhundert. 4 Bde. Freiburg, 1948 - 1955.

Seton - Watson Hugh, The Decline of Imperial Russia 1855 - 1914. Iondon, 1952. 
Simmons Ernest J., Continuity and Change in Russian and Soviet Thought. Cambridge, Mass., 1955.

Skabiðevskif A. M., Literaturnye vospominanija. Moskva, Leningrad, 1928.

Sodhi K. S., Bergius R., Nationale Vorurteile. Eine sozialpsychologische Untersuchung an 881 Personen. Berlin, 1953.

Stamm Eugen, Konstantin Frantz 1857 - 1866. Stuttgart, 1930.

Stökl Günther, Die deutsch-russischen Bezkehungen in der Geschichte. In: Osterreichische Osthefte. 13 / 1971, H. 3, S. $189-200$.

- Russische Geschichte von den Anfängen bis zur Gegenwart. Stuttgart, 21965 ( = Kröners Taschenausgabe, Bd. 244 ).

Struve P. B., Zur Bourtheilung der kapitalistischen Entwickelung RuBlands. In: Sozialpolitisches Centralblatt $3 / 1893$, H. 1, S. 1 - 3 .

- Kritiðeskija zametki $k$ voprosu ob ékonomiCeskom razvitii Rossii. St. Petersburg, 1894.

Teitel Jakov J., Iz moej Žizni. Paris, 1925.

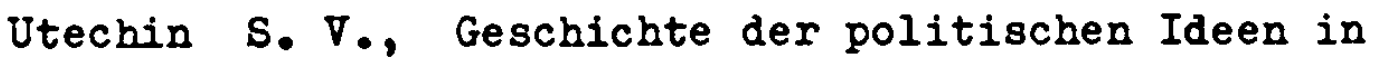
RuBland. Stuttgart, Berlin, Köln, Mainz, 1966. 
Venturi Franco, Roots of Revolution. A History of the Populist and Socialist Movements in Nineteenth Century Russia. London, ${ }^{2} 1964$.

Vodolazov G. G., Ot Černyకevskogo k Flechanovu. Ob osobennostjach razvitija socielisticeskoj mysli v Rossii. Moskva, 1969.

Vorurteile, ihre trforschung und ihre Bekämpfung. Hrsg. Kl. D. Hartmann. Frankfurt/M., 1964 ( = Politische Psychologie, Bd. 3 ).

Vorurteile in der Gegenwart. Begriffsanalyse - Funktionen - Wirkung - Störfaktor. Hrsg. Axel silenius. Frankfurt/M., 1966.

Vrangel' I., Russkoe Bogatstvo i Mir Bozij. In: Novyj Zurnal, New York 69 / 1962, S。 161 169.

Walkin Jacob, The Rise of Democracy in Pre-Revolutionary Russia. Political and Social Institutions under the Last Three Czars. New York, 1962.

Wolfe Bertram D., Three Who Made a Revolution. A biographical History. New York, 1948.

Wortman Richard, The Crisis of Russian Populism。 Cambridge, 1967.

Yarmolinsky Avrahm, Road to Revolution. A Century of Russian Radicalism. London, 1957.

Zmarzlik Hans-Günter, Das Bismarckbild der Deutschen - gestern und heute. Freiburg, o.J. (Vortrag, gehalten am 24. November 1965 im Studium Generale der Universitat Preiburg i.Br.). 


\section{ARBEITEN UND TEXTE ZUR SLAVISTIK HERAUSGEGEBEN VON WOLFGANG KASACK}

1 Sabine Appel: Jur1J Oleకa."Zavist"" und "Zagovor Cuvstv". Ein Vergleich des Romans mit seiner dramatisierten Fassung. 1973.

2 Renate Menge-Verbeeck: Nullsuffix und Nullsuffigierung Im Russischen. Zur Theorle der Wortbildung. 1973.

3 Jozef Mistrik: Exakte Typologie von Texten. 1973.

4 Andrea Hermann: Zum Deutschlandbild der nichtmarxistischen russischen Sozialisten. Analyse der Zeltschrift

"Russkoe Bogatstvo" von 1880 b1s 1904. 1974.

München - Verlag Otto Sagner in Kommission 